\title{
SoilSaw $^{\mathrm{TM}}$ Demonstration
}

\section{Final Report \\ September 1992 - January 1995}

\section{Kent Saugier}

Roy E. Isaac

February 1996

Work Performed Under Contract No.: DE-AC21-92MC29114

U.S. Department of Energy

Office of Environmental Management Office of Technology Development

Washington, DC

By

Halliburton NUS Corporation

Houston, Texas
For

U.S. Department of Energy

Office of Fossil Energy

Morgantown Energy Technology Center

Morgantown, West Virginia

\section{MASTER}

DISTRIBUTION OF THIS DOCUMENT IS UNLIMITED 


\section{DISCLAIMER}

This report was prepared as an account of work sponsored by an agency of the United States Government. Neither the United States Government nor any agency thereof, nor any of their employees, makes any warranty, express or implied, or assumes any legal liability or responsibility for the accuracy, completeness, or usefulness of any information, apparatus, product, or process disclosed, or represents that its use would not infringe privately owned rights. Reference herein to any specific commercial product, process, or service by trade name, trademark, manufacturer, or otherwise does not necessarily constitute or imply its endorsement, recommendation, or favoring by the United States Government or any agency thereof. The views and opinions of authors expressed herein do not necessarily state or reflect those of the United States Government or any agency thereof.

This report has been reproduced directly from the best available copy.

Available to DOE and DOE contractors from the Office of Scientific and Technical Information, 175 Oak Ridge Turnpike, Oak Ridge, TN 37831; prices available at (615) 576-8401.

Available to the public from the National Technical Information Service, U.S. Department of Commerce, 5285 Port Royal Road, Springfield, VA 22161; phone orders accepted at (703) 487-4650. 
善

瓷

ํㅗㄹ 


\title{
SoilSaw $^{\mathrm{TM}}$ Demonstration
}

\author{
Final Report \\ September 1992 - January 1995
}

Kent Saugier

Roy E. Isaac

Work Performed Under Contract No.: DE-AC21-92MC29114

U.S. Department of Energy

Office of Environmental Management

Office of Technology Development

1000 Independence Avenue

Washington, DC 20585
For

U.S. Department of Energy

Office of Fossil Energy

Morgantown Energy Technology Center

P.O. Box 880

Morgantown, West Virginia 26507-0880

By

Halliburton NUS Corporation

4100 Clinton Drive (77020-6299)

Post Office Box 3

Houston, Texas 77001-0003

February 1996 


\section{ABSTRACT}

The US. Department of Energy (DOE) has identified leaking underground storage tanks and buried mixed waste at numerous sites within the DOE complex. Preventing these wastes from entering the environment is a challenging task. One method of preventing waste migration is to isolate the contaminants using subsurface containment barriers ${ }_{\odot}$ Isolation and containment can be accomplished by both in situ and ex situ methods. This report describes a novel in situ construction method of forming vertical containment barriers (slurry walls) using the SoilSaw ${ }^{\mathrm{TM}}$ Barrier System.

The SoilSaw ${ }^{\mathrm{TM}}$ Barrier System is shown to be a feasible process for constructing subsurface vertical containment barriers to depths of fifty feet. The process is most efficient in sandy soil (including free flowing sand) with barrier construction rates of over one hundred thirty square feet per minute. Productivity diminishes to approximately thirty square feet per minute as soils become harder and more cohesive. The present hardware is designed to form a barrier of approximately 12 inch in width. Additional barrier widths can be constructed with this technology by application of wider jet heads. The requirement for a varied arrangement of barrier widths is an increase in hydraulic horse power and additional jet heads.

Both traditional materials of construction such as cement and bentonite and novel materials such as Montan Wax emulsions were used in the demonstration. Small amounts of chemical additives were used to modify slurry properties.

Barrier properties for the soil-cement-bentonite barriers constructed are characterized in terms of unconfined compressive strength (ASTM D 2166) and hydraulic permeability (ASTM D 5084). Barrier strengths are proportional to the amount of cement used in the grout and range from less than five psi for soil-bentonite barriers to greater than one hundred psi for soil-cement-bentonite barriers. Hydraulic permeability's range from $10-5$ to $10-9 \mathrm{~cm} / \mathrm{sec}$. Typical permeability values

for soil-cement-bentonite barriers constructed with the SoilSaw ${ }^{\mathrm{TM}}$ Barrier System are between $10-6$ and $10-7 \mathrm{~cm} / \mathrm{sec}$.

Costs range from $\$ 3.00$ to $\$ 7.00$ per square foot for construction of soil-cement-bentonite barriers. Costs vary depending on materials of construction, soil type, location and depth of barrier. 


\section{CONTENTS}

Section

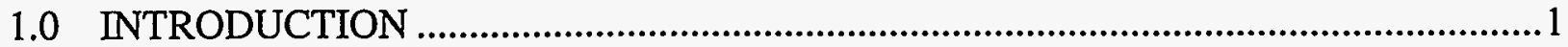

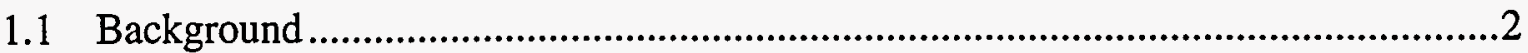

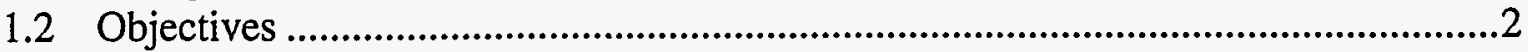

2.0 DESCRIPTION OF TECHNOLOGY ........................................................................

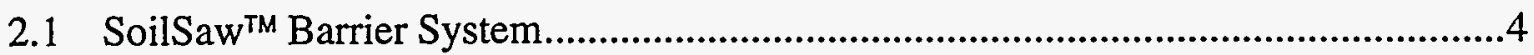

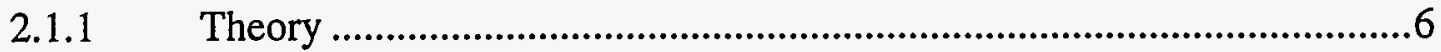

2.1.2 Site Investigation and Characterization ..................................................6

2.2 Equipment.....................................................................................................

2.2.1 Jetting Beam ..........................................................................................

2.2.2 Crawler Work Platform......................................................................10

2.2.3 Data Acquisition ...................................................................................10

2.2.4 Pumping Equipment...................................................................................10

2.2.5 Pipeline ................................................................................................11

2.2.6 Grout Plant..............................................................................................11

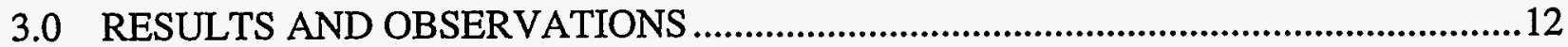

3.1 Demonstration \#1, Rush Springs, OK ......................................................................12

3.1.1 Introduction ..........................................................................................12

3.1.2 Objective...............................................................................................12

3.1.3 Site Soil Description ............................................................................12

3.1.4 Grout Formulation ........................................................................12

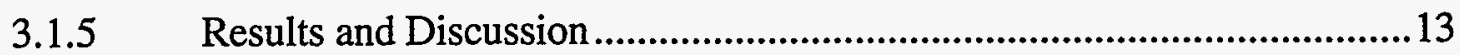

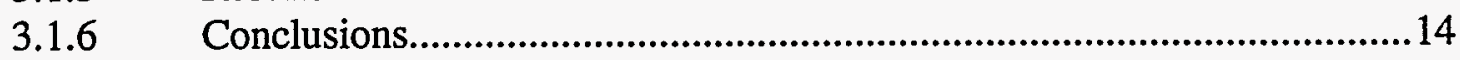

3.2 Demonstration \#2, Palestine, TX .....................................................................14

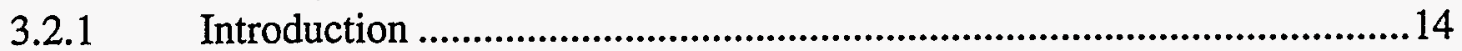

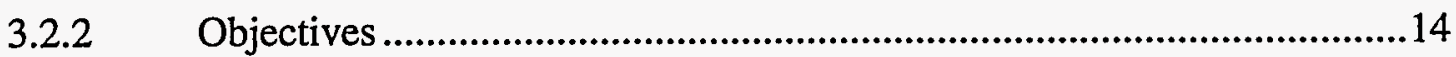

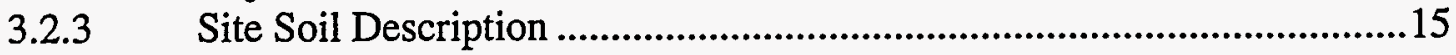

3.2.4 Grout Formulations ...................................................................................15

3.2.5 Results and Discussion Construction performance.....................................17

3.2.6 Barrier Quality ...................................................................................18

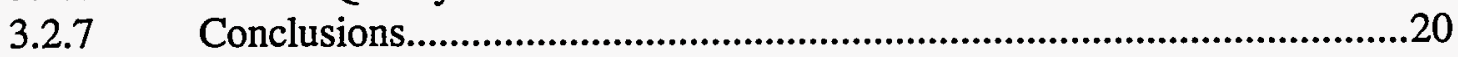

3.3 Demonstration \#3, DOE Savannah River Site, SC ....................................................20

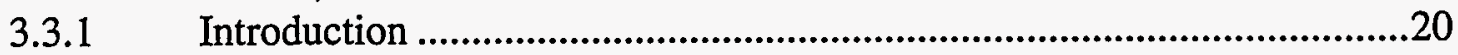

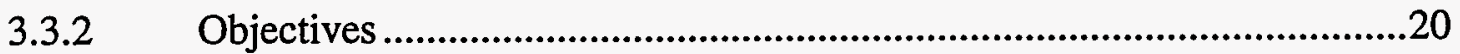

3.3.3 Site Equipment Layout................................................................................21

3.3.4 Site Soil Description ...........................................................................24

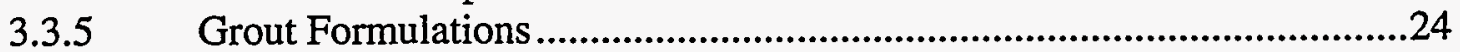

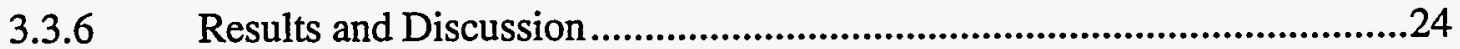

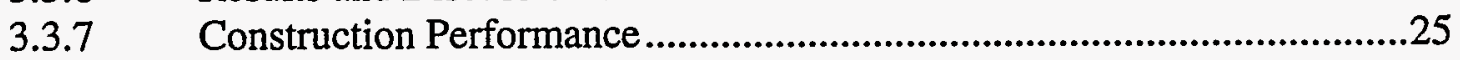

3.3.8 Barrier Quality ......................................................................................25

3.3.9 Conclusions............................................................................................27

3.4 Montan Wax Demonstration...............................................................................27

3.4.1 Objectives ............................................................................................27

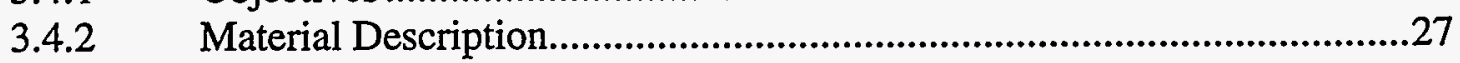

3.4.3 Pure Montan Wax Composition: ...............................................................27

3.4.4 Montan Wax Emulsion: ...........................................................................28 
G.4.5 Grout Formulation .......................................................................28

3.4.6 Results and Discussion ...................................................................28

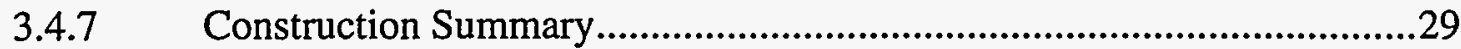

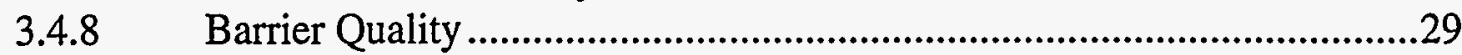

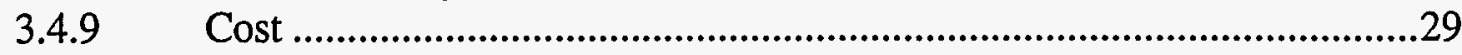

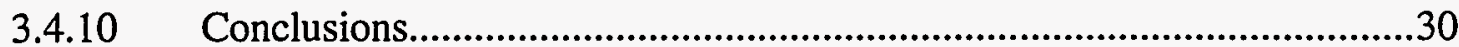

3.5 SoilSaw ${ }^{\mathrm{TM}}$ Depth Potential ........................................................................30

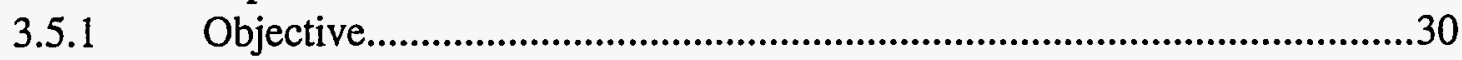

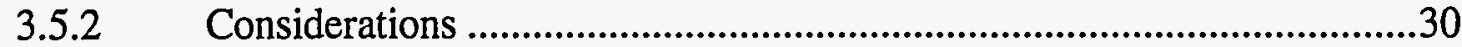

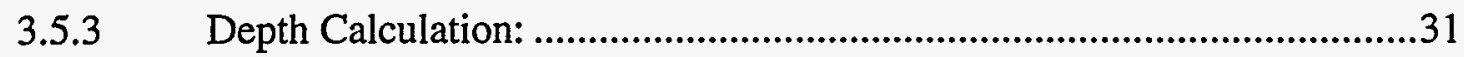

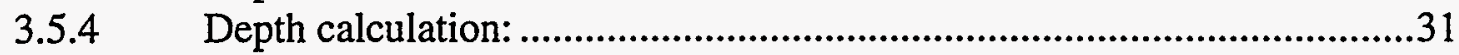

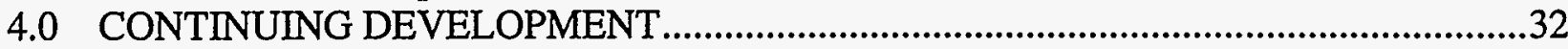

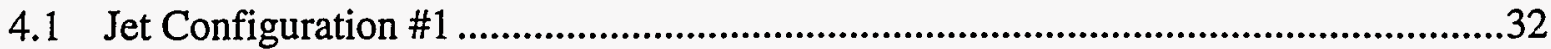

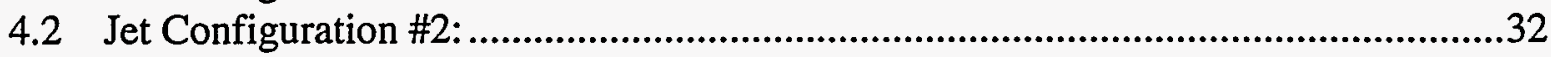

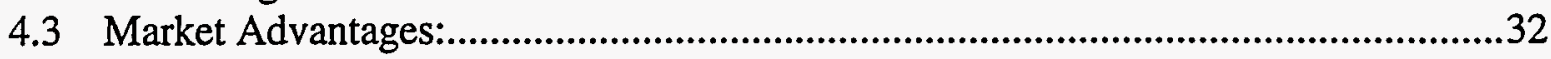

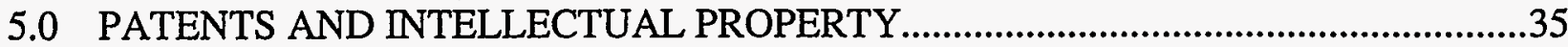

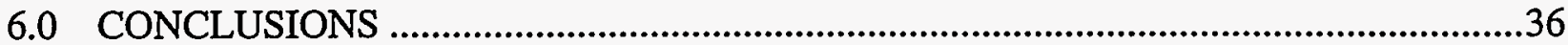

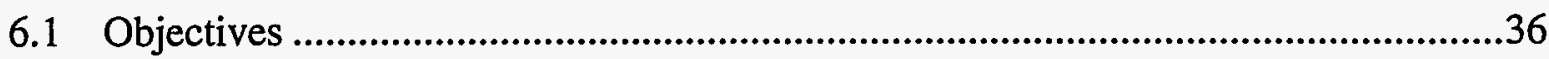

6.2 Advantages of the SoilSaw ${ }^{\mathrm{TM}}$ Method ..............................................................38

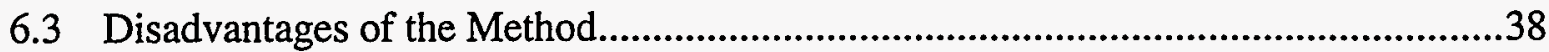

6.4 Cost for SoilSaw ${ }^{\mathrm{TM}}$ Production...........................................................................39

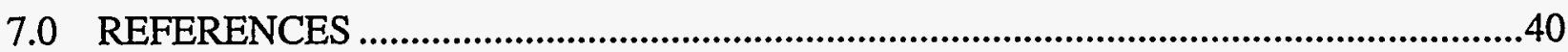

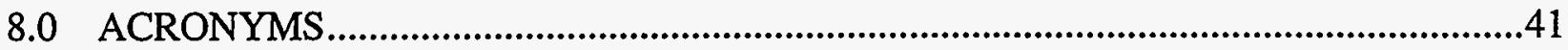

Appendix

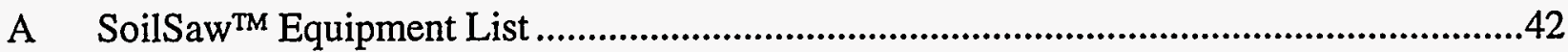

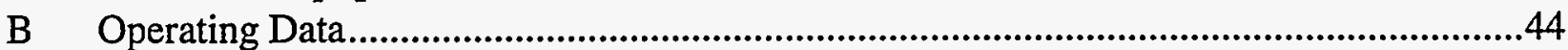

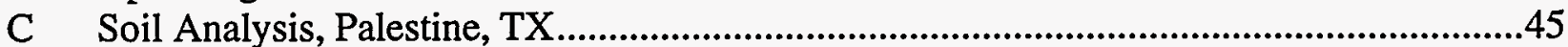

D Permeability, Strength, Soil and Formulation Data..............................................46

E Construction and Barrier Excavation Photographs.................................................47 


\section{TABLES}

Table

1 Grout Formulation, Rush Springs, OK Weight \% of Components .................................13

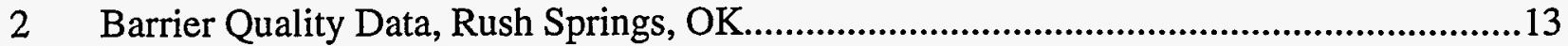

3 Grout Formulations, Palestine, TX Weight \% of Components.........................................15

$4 \quad$ Barrier Quality Data, Palestine, TX............................................................................19

5 Grout Formulations, SRS, SC Weight \% of Components ...............................................24

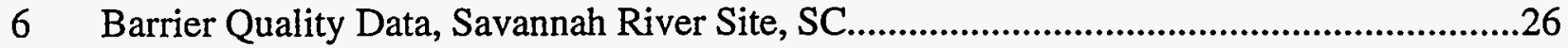

7 Montan Wax Composition and Grout Formulation Weight \% by Component ....................28

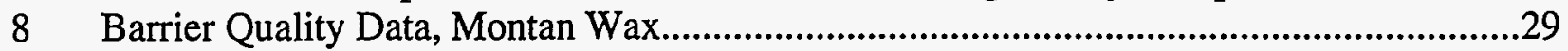

\section{FIGURES}

Figure

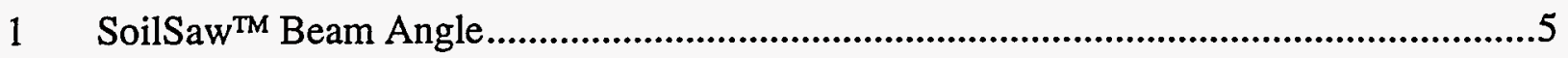

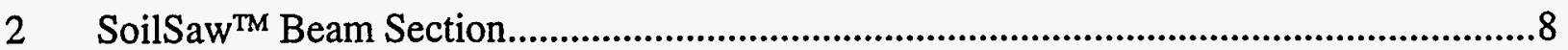

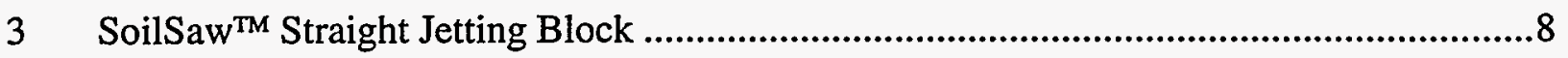

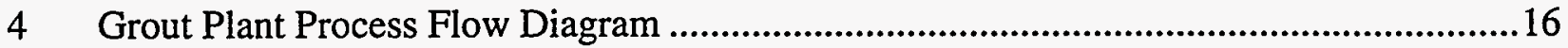

5 Site Equipment Diagram, Savannah River Site..........................................................22

6 Site Equipment Layout Savannah River Site ...........................................................23

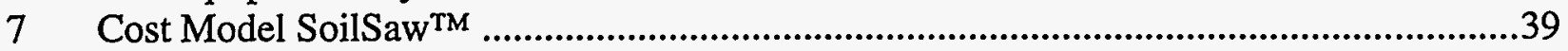




\subsection{INTRODUCTION}

Containment of buried hazardous, radioactive and mixed waste is a continuing problem in the United States. The goal of containment is to isolate hazardous, radioactive or mixed waste from the environment and, through isolation, prevent or halt existing waste sources from contaminating soil and ground water and, ultimately, negatively impacting human health.

Waste containment can be accomplished in situ or ex situ.

Ex situ methodologies for containment have the advantage of using well developed unit processes long deployed in the industrial community for similar work in non contaminated materials such as excavation, sorting, packaging and storage. However, the need to excavate and handle the waste has several significant drawbacks including increasing human exposure potential as well as increasing costs. Many of the existing waste problems within the DOE community are insoluble using ex situ methodology due to cost or technical feasibility.

In situ methodologies have the potential to isolate large volumes of waste from the environment without substantial increases in human exposure during the process. In contrast to ex situ methodologies, there are few unit processes available for in situ barrier formation to build upon.

However, in spite of this drawback, the case for in situ containment is a strong one. In terms of the volume of waste remediated or contained, the costs of in situ containment should be substantially less than ex situ processes. Environmental exposure during in situ containment should be orders of magnitude lower and, by avoiding handling and excavating equipment, additional waste generation is minimized.

Isolation of buried waste via in situ barrier construction has been identified as a viable strategy to prevent or halt existing waste sources from contaminating soil and ground water.

In situ barrier construction may be a lower cost option for containing certain types of waste. Some buried mixed wastes are presently being robotically excavated, handled, packaged and decontaminated to isolate them from the environment. Potentially wastes like these could be isolated in place by constructing in situ barriers. The high cost of ex situ containment suggests in situ methods could offer cost effective alternatives.

Not all buried waste problems can be adequately addressed with current technology. In situ containment, in addition to being potentially a more cost effective method for isolating hazardous waste, could, by preventing migration, provide additional time to allow cheaper or more effective methods for remediating waste to be developed. And current remediation methods deemed to be too slow to be practicable might become viable if remediation time could be extended by years, decades or centuries by forming an in situ remediation vessel through in situ containment.

This paper describes an in situ method of barrier construction. 


\subsection{Background}

The Halliburton Company has over 75 years experience in oil field technology. Combining this expertise with Halliburton NUS' recognition of the need for better methods of in situ containment of hazardous waste and contaminated ground water led to development of the SoilSaw ${ }^{T M}$ Barrier System. Four areas of technical expertise were essential to the success of the initial tests, grout formulation, grout mixing, high pressure grout pumping and Jet Grouting.

While all four areas are intimately involved in SoilSaw ${ }^{\top M}$ technology, Jet Grouting provides the foundation for the SoilSaw ${ }^{\mathrm{TM}}$ Barrier System.

Jet Grouting is a process for constructing columns of soil/cement by using high pressure grout jets to disrupt soil combining it in situ with the disrupting grout to form vertical columns of the resulting soil/cement mixture. The process is quite effective at forming columns and, when the columns are constructed side by side overlapping each other, at constructing subsurface barriers.

A modification of the Jet Grouting process instituted to improve the efficiency of constructing Jet Grouted barriers was broaching. Broaching is best described as continuous Jet Grouting where the Jet Grouting lance is never completely removed from the ground but is dragged sideways through the top part of the columns while continuing to operate normally to construct lower portions of the barrier.

The broaching concept was modified to incorporate a much larger, heavier lance with multiple jets on twelve foot centers with the whole apparatus operating at an angle and reciprocated in twelve foot strokes.

A pilot study confirmed feasibility of the process but raised may questions concerning practicality and profitability. To address the new issues a full scale feasibility test of SoilSaw ${ }^{\mathrm{TM}}$ was carried out in Rush Springs, OK, in the summer of 1992.

Patent applications covering SoilSaw ${ }^{\mathrm{TM}}$ technology have been submitted to the US. PTO.

\subsection{Objectives}

The objectives of the PRDA program for the SoilSaw ${ }^{\mathrm{TM}}$ Barrier System (SoilSaw ${ }^{\mathrm{TM}}$ ) were to develop a prototype SoilSaw ${ }^{\top \mathrm{M}}$, demonstrate its use to construct subsurface barriers and determine SoilSaw ${ }^{\mathrm{TM}}$ barrier quality.

There are two types of SoilSaw ${ }^{\mathrm{TM}}$ project objectives, those targeting constructability and practical implementation issues, and those targeting barrier performance issues. The first three objectives target constructability and implementation and the last two target barrier performance (quality).

The objectives are divided in this way because the relationship between a particular method of construction and the qualities of the barrier produced are not always related. Some construction methods produce inherently higher quality barriers than others but the interaction between 
construction method, contractor, soil type, grout formulation and barrier quality is not well established.

Therefore it is appropriate to evaluate the SoilSaw ${ }^{\mathrm{TM}}$ as a barrier construction method independently of evaluating the quality of the barriers constructed. This is reflected in the project objectives.

Project objectives and measures of success for the SoilSaw ${ }^{\mathrm{TM}}$ Projects are shown below:

\section{Objective}

1. Determine feasibility of operating at fifty foot depths

2. Model the depth potential of the SoilSaw ${ }^{\top M}$

3. Establish productivity for the SoilSaw ${ }^{\mathrm{TM}}$

4. Quantify SoilSaw ${ }^{\mathrm{TM}}$ bärrier quality

5. Assess Montan Wax use in the SoilSaw ${ }^{\top M}$ Barrier System

\section{Measure of Success (units)}

Operating depth (ft.)

Max. depth (ft.)

Productivity (sq. ft./min.)

Permeability $(\mathrm{cm} / \mathrm{sec}$.) Compressive strength (ucs) Permeability $(\mathrm{cm} / \mathrm{sec}$.)

Compressive strength (ucs)

Description of wax use

The decision to proceed with commercialization, pursue continued development or abandon the technology is supported by the objectives. 


\subsection{DESCRIPTION OF TECHNOLOGY}

\subsection{SoilSaw ${ }^{\mathrm{TM}}$ Barrier System}

The SoilSaw ${ }^{\mathrm{TM}}$ barrier system forms a similar final product to conventional slurry wall techniques, however it is actually a method of forming a "mixed-in-place" barrier. Unlike other mixed-in-place technologies this method is self-proving as to continuity. The method is inherently a continuous wall forming process. There are no joints or overlaps in the barriers constructed with the SoilSaw ${ }^{\mathrm{TM}}$.

The SoilSaw ${ }^{\top M}$ Barrier System uses high-energy grout "jetting" combined with mechanical reciprocating action to "cut" a narrow trench to great depth, blending the soils in situ with a permeability reducing agent, such as a cement/bentonite-based grout. The soil/grout mixture, may then harden, if desired, to form a plastic diaphragm wall. The Soil/grout mixture is generally as dense as the soil. This prevents native soil from sloughing off into the trench.

Instead of relying on mechanical stiffness of an excavating arm the SoilSaw ${ }^{\top \mathrm{M}}$ is continually positioned against the face of the trench by gravity acting on the SoilSaw ${ }^{\top M}$ Beam. The weight of the below-ground portions of the beam cause it to "fall" under the influence of gravity and press the cutting jets against the face of the trench. The beam is sufficiently heavy to resist the considerable thrust of the high-pressure jets which are eroding the soil face of the trench. As a result of this "falling beam" design, the SoilSaw ${ }^{\mathrm{TM}}$ beam is not subjected to significant mechanical loading, in normal operation, regardless of depth.

When the system is operating the jetting beam is reciprocated and soil under the beam is liquefied along the entire length of the beam and the free end (or toe) of the beam sinks into the ground.

As the beam reaches its working angle of about 45 degrees, the crawler machine begins to move at a rate which is continually adjusted to maintain the angle of the jetting beam. As the soil under the beam is mixed with the jetted grout it liquefies to a consistency similar to six-inch slump cement. At this point the jetting beam's weight causes it to sink through the processed soil/grout mixture. Sensors connected to the system's operating computer continuously record the jetting beam angle, crawler position, grout slurry pressure, and grout slurry density. Knowledge of the beam angle allows the true depth of the wall to be accurately computed as shown in Figure 1. 


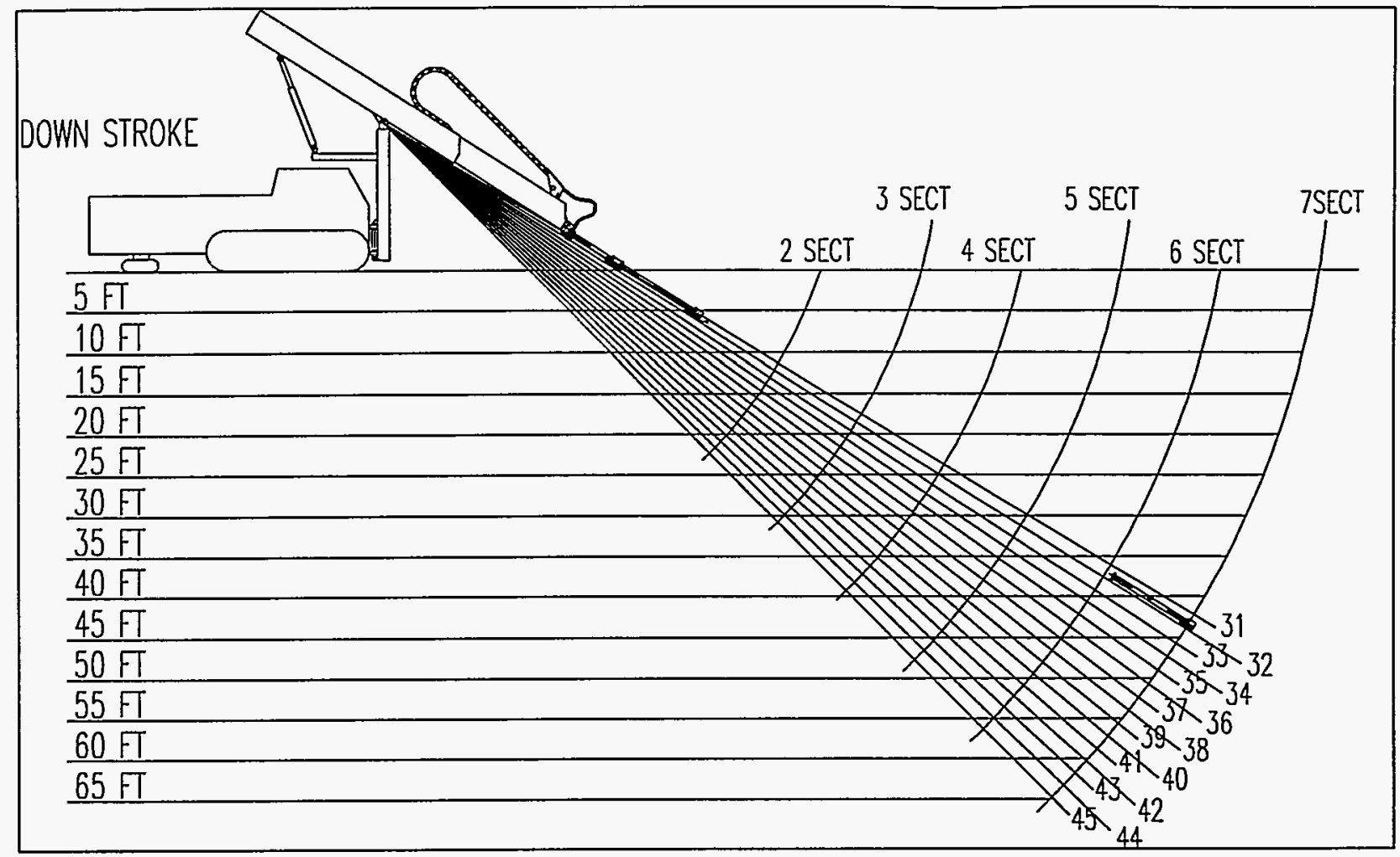

Figure 1 SoilSaw ${ }^{\mathrm{TM}}$ Beam Angle

The barrier wall key-in is determined by the depth of the barrier constructed. During the feasibility evaluation of the barrier wall, the aquiclude characteristics and depth are determined. The key-in can be straightforward in clay and weathered rock, but more complex in thin, discontinuous and fractured aquiclude. A sufficient seal can be formed between the barrier and hard bedrock as the jet head passes over the rock surface blasting it clean, which allows the grout/soil to bond to the rock.

High pressure grout slurry is supplied from mobile pumping equipment which moves ahead of the unit. When the crawler unit completes a section of wall, the jetting beam is pulled out of the hole and cleaned. The next day the jetting beam will make a new cut into the previous day's product beginning a new day's production and forming a seamless barrier wall.

\subsubsection{Theory}

The relative proportions of the grout slurry-to-soil ratio may be varied somewhat by changing the pressure or nozzle orifice size. The grout slurry materials are designed to allow the finished product to meet performance specifications for a variety of soil types and soil-to-grout ratios. Cement/bentonite grout slurries are designed to have a delayed set time and produce a product which has a high static gel strength and a density equal to that of the native soil. This prevents settling of rocks to the bottom of the wall or ground water intrusion. It also serves to limit product escape into underground voids or unstable formations. 
Unlike conventional methods of barrier wall construction, the SoilSaw ${ }^{\mathrm{TM}}$ method resolves many of the problems which may occur, too much backfill slump, too little slump, backfill fold over and sudden slurry loss. When the proper soil-to-grout ratios have been accomplished, the placement problems do not occur, except some soils may cause difficulty during sample taking. This problem has been resolved by the use of an appropriate amount of retarder. It has been demonstrated that a sudden slurry loss will not occur during barrier construction with the SoilSaw ${ }^{\mathrm{TM}}$.

Because the energy is conveyed to the bottom of the trench by fluid pressure, and forward thrust is supplied by gravity, the device can be configured to operate at great depth with no significant loss of efficiency. Mechanical excavating systems expend most of their limited power in overcoming friction, which increases with depth. The SoilSaw ${ }^{\mathrm{TM}}$ system is powered by standard Halliburton oil field cement slurry pumping units which are capable of supplying thousands of hydraulic horsepower to the cutting and mixing area. The SoilSaw ${ }^{\mathrm{TM}}$ Barrier System is able to effectively deliver over 2000 horsepower of useful work to the soil. This eliminates many historical productivity limits.

Since the energy is transmitted by pressure, the process is nearly free of mechanical vibration. The physics of the soil cutting and mixing process is a hydro-kinetic erosion process similar to jet grouting. It is more efficient than jet grouting since the jet stream does not have to pass through a thick layer of fluid before striking the work face. Just as in jet grouting, the high pressure of the fluid is converted to high kinetic energy as it exits the jets into the fluid filled open trench. Therefore, high pressure conditions do not exist in the trench itself since the fluid is not contained. This is significant because it allows the tools to be used in levee repair work where excess hydrostatic pressure could cause the toe of the levee to give way.

\subsubsection{Site Investigation and Characterization}

There are several factors to be taken into consideration during the site investigation and characterization phase of a barrier wall. For the most part during the demonstration period of the SoilSaw ${ }^{\top M}$, the subsurface investigation was determined to be most important in determination of soil hardness. This is directly related to jetting efficiency/square footage per minute of barrier constructed. This section of the site investigation will be performed as a matter of course by the design firm to formulate specifications for the remedial measures to be implemented at the site. The Geotechnical Services Report (Appendix C) represents an example of a subsurface investigation as completed for the demo site at Palestine, TX. In theory this data will be utilized as history for correlation of soil type to jetting efficiency of the SoilSaw ${ }^{\mathrm{TM}}$ and barrier quality.

It is not anticipated that a great variation of the geotechnical evaluation of a site be made specific to the utilization of the SoilSaw ${ }^{\top M}$.

\subsection{Equipment}

The SoilSaw ${ }^{\mathrm{TM}}$ Barrier System jetting beam consists of a 6-1/2 inch diameter heavy pipe with enlarged 12 inch diameter spools at regular intervals along the length of the pipe. These spools have a transverse row of jet orifices across their flat bottom, which are directed downward. This pipe is attached to a mechanical crawler machine at the upper end which has means to 
reciprocate the pipe along its length with a stroke equal to the spacing between the rows of jets (12 feet). The pipe is free to pivot vertically at the point it is attached to the crawler machine. The heavy pipe, or "jetting beam" is supplied with high pressure slurry from external mixing and pumping equipment at pressures of approximately $5000 \mathrm{psi}$. and rates of about $500 \mathrm{gpm}$.

\subsubsection{Jetting Beam}

The jetting beam is an assembly of modular 12 foot long units each consisting of three main components, a beam section, a spool section and a jetting block. A section of beam, the attached spool and a jetting block is shown below in Figure 2. Each beam is a 11 foot long section of 6$1 / 2$ inch diameter pipe with a 3 " internal bore weighing approximately $100 \mathrm{lbs}$./linear foot with a 12" diameter flange on each end used for modular assembly. Each spool section is one foot in diameter with a 3" internal bore, one foot long and has a key slot in the bottom for insertion of the jetting block. Grout channels in the spool connect the jetting block keyway to the internal bore of the spool. Jetting blocks are one foot wide rectangular blocks with grout channels bored into the downward face terminating in threaded openings for accepting grout jet nozzles. Jet openings in the jet block determine the pattern of grout placement and how it impacts the soil. Jets are arrayed in a straight pattern along the center axis of the block such that $7-10$ jets equally divide the width of the jetting block as shown in Figure 3. 


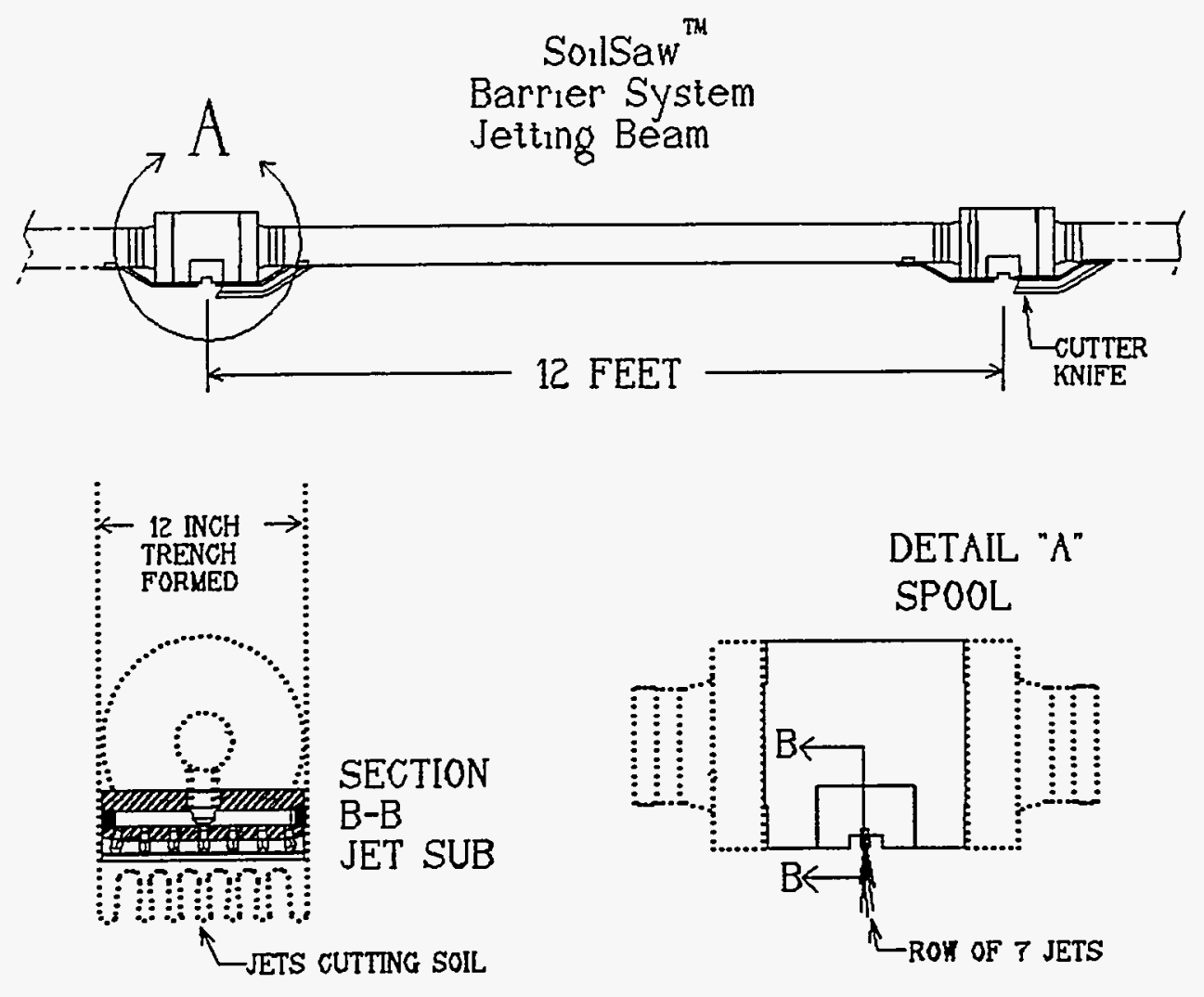

Figure 2 SoilSaw ${ }^{\mathrm{TM}}$ Beam Section 


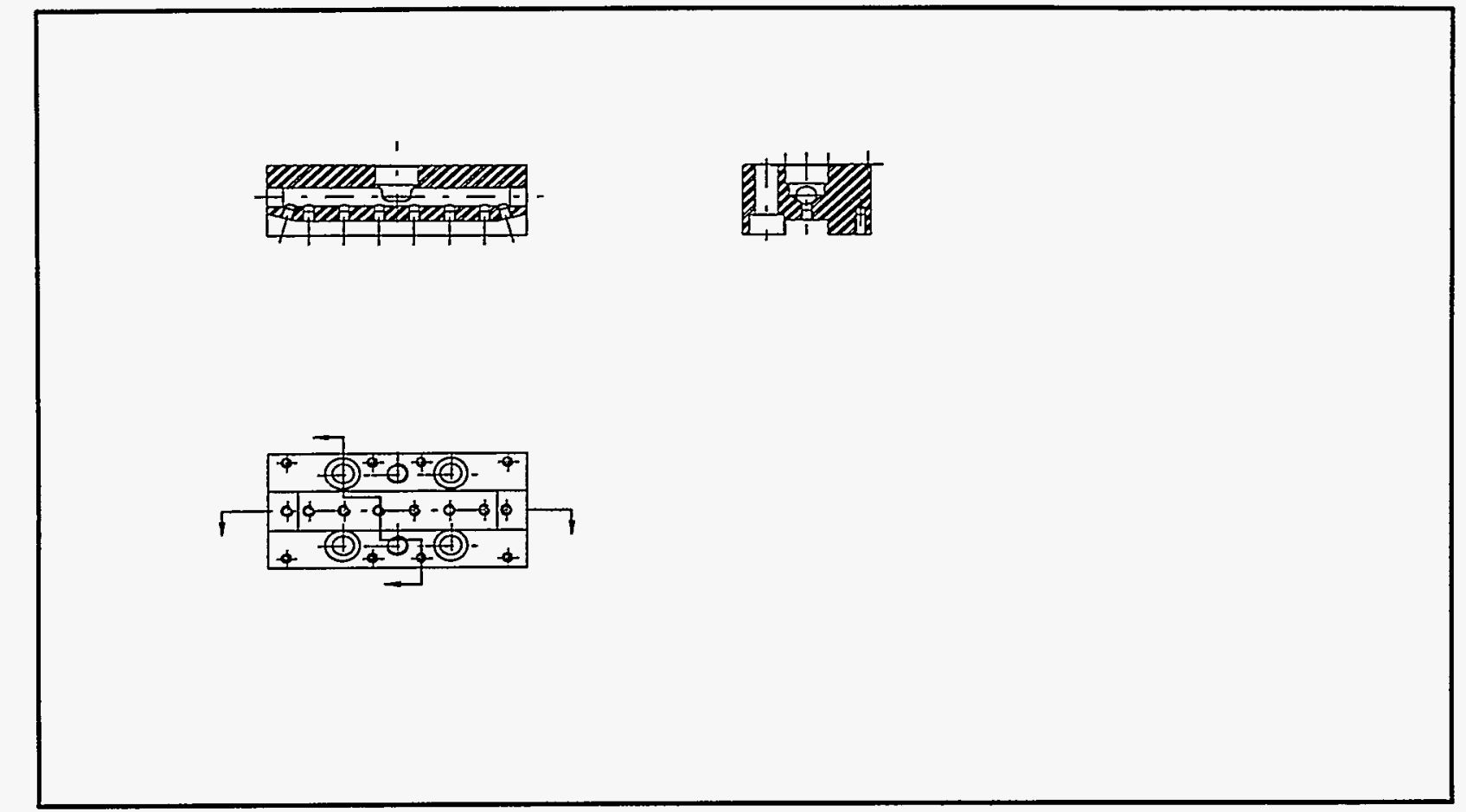

Figure 3 SoilSaw ${ }^{\mathrm{TM}}$ Straight Jetting Block 


\subsubsection{Crawler Work Platform}

At the beginning of the SoilSaw ${ }^{\mathrm{TM}}$ Demonstration Program the crawler work platform was a Gradall $880 \mathrm{E}$, a commercially available tracked excavator. The Gradall excavator is one of the few standard pieces of construction equipment specifically designed with the stroking movement required for the SSBS. The $880 \mathrm{E}$ is the largest track mounted GradalL available. Three modifications of the Gradall 880 were required:

- An optional high cradle was added to raise the pivot point of the arm.

- A hose track for the high pressure grout lines was added.

- A special link assembly mounting fixture replaced the standard bucket mount.

The major lesson learned during the demonstrations was that although the Gradall was suitable for sandy sites, dense clays and hard soils encountered at some sites would require more horsepower and more weight in the crawler.

Thus after the first demonstration (Palestine, TX) Halliburton NUS decided to construct a custom production scale stroking platform for the SoilSaw ${ }^{\mathrm{TM}}$ beam.

The production scale crawler machine built by Halliburton NUS is a specially modified Caterpillar D9 tractor as shown in photograph 13 and 14 (Appendix E).

The modified Caterpillar D9 weighs more than 150,000 lbs. fully deployed in the field. The custom made stroking boom is mounted at the rear of the D9. It is a modified, 50 ton telescoping hydraulic crane boom, fitted with an eight inch by 23 foot hydraulic cylinder. The boom is capable of delivering 75,000 pounds of force on the down stroke and 125,000 pounds of force on the upstroke.

\subsubsection{Data Acquisition}

Sensors on the crawler include boom and beam angle and travel distance. This information is simultaneously fed to an onboard display and data collection unit and a data acquisition system generally operated outside the unit. The data acquisition system combines the crawler data with grout data such as grout pressure, flow and density to provide a complete record of system operation. The onboard display unit provides the operator with information on the crawler operation as well as key slurry parameters. With the automation of stroking motion and tracking speed, the operator has ample time to monitor system performance and make adjustments to operating parameters.

\subsubsection{Pumping Equipment}

High pressure grout is supplied by standard truck mounted Halliburton HT-400 Frac Twins.

- Each pumping unit is capable of providing $250 \mathrm{gpm}$ of grout at pressures in excess of 10,000 psi. This equipment is further described in Appendix A. 


\subsubsection{Pipeline}

Grout is supplied to the high pressure pumps via 6" agricultural pipe or coiled 5" HDPE tubing. Agricultural pipe has proven problematic due to particulate matter in the pipe contaminating grout going to the high pressure pumps. Use of seamless coiled HDPE pipe solved this problem.

\subsubsection{Grout Plant}

Grout is prepared from bulk dry materials stored in special Halliburton high pressure dry storage bins, water and bulk liquid grout additives. These bulk materials are combined in open top tubs employing either physical paddle mixers, recalculation pumps or both to ensure uniform mixing. Grout properties are controlled by monitoring density of the finished product. Grout exits the grout mixing stage onto 50 micron stainless steel power screens to remove particulate from the finished grout. Finished grout is held in a 2,000 bbl surge tank prior to low pressure delivery to the high pressure grout pumps. 


\subsection{RESULTS AND OBSERVATIONS}

\subsection{Demonstration \#1, Rush Springs, OK}

\subsubsection{Introduction}

Prior to DOE funding, SoilSaw ${ }^{\top M}$ construction feasibility tests were completed in Rush Springs, OK. The site was chosen because it had deep free flowing sand, a classically difficult condition for barrier construction.

Prior to DOE funding, test objectives were focused on construction feasibility and qualitative evaluation of barrier quality. As part of the PRDA program it was proposed that the Rush Springs barrier quality be evaluated quantitatively (permeability and UCS) as well as qualitatively as originally planned.

Originally barrier permeability and strength were considered secondary issues because low quality grout formulations costing less could be used to evaluate barrier construction feasibility (the primary objective) without compromising our objectives. Thus, grout materials for the feasibility test were selected based on low cost and material availability. Permeability and strength of the Rush Spring barriers does not represent typical performance for SoilSaw ${ }^{\mathrm{TM}}$ barriers. Because raw materials for construction were not quality controlled the grout formulation shown for the barriers at Rush Springs is approximately what was used for the bulk of the work but may not represent the exact composition of grout used during construction of all sections of all the barriers.

\subsubsection{Objective}

Excavate and describe the physical appearance and geotechnical properties of barriers constructed with the SoilSaw ${ }^{\mathrm{TM}}$.

\subsubsection{Site Soil Description}

Soil at the Rush Springs site was sandy with no clay, gravel or silt indicated to a depth of 33 feet where an abrupt transition to sandstone occurred. Blow counts in the sandy surface soil ranged from 0 to 14 in the spt, indicating the absence of hard or cohesive soil in the top 33 feet of the test area. The water table was near the surface $0-10 \mathrm{ft}$.

\subsubsection{Grout Formulation}

The grout formulation was selected to minimize cost, not for geotechnical performance. The grout formulation used was a 1:1 by weight mixture of API class $\mathrm{H}$ cement and class F fly ash suspended in water to achieve a final grout density of 12 to 13 pounds per gallon, refer to Table 1.

This basic cementing composition consists of portland cement, class $\mathrm{H}$ and a pozzolanic material class F (Pozmix). This cement can be modified with accelerators or retarders to meet a wide range of temperature conditions. It is chemically similar to API Class B cement but is manufactured to more rigorous chemical and physical specifications which result in a more 
uniform product. As manufactured it contains no accelerators, retarders or viscosity control agents other than gypsum normally ground with cement clinkers. By definition a pozzolan is a siliceous material which reacts with lime and water to form calcium silicates having cementitious properties. Advantages of this reaction are utilized with Pozmix Cement since portland cements release approximately 15 per cent free lime when they react with water, and the lime will subsequently react with the Pozmix to yield a more durable mass of calcium silicates. Because this type of composition is less expensive than the other basic materials and performs well with most additives, it has almost universal application in oil well cementing.

Table 1 Grout Formulation, Rush Springs, OK

\begin{tabular}{|l|c|c|c|}
\hline & Cement & Fly Ash & Water \\
\hline $12 \mathrm{lb} . / \mathrm{gal}$ Grout & 25 & 25 & 50 \\
\hline
\end{tabular}

Weight \% of Components

\subsubsection{Results and Discussion}

Two barriers were constructed at the Rush Springs site. Each barrier was excavated in two locations and visually inspected for uniformity, color, inclusions and evidence of sloughing. The exposed portions of barriers $A$ \& $B$ are shown in photographs 1 and 2 respectively (Appendix E). The barriers appeared homogenous. No apparent variability of barrier color or consistency with depth was observed and no inclusions of sand pockets or other material was apparent within the barrier. The sides or edges of the barriers were consistently smooth resulting in a barrier of uniform one foot thickness. Barrier samples were collected with Shelby tubes, by in situ coring or by coring one cubic foot blocks of the barrier which were excavated and brought to the surface. All of the samples collected were from fully cured barriers (greater than 28 days in situ curing prior to sampling). A total of nine samples were taken for permeability and unconfined compressive strength testing.

Barrier quality data on permeability and unconfined compressive strength for the nine samples is shown below in Table 2:

Table 2 Barrier Quality Data, Rush Springs, OK

\begin{tabular}{|l|c|l|r|}
\hline & Sample Type & \multicolumn{1}{|c|}{ Permeability } & \multicolumn{1}{c|}{ Strength } \\
\hline Barrier A & Cured & $1.2 \times 10^{-5} \mathrm{~cm} / \mathrm{sec}$ & $6.9 \mathrm{psi}$ \\
\hline Barrier A & Cured & $1.5 \times 10^{-6} \mathrm{~cm} / \mathrm{sec}$ & $10.4 \mathrm{psi}$ \\
\hline Barrier A & Cured & $3.1 \times 10^{-6} \mathrm{~cm} / \mathrm{sec}$ & $25.0 \mathrm{psi}$ \\
\hline Barrier A & Cured & $5.0 \times 10^{-6} \mathrm{~cm} / \mathrm{sec}$ & $43.7 \mathrm{psi}$ \\
\hline Barrier A & Cured & $1.9 \times 10^{-6} \mathrm{~cm} / \mathrm{sec}$ & $44.4 \mathrm{psi}$ \\
\hline Barrier B & Cured & $7.3 \times 10^{-6} \mathrm{~cm} / \mathrm{sec}$ & $100.7 \mathrm{psi}$ \\
\hline Barrier B & Cured & $2.0 \times 10^{-6} \mathrm{~cm} / \mathrm{sec}$ & $22.9 \mathrm{psi}$ \\
\hline Barrier B & Cured & $5.6 \times 10^{-6} \mathrm{~cm} / \mathrm{sec}$ & $22.9 \mathrm{psi}$ \\
\hline Barrier B & Cured & $4.1 \times 10^{-6} \mathrm{~cm} / \mathrm{sec}$ & $153.4 \mathrm{psi}$ \\
\hline Standard & Cured & $1.0 \times 10^{-6} \mathrm{~cm} / \mathrm{sec}$ & $0-1,500 \mathrm{psi}$ \\
\hline
\end{tabular}

Values for SoilSaw ${ }^{\mathrm{TM}}$ barrier permeability's range from $1.2 \times 10^{-5} \mathrm{~cm} / \mathrm{sec}$ to $1.5 \times 10^{-6} \mathrm{~cm} / \mathrm{sec}$. These values are higher than the commonly specified standard barrier value shown in the table of $1.0 \times 10^{-6} \mathrm{~cm} / \mathrm{sec}$ and would not meet typical permeability requirements for commercial 
barrier performance. The most commonly used measure of barrier wall performance is the permeability of the completed cut-off. Often, the maximum permeability is specified at 10-7 $\mathrm{cm} / \mathrm{sec}$ (Lager 1982) for a soil/bentonite barrier. The permeability of cement/bentonite barriers is normally about $10-6 \mathrm{~cm} / \mathrm{sec}$ (Case 1982).

UCS values range from 6.9 psi to 153.4 psi. These values are well within the range of commercially acceptable values and would meet typical commercial barrier performance requirements.

The strength of soil/bentonite barrier walls in not usually of primary concern when designing pollution migration cut-offs. These walls are usually designed to be comparable in strength to the surrounding ground (Jefferis 1981b). Traffic caps are usually designed where traffic must pass over the barrier.

The strength of cement/bentonite barriers walls is designed to be slightly greater than that of the surrounding ground, and is typically comparable in strength to stiff clay (Jefferis 1981b, Millet and Perez 1981). Strengths of barriers can range from 10 to 1,000 psi., ultimate strengths are generally about 20 to 45 p.s.i. and are achieved after 28 days (Xanthakos 1979, Cavalli 1982).

Considering the grout formulation was chosen for low cost, with no consideration given to geotechnical performance, the results are surprisingly good. Addition of small amounts of bentonite or other permeability reducing agents to the grout formulation would be expected to improve permeability performance to meet typical standard commercial requirements.

\subsubsection{Conclusions}

The Rush Springs, OK, excavations show that in free flowing sand the following conclusions can be drawn about SoilSaw ${ }^{\mathrm{TM}}$ barriers:

1. Barriers are uniform, homogeneous and without inclusions

2. Barrier width is uniform and consistent

3. Barrier strength meets commercial performance requirements

4. Grout formulations that give better permeability should be used

\subsection{Demonstration \#2, Palestine, TX}

\subsubsection{Introduction}

The Palestine site was selected for its proximity to Houston and the length of barrier desired.

\subsubsection{Objectives}

The objectives for the Palestine, TX, demonstration fall into the two categories established earlier for the demonstration, construction objectives and barrier quality objectives. The objectives and measures of success for Palestine, TX, demonstration are shown below: 


\section{Construction Objectives}

1. Construct a barrier 30 feet deep

2. Establish productivity for the SoilSaw ${ }^{\mathrm{TM}}$

Barrier Quality Objectives

3. Quantify SoilSaw ${ }^{\top M}$ barrier quality
Measure of Success

Depth of barrier (ft.)

Productivity range (sq. ft./min.)

Measure of Success

Permeability $(\mathrm{cm} / \mathrm{sec}$.)

Compressive strength (ucs)

\subsubsection{Site Soil Description}

The Palestine, TX, site was a formerly used industrial smelting site in the East Texas rolling hills.

\section{Typical Depth \\ $0-4^{\prime}$ \\ 4 - 10' \\ $10-35^{\prime}$}

\section{Soil Description}

Firm to very stiff sandy clay and some fill

Very stiff sandy clay and silty clay

Stiff to very dense sandy clay

\subsubsection{Grout Formulations}

The grout formulations for the Palestine, TX, site were selected to provide acceptable permeability data and sufficient strength to provide a stable road subsurface upon restoration of the site.

Improvements were expected in the permeability by adding bentonite to the formulation. However, upon addition of cement to pre hydrated bentonite the mixture instantly gelled to form a non-freeflowing, unpumpable mixture. To remedy this problem, additives were tested to reduce the gelling and allow the desired grout mixture to be successfully pumped. Two different concentrations of cement and bentonite grouts along with a straight $5.9 \%$ pre hydrated bentonite grout were used.

Shown in Table 3 are the grout formulations used in the Palestine, TX, demonstrations:

Table 3 Grout Formulations, Palestine, TX

\begin{tabular}{|l|l|l|l|l|l|}
\hline & Bentonite & Cement & Water & Additive & Final Density \\
\hline 1. & 5.9 & & 94.1 & & $8.6 \mathrm{lb} . / \mathrm{gal}$ \\
\hline 2. & 4.2 & 29.3 & 66.5 & $<0.5$ & $10.8 \mathrm{lb} . / \mathrm{gal}$ \\
\hline 3. & 4.6 & 21.7 & 73.7 & $<0.5$ & $10.1 \mathrm{lb} . / \mathrm{gal}$ \\
\hline
\end{tabular}

Weight \% of Components 
A process flow diagram for the grout plant is shown in Figure 4. Photographs 3,4 and 5 (Appendix E) are of the actual plant.

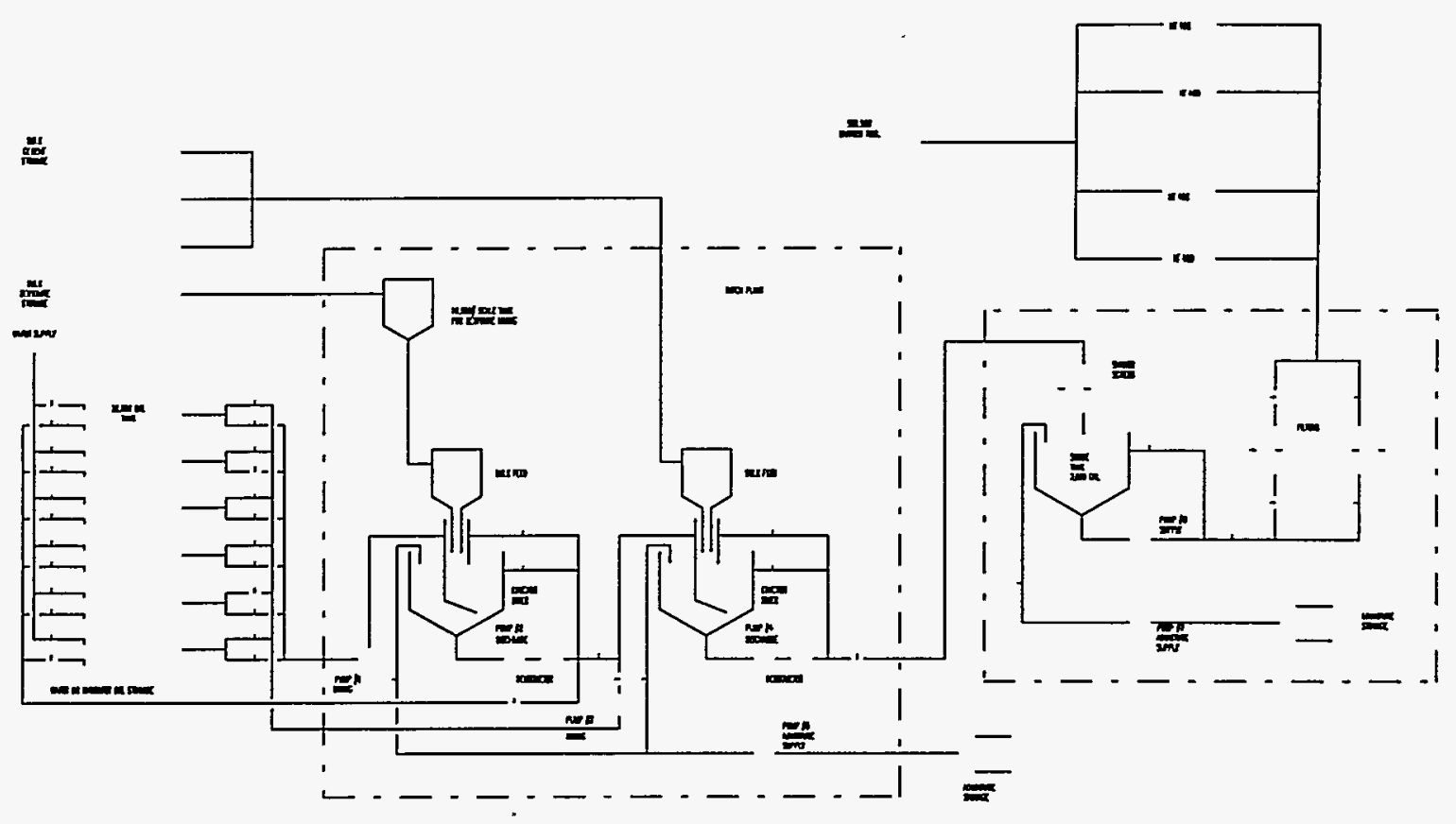

Figure 4 Grout Plant Process Flow Diagram 


\subsubsection{Results and Discussion Construction Performance}

Barriers were constructed at depths to 24 feet deep. Most of the barrier was constructed at 18 22 feet deep. Production rates were $18-44$ sq. ft./min. A $4-8$ inch thick rock layer was penetrated during construction and a barrier installed while cutting through the layer with a production rate of $20 \mathrm{sq}$. $\mathrm{ft} . / \mathrm{min}$.

Soils were very hard. Blow counts obtained by standard penetrometer testing (spt) during soil sampling ranged up to 100 indicating the presence of very hard materials, refer to Geotechnical Services Report (Appendix C). While not designed to operate in rock, the SoilSaw ${ }^{\mathrm{TM}}$ was able to penetrate and construct a barrier through stringers of hard, rock like, soil materials. Spoil produced during construction ranged from $115-250 \%$ of trench volume depending on cutting rate and soil type. A trench 20 feet deep and one foot wide generates from $10-50$ cubic feet of spoils as a mound on top of the trench as shown in photographs 6 and 7 in (Appendix E).

Productivity was characterized during four days of construction with periods calculation from 14 minutes to 94 minutes. The productivity during barrier construction at Palestine, TX ranged from $22-43$ sq. ft./min.

For the Palestine demonstration, the SoilSaw ${ }^{\mathrm{TM}}$ was mounted on a Gradall model $880 \mathrm{E}$ tractor. During construction the stroke rate was variable due to insufficient horsepower. This observation was substantiated by frequent stalling of the Gradall engine during construction of the barrier where stroking appeared to be most difficult.

The Gradall also appeared to be an unstable platform for the SoilSaw ${ }^{\top M}$ due to it's lightweight construction. During barrier construction the Gradall would at times be displaced from it's position by the action of the stroking cylinder powering the SoilSaw ${ }^{\mathrm{TM}}$ beam.

From these observations it was concluded that a larger more powerful stroking device and platform was needed for the SoilSaw ${ }^{\mathrm{TM}}$. In addition, a more powerful stroking device was needed to reciprocate the SoilSaw ${ }^{\mathrm{TM}}$ beam. To accomplish this an entirely new platform, stroking device and control system were needed.

Support equipment and systems were also evaluated during the Palestine, TX, demonstration. The combined function of all of the support systems was to provide the SoilSaw ${ }^{\mathrm{TM}}$ with up to $500 \mathrm{gpm}$ of specified grout mix at 5,000 psi through 200 feet of flexible hose. In addition there should be a continuous electronic and hard copy record of grout pressure, flow and density at both the SoilSaw and at the high pressure pumps, the boom, beam angle and the SoilSaw ${ }^{\mathrm{TM}}$ position. A representative example of SoilSaw ${ }^{\top M}$ operating data collected is shown in Appendix B.

The batch plant mixed and supplied contamination free grout as required although it operated at $100 \%$ capacity during some runs. The apparent production limitation was eductor size. Oil field shaker screens were completely effective in removing contamination from grout at the batch plant but as with the eductor, the screens used operated at capacity during some runs and may have been undersized. 
Mobilization and rig up took five days and only three were scheduled.

Low pressure grout delivery was accomplished using agricultural irrigation pipe. However, nominally clean agricultural piping, even after planning, contained enough contamination to clog all downstream low pressure filters multiple times. Pigging these low pressure lines did not provide the required level of contaminant removal. Low pressure filters installed as a prophylactic against contamination in the low pressure grout supply system worked perfectly and saved a tremendous amount of down time that would have been experienced due to low pressure grout supply contamination.

A mobile surge tank supplied a grout supply buffer and provided tractive force for the high pressure pumps.

The high pressure pumps supplied 5,000 psi grout as required. The engines and pumps had some hydraulic leaks. This may be an issue and needs to be corrected. High pressure pumping capacity was excellent, the use of two pumping units was somewhat awkward to rig but performed well.

Data collecting was almost flawless but a full-time data collection operator was required to maintain recording function. Some of the instruments needed mechanical strengthening.

Incremental improvements to the SoilSaw ${ }^{\mathrm{TM}}$ suggested during this demonstration include widening jet subs, adapting the nose sub, fabricating more aggressive teeth and modifying the link assembly.

\subsubsection{Barrier Quality}

Two barriers were constructed at Palestine, TX, using three different grout formulations. Each barrier was excavated and all grout formulations were exposed, sampled and visually inspected for uniformity, color, inclusions and evidence of sloughing. Exposed portions of barriers 1 - 3 are shown in Photographs 8, 9,10,11 and 12 (Appendix E).

The barriers were highly homogenous. No apparent variability of barrier color or consistency with depth was observed. This is especially significant and conclusive at Palestine due to the highly varied color of the soil by depth. No inclusions of sand pockets or other material was apparent within the barrier. The sides or edges of the barriers were consistency smooth resulting in a barrier of uniform one foot thickness.

Barrier samples were collected with Shelby tubes, by in situ coring or by coring one cubic foot blocks of the barrier which were excavated and brought to the surface. All of the samples collected were from fully cured barriers (greater than 28 days in situ curing prior to sampling).

Barrier quality data on permeability and unconfined compressive strength is shown in Table 4. 
Table 4 Barrier Quality Data, Palestine, TX

\begin{tabular}{|l|l|l|l|}
\hline & Sample Type & Bulk & Permeability \\
\hline Barrier 1 & Bulk & $9.1 \times 10^{-9} \mathrm{~cm} / \mathrm{sec}$ & $0.9 \mathrm{psi}$ \\
\hline Barrier 1 & Bulk & $1.6 \times 10^{-8} \mathrm{~cm} / \mathrm{sec}$ & $0.45 \mathrm{psi}$ \\
\hline Barrier 1 & Bulk & $1.1 \times 10^{-8} \mathrm{~cm} / \mathrm{sec}$ & $1.38 \mathrm{psi}$ \\
\hline Barrier 1 & Bulk & $5.6 \times 10^{-9} \mathrm{~cm} / \mathrm{sec}$ & $1.03 \mathrm{psi}$ \\
\hline Barrier 2 & $\mathrm{pt}$ & $6.4 \times 10^{-7} \mathrm{~cm} / \mathrm{sec}$ & $53.5 \mathrm{psi}$ \\
\hline Barrier 2 & $\mathrm{pt}$ & $1.1 \times 10^{-6} \mathrm{~cm} / \mathrm{sec}$ & $12.5 \mathrm{psi}$ \\
\hline Barrier 2 & $\mathrm{pt}$ & $8.6 \times 10^{-7} \mathrm{~cm} / \mathrm{sec}$ & $41.7 \mathrm{psi}$ \\
\hline Barrier 2 & $\mathrm{pt}$ & $4.2 \times 10^{-5} \mathrm{~cm} / \mathrm{sec}$ & $65.9 \mathrm{psi}$ \\
\hline Barrier 2 & Core & $7.6 \times 10^{-6} \mathrm{~cm} / \mathrm{sec}$ & $52.8 \mathrm{psi}$ \\
\hline Barrier 2 & Core & $2.5 \times 10^{-5} \mathrm{~cm} / \mathrm{sec}$ & $26.4 \mathrm{psi}$ \\
\hline Barrier 2 & Shelby & $6.6 \times 10^{-7} \mathrm{~cm} / \mathrm{sec}$ & $45.8 \mathrm{psi}$ \\
\hline Barrier 2 & Shelby & $1.1 \times 10^{-6} \mathrm{~cm} / \mathrm{sec}$ & $76.4 \mathrm{psi}$ \\
\hline Barrier 2 & Core & $9.1 \times 10^{-6} \mathrm{~cm} / \mathrm{sec}$ & $54.8 \mathrm{psi}$ \\
\hline Barrier 2 & Core & $2.9 \times 10^{-6} \mathrm{~cm} / \mathrm{sec}$ & $56.3 \mathrm{psi}$ \\
\hline Barrier 3 & Bulk & $2.9 \times 10^{-7} \mathrm{~cm} / \mathrm{sec}$ & $48.6 \mathrm{psi}$ \\
\hline Barrier 3 & Bulk & $1.2 \times 10^{-7} \mathrm{~cm} / \mathrm{sec}$ & $49.3 \mathrm{psi}$ \\
\hline Barrier 3 & Bulk & $5.8 \times 10^{-7} \mathrm{~cm} / \mathrm{sec}$ & $31.3 \mathrm{psi}$ \\
\hline Barrier 3 & Core & $4.9 \times 10^{-6} \mathrm{~cm} / \mathrm{sec}$ & $37.5 \mathrm{psi}$ \\
\hline Barrier 3 & Core & $1.6 \times 10^{-6} \mathrm{~cm} / \mathrm{sec}$ & $25.0 \mathrm{psi}$ \\
\hline Barrier 3 & Core & $3.9 \times 10^{-6} \mathrm{~cm} / \mathrm{sec}$ & $21.5 \mathrm{psi}$ \\
\hline Barrier 3 & Core & $7.2 \times 10^{-6} \mathrm{~cm} / \mathrm{sec}$ & $40.3 \mathrm{psi}$ \\
\hline Standard & Cured & $1.0 \times 10^{-6} \mathrm{~cm} / \mathrm{sec}$ & $0-1,500 \mathrm{psi}$ \\
\hline
\end{tabular}

Values for SoilSaw ${ }^{\mathrm{TM}}$ barrier permeability's show different ranges according to the formulation. Soil/bentonite barriers (grout formulation 1) range in permeability's from $5.6 \times 10^{-9} \mathrm{~cm} / \mathrm{sec}$ to $1.6 \times 10^{-8} \mathrm{~cm} / \mathrm{sec}$. These values are much better than the commonly specified barrier standard shown in Table 4 of $1.0 \times 10^{-6} \mathrm{~cm} / \mathrm{sec}$ and would exceed typical permeability requirements for commercial barrier performance.

UCS values for soil/bentonite barriers range from $0.5 \mathrm{psi}$ to $1.38 \mathrm{psi}$. These values are well within the range of commercially acceptable values and would meet typical commercial barrier performance requirements.

Values for soil/cement/bentonite barriers (grout formulations 2 and 3), when sampled by coring, Shelby or push tube methods, range in permeability's from $4.2 \times 10-5 \mathrm{~cm} / \mathrm{sec}$ to $1.2 \times 10-7$ $\mathrm{cm} / \mathrm{sec}$. These values span the commonly specified barrier permeability standard of $1.0 \times 10-6$ $\mathrm{cm} / \mathrm{sec}$ and would not all meet typical permeability requirements for commercial barrier performance. Since obtaining these samples, it has been shown that the three methods used to sample the Palestine barrier, coring, Shelby or push tube, all contribute to poor laboratory permeability's and thus these samples probably represent maximum permeability values for this site and grout formulation. 
Failed samples from Table 4 are suspect due to method of retrieval (undisturbed sampling) which has proved to be an unacceptable method of sampling. Should the specification call for undisturbed sampling and samples did not pass permeability and or strength requirements, grout formulation would be reviewed for that specific area of the barrier and adjusted accordingly. If the barrier type was soil/bentonite a new barrier could be placed in the same trench or if required placed next the suspect barrier. If the barrier was constructed of cement/bentonite it may be necessary to construct a new barrier next to the failed unit. In both cases grout formulation would be reviewed and changed accordingly.

UCS values for soil/bentonite barriers range from $12.5 \mathrm{psi}$ to $76.4 \mathrm{psi}$. These values are well within the range of commercially acceptable values and would meet typical commercial barrier performance requirements.

Use of small amounts of pre-hydrated bentonite in the grout formulation improved permeability performance as predicted but, due to sampling effects, failed to produce barriers uniformly meeting typical standard commercial requirements.

\subsubsection{Conclusions}

1. Barrier construction was successful at a depth of 24 feet

2. Productivity of $44 \mathrm{sq} . \mathrm{ft} . / \mathrm{min}$. is established

3. Barrier quality exceeds standards for some formulations used

4. Barriers are uniform, homogeneous and without inclusions

5. Barrier width is uniform and consistent

6. Barrier strength meets commercial performance requirements

\subsection{Demonstration \#3, DOE Savannah River Site, SC}

\subsubsection{Introduction}

Savannah River Site (SRS) was included to demonstrate the SoilSaw ${ }^{\top M}$ in another soil type and on a DOE site.

\subsubsection{Objectives}

The objectives for the SRS demonstration are shown below. Within two of the objectives were sub-objectives based on improvements and observations made in response to previous demonstrations.

1. Construct barriers 25 and 50 feet deep

a. Evaluate the new stroking device and the $\mathrm{D} 9 \mathrm{H}$ as a platform for the SoilSaw ${ }^{\mathrm{TM}}$

b. Evaluate HDPE hose reel for low pressure grout supply

2. Demonstrate good barrier quality

a. Use new "trim" method to sample cured barriers for permeability testing 
3. Assess Montan Wax compatibility and performance

\subsubsection{Site Equipment Layout}

Figure 6 represents the site equipment diagram for the grout flow process. The actual Savannah River Site Equipment Layout is represented in Figure 7. The grout mixing plant and laydown area utilized approximately a $200 \times 200$ foot space. The space is ample for a full scale operation and could be sized down if required. The high pressure pumping equipment can be placed inline with the SoilSaw ${ }^{\top M}$ and moved as required, however space at the Savannah River Site allowed the equipment to be set-up stationary. A width of 14 foot will accommodate the SoilSaw ${ }^{\mathrm{TM}}$ in-line concept with ample room for hose movement and rig-up around the unit. 


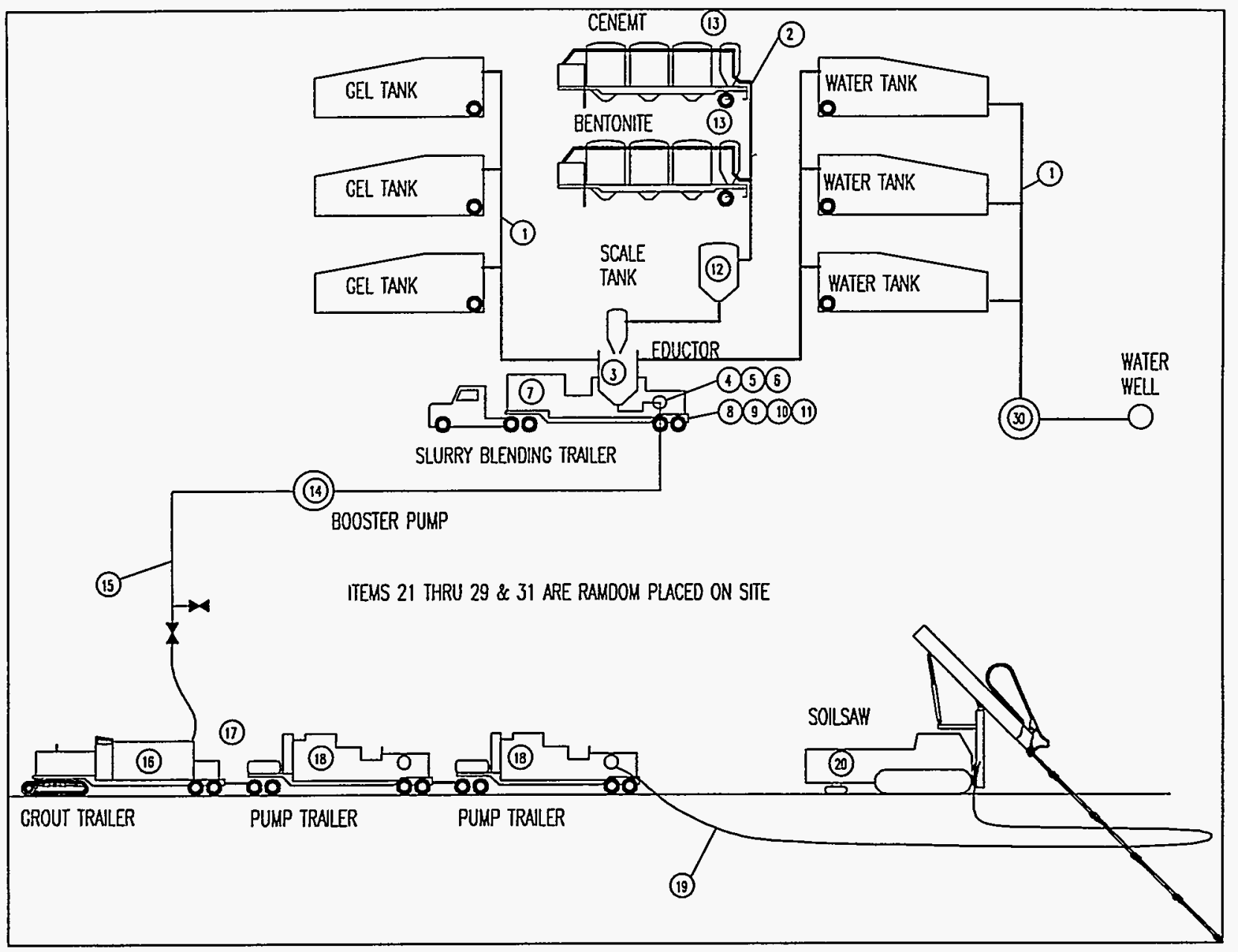

Figure 5 Site Equipment Diagram, Savannah River Site 
meor ancos

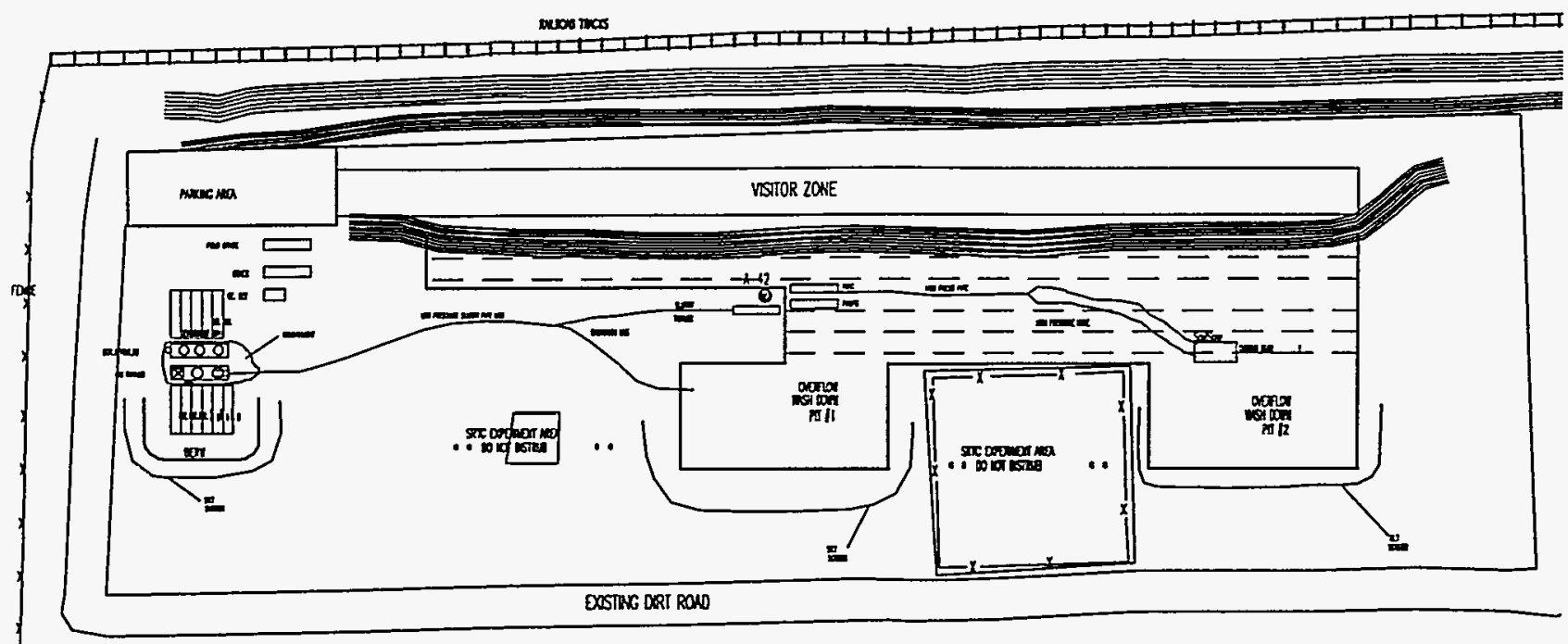

Figure 6 Site Equipment Layout Savannah River Site 


\subsubsection{Site Soil Description}

The SRS has interbedded layers of clay and sand to depths of hundreds of feet. The demonstration site was in an area preselected for technology demonstrations and CPT data was available for representative locations within the site.

Existing CPT data indicated clayey silt and clayey sand to depths in excess of 50 feet with narrow sand stringers. Blow counts were high in the top portions of the site with some values in excess of 100 indicating the presence of hard soil. A summary of the available geotechnical data is shown below:

\section{Typical Depth Soil Description \\ $0-10^{\prime} \quad$ Clay with fine gravel \\ $10-20^{\prime} \quad$ Clayey silt \\ 20- 37 Clay \& sand \\ $37-40$, Sandy \\ 40- 65' Clayey silt, sandy silt}

\subsubsection{Grout Formulations}

Grout formulations used in Palestine, TX, set much more quickly than was desirable (within one hour) making sampling difficult and beam extraction and reinsertion difficult if not impossible. As a remedy to the rapid set problem a grout formulation was developed with less cement and more retarder to facilitate working in clay soils. The retarder utilized in the formulation was from the Lignin chemical family, Lignosulfonic Acid, Sodium Salt; CAS \# 8061-51-6, LIGNOSITE® 431-H; Sodium Lignosulfonate.

Shown below in Table 5 are the formulations developed for SRS:

Table 5 Grout Formulations, SRS, SC Weight \% of Components

\begin{tabular}{|l|l|l|l|l|l|}
\hline & Bentonite & Cement & Water & Additive & Final Density \\
\hline 1. & 8.3 & -- & 91.8 & -- & $8.8 \mathrm{lb} . / \mathrm{gal}$ \\
\hline 1a. & 6.6 & $-\cdots$ & 93.3 & -- & $8.7 \mathrm{lb} . / \mathrm{gal}$ \\
\hline $3 \mathrm{a}$. & 5.8 & 12.0 & 80.4 & 1.8 & $9.6 \mathrm{lb} . / \mathrm{gal}$ \\
\hline 5. & 4.3 & -- & 95.7 & -- & $8.6 \mathrm{lb} . / \mathrm{gal}$ \\
\hline $5 \mathrm{a}$. & 6.6 & -- & 91.5 & 1.8 & $8.7 \mathrm{lb} . / \mathrm{gal}$ \\
\hline
\end{tabular}

\subsubsection{Results and Discussion}




\subsubsection{Construction Performance}

Eight inches of rain fell during the demonstration slowing operations and highlighting the time required to reconfigure the SoilSaw ${ }^{\top M}$ beam. While this is an issue during prototype testing and SoilSaw ${ }^{\top M}$ technology development, it is not anticipated that frequent beam changes would be necessary on commercial jobs because barriers are usually of relatively uniform depth and the SoilSaw ${ }^{\top M}$ can adjust the depth of barrier construction by adjusting the angle of operation. Thus, while in a demonstration mode, beam reconfiguration is slow, modification to improve handling characteristics is probably not worth the cost.

All of the support systems performed well, the grout plant and high pressure pump trucks consistently supplied 5,000 psi grout at up to $550 \mathrm{gpm}$ upon demand, data collection was almost flawless and use of the $\mathrm{D} 9 \mathrm{H}$ in place of the Gradall solved SoilSaw ${ }^{\mathrm{TM}}$ platform issues observed at Palestine, TX. Refer to photographs 13 and 14 for the SoilSaw ${ }^{\top M}$ D9H while grouting at Savannah River site.

Cutting in (beginning barrier construction) was executed as done previously by starting the SoilSaw ${ }^{\top M}$ beam on the surface and stroking it back and forth while supplying grout at high pressure. The beam attained the targeted angle somewhat slower than expected and continued to function as planed, constructing barrier at a rate of $28 \mathrm{sq}$. ft./minute.

Soils at SRS were primarily hard clay and hard silty clay and productivity ranged from $28-35$ sq. ft./minute.

\subsubsection{Barrier Quality}

Two barriers were constructed at SRS using three different grout formulations. Each barrier was excavated and all grout formulations were exposed and sampled and visually inspected for uniformity, color, inclusions and evidence of sloughing. Exposed portions of the barriers are shown in photographs 15,16, 17, 18, 19 and 20 respectively (Appendix E).

The barriers were highly homogenous. No apparent variability of barrier color or consistency with depth was observed although barriers constructed with different formulations were different colors and consistencies. This is especially apparent at SRS due to the highly varied color of the soil by depth. No inclusions of sand pockets or other material was apparent within the barrier. In one excavated sample taken from a portion of the barrier constructed through a highly colored purple clay layer inclusions of purple clay approximately 0.25 inch in diameter are visible. There was no measured effect on barrier quality due to the inclusions. Sides and edges of the barriers were consistently straight as shown in photographs 19 and 20, confirming the earlier observations that the barrier is of uniform one foot thickness.

All of the samples were collected from fully cured barriers (greater than 28 days in situ curing prior to sampling). A total of thirteen samples were taken for permeability and unconfined compressive strength testing.

Barrier quality data on permeability and unconfined compressive strength is shown below in Table 6. 
Table 6 Barrier Quality Data, Savannah River Site, SC

\begin{tabular}{|l|l|l|l|}
\hline & Sample Type & Permeability & Strength \\
\hline Barrier 1 & Bulk & $1.4 \times 10^{-8} \mathrm{~cm} / \mathrm{sec}$ & $2.4 \mathrm{psi}$ \\
\hline Barrier 1 & Bulk & $1.1 \times 10^{-8} \mathrm{~cm} / \mathrm{sec}$ & $2.6 \mathrm{psi}$ \\
\hline Barrier 1 & Trim & $3.2 \times 10^{-8} \mathrm{~cm} / \mathrm{sec}$ & $1.2 \mathrm{psi}$ \\
\hline Barrier 1 & Trim & $2.0 \times 10^{-8} \mathrm{~cm} / \mathrm{sec}$ & $1.6 \mathrm{psi}$ \\
\hline & & & \\
\hline Barrier 3a & Bulk & $1.9 \times 10^{-7} \mathrm{~cm} / \mathrm{sec}$ & $45 \mathrm{psi}$ \\
\hline Barrier 3a & Bulk & $2.6 \times 10^{-7} \mathrm{~cm} / \mathrm{sec}$ & $40 \mathrm{psi}$ \\
\hline & & & \\
\hline Barrier 3a & Trim & $9.3 \times 10^{-7} \mathrm{~cm} / \mathrm{sec}$ & $71 \mathrm{psi}$ \\
\hline Barrier 3a & Trim & $7.5 \times 10^{-7} \mathrm{~cm} / \mathrm{sec}$ & $31 \mathrm{psi}$ \\
\hline Barrier 3a & Trim & $7.5 \times 10^{-7} \mathrm{~cm} / \mathrm{sec}$ & $32 \mathrm{psi}$ \\
\hline & & & \\
\hline Barrier 3a & Bulk & $3.1 \times 10^{-7} \mathrm{~cm} / \mathrm{sec}$ & $50 \mathrm{psi}$ \\
\hline Barrier 3a & Bulk & $2.9 \times 10^{-7} \mathrm{~cm} / \mathrm{sec}$ & $47 \mathrm{psi}$ \\
\hline Barrier 3a & Bulk & $2.8 \times 10^{-7} \mathrm{~cm} / \mathrm{sec}$ & $9 \mathrm{psi}$ \\
\hline Barrier 3a & Bulk & $4.0 \times 10^{-7} \mathrm{~cm} / \mathrm{sec}$ & $12 \mathrm{psi}$ \\
\hline & & & $0-1,500 \mathrm{psi}$ \\
\hline Standard & Cured & $1.0 \times 10^{-6} \mathrm{~cm} / \mathrm{sec}$ & \\
\hline
\end{tabular}

Values for SRS barrier permeability's show different ranges according to the formulation. The soil/bentonite barrier samples (barrier l) had a range of permeability's from $1.1 \times 10-8 \mathrm{~cm} / \mathrm{sec}$ to $3.2 \times 10-8 \mathrm{~cm} / \mathrm{sec}$. As seen previously at Palestine, TX, for soil/bentonite barriers these values are all an order of magnitude better than commonly specified barrier standard as shown in Table $6(1.0 \times 10-6 \mathrm{~cm} / \mathrm{sec})$ and would exceed typical permeability requirements for commercial barrier performance.

As expected, ucs values for soil/bentonite barriers are low and range from 1.2 psi to $2.6 \mathrm{psi}$. These values are normal and well within the range of commercially acceptable values and would meet typical commercial barrier performance requirements.

Values for SRS samples of soil/cement/bentonite barriers (barrier 3a) range in permeability from $9.3 \times 10-7 \mathrm{~cm} / \mathrm{sec}$ to $1.9 \times 10-7 \mathrm{~cm} / \mathrm{sec}$. These values are all better than the commonly specified barrier standard shown in Table 6 of $1.0 \times 10-6 \mathrm{~cm} / \mathrm{sec}$ and would meet typical permeability requirements for commercial barrier performance.

UCS values for soil/bentonite barriers range from $9.0 \mathrm{psi}$ to $71 \mathrm{psi}$. These values are well within the range of commercially acceptable values and would meet typical commercial barrier performance requirements. Changing the sampling methodology to the trim method may have contributed to the permeability values obtained for the cured SRS samples. 
The use of small amounts of pre hydrated bentonite in the grout formulation once again demonstrated improved permeability performance and with the new trim sampling methodology produced barriers uniformly meeting typical standard commercial requirements.

\subsubsection{Conclusions}

1. Barriers to a depth of 50 feet were constructed.

2. New stroking platform (D9) is suitable for SoilSaw ${ }^{\top \mathrm{M}}$

3. Hose reel improves grout plant performance but needs to be at least 5" id.

4. All barrier samples exceeded barrier quality standards

5. All SoilSaw ${ }^{\mathrm{TM}}$ support systems performed well

6. Productivity was lower than hoped for

\subsection{Montan Wax Demonstration}

\subsubsection{Objectives}

The objectives of incorporating Montan Wax in the SoilSaw ${ }^{\mathrm{TM}}$ demonstration were:

1. Test Montan Wax emulsions with the SoilSaw ${ }^{\mathrm{TM}}$ for equipment and process compatibility.

2. Evaluate the geotechnical performance of Montan Wax barriers.

\subsubsection{Material Description}

Pure Montan Wax consists of a mixture of wax and resin materials, and in lower amounts, asphalt's. Montan wax is extracted from brown coal mined in Germany.

The formation of coal is attributed to transformation processes of prehistoric plant materials. The wax compounds present on all plants as surface wax layers appear to have been preserved in coal deposits, particularly in coal from the Halle/Leipzig region in Germany.

Raw Montan Wax is separated from brown coal by means of a hot organic solvent extraction process. The solvent is distilled from the Montan Wax solution and removed fully with super heated steam to product the pure wax product.

Pure Montan Wax is a very dark, hard, microcrystaline solid with a melting point of $85-115^{\circ} \mathrm{C}$. Manufacturers report that Montan Wax is non toxic.

\subsubsection{Pure Montan Wax Composition}

$80-85 \%$ wax materials (mainly $C_{28}$ wax acids and $C_{30}$ wax esters and alcohol's)

$10-15 \%$ polyterpene resins

$2-5 \%$ asphalt's (dark) 


\subsubsection{Montan Wax Emulsion}

Pure Montan Wax is processed with surfactants to produce an emulsion of very fine drops/particles of Montan Wax in water. The emulsion is a non-viscous, white, opaque, free flowing liquid with a density close to that of water and a distinctive odor commonly associated with petroleum products.

In the presence of ionic materials, hydrated bentonite suspensions, and some soils, Montan Wax emulsions separate into water and wax phases. The wax phase is water impermeable, and chemically resistant to acids, bases and salt solutions, all desirable properties for barrier materials.

\subsubsection{Grout Formulation}

The proscribed dilution of Montan Wax with pre hydrated bentonite (based on treatability studies performed by Mibrag with German bentonite) needed to be slightly modified to prevent premature gelling of the grout. The concentration of pre hydrated bentonite was decreased from $7 \%$ to $4.5 \%$ based on comparative mixes made on site using US. and German bentonite side by side.

Table 7 Montan Wax Composition and Grout Formulation

\begin{tabular}{|c|c|c|c|c|}
\hline & Montan Wax & $\begin{array}{c}\text { Nonionic } \\
\text { Surfactant }\end{array}$ & Bentonite & Water \\
\hline Montan Wax Emulsion & $20 \%$ & $2.5 \%$ & $0.0 \%$ & $77.5 \%$ \\
\hline Suggested Formulation & $10 \%$ & $1.2 \%$ & $3.5 \%$ & $85.3 \%$ \\
\hline Actual Formulation: & $11 \%$ & $1.4 \%$ & $2.0 \%$ & $85.6 \%$ \\
\hline
\end{tabular}

Weight \% by Component

A 4.5 weight $\%$ pre-hydrated bentonite suspension was mixed with a 20 weight $\%$ Montan Wax emulsion in a ratio of 10:12 to achieve the actual formulation.

\subsubsection{Results and Discussion}

Montan wax was supplied in 150 drums each containing 200 liter of Montan Wax Emulsion (7,926 gallons). The drums were fitted with a side bung for removal of the contents. The wax was readily pumped from the barrels with a diaphragm pump to a steam cleaned 20,000 gallon frac tank for storage prior to use as a grout material. The Montan Wax emulsion foamed considerably during transfer to the tank, probably due to the high emulsifier concentration and the method of transfer (drop tube from pump discharge into the bottom of the tank).

The wax was combined with pre hydrated bentonite suspensions in an eductor mixer and delivered to the SoilSaw ${ }^{\mathrm{TM}}$. During the mixing process the wax foamed considerably in the eductor mixer. A simple modification to the system could avoid the use of an eductor to mix the wax and avoid the foaming problem. 
The SoilSaw ${ }^{\top M}$ was switched from pumping a cement/bentonite grout to pumping the Montan Wax by turning a valve and resumption of work.

The SoilSaw ${ }^{\mathrm{TM}}$ appeared to function identically with Montan Wax grout as with bentonite or cement/bentonite grouts with the exception that high pressure delivery was hindered by foam during parts of the run. The presence of foam probably decreased efficiency of barrier construction during the use of the wax grout.

\subsubsection{Construction Summary}

\begin{tabular}{|c|c|c|c|c|}
\hline Time & Depth & Wax Placed & Barrier Produced & Note \\
\hline $15: 34$ & $22^{\prime}$ & $0 \mathrm{ft}^{3}$ & $0 \mathrm{ft}^{3}$ & Start of wax run \\
\hline $16: 12$ & 22 & $1628 \mathrm{ft}^{3}$ & $660 \mathrm{ft}^{3}$ & End of wax run \\
\hline
\end{tabular}

The ratio of formulated wax grout to soil was 2.47 to 1.0 for the demonstration. This ratio is higher than the planned ratio of $1: 1$ due to a decrease in construction efficiency caused by grout foaming and low delivery pressure.

\subsubsection{Barrier Quality}

Excavation of the Montan Wax barrier showed the barrier to be of a similar consistency to barriers of bentonite - viscous but not free flowing. Performance data for the Montan Wax barriers is shown below:

Table 8 Barrier Quality Data, Montan Wax

\begin{tabular}{|l|l|l|l|}
\hline & \multicolumn{1}{|c|}{ Sample Type } & \multicolumn{1}{c|}{ Permeability } & \multicolumn{1}{c|}{ Strength } \\
\hline Sample 1 & Fresh Bulk & $7.3 \times 10^{-8} \mathrm{~cm} / \mathrm{sec}$ & $2.7 \mathrm{psi}$ \\
\hline Sample 2 & Fresh Bulk & $8.1 \times 10^{-8} \mathrm{~cm} / \mathrm{sec}$ & $2.0 \mathrm{psi}$ \\
\hline Sample 3 & Cured & $1.1 \times 10^{-7} \mathrm{~cm} / \mathrm{sec}$ & $2.9 \mathrm{psi}$ \\
\hline Sample 4 & Cured & $1.01 \times 10^{-7} \mathrm{~cm} / \mathrm{sec}$ & $2.8 \mathrm{psi}$ \\
\hline Sample 5 & Cured & $6.0 \times 10^{-8} \mathrm{~cm} / \mathrm{sec}$ & $4.6 \mathrm{psi}$ \\
\hline Sample 6 & Cured & $1.7 \times 10^{-7} \mathrm{~cm} / \mathrm{sec}$ & $2.7 \mathrm{psi}$ \\
\hline Standard & Cured & $1.0 \times 10^{-6} \mathrm{~cm} / \mathrm{sec}$ & $0-15,000 \mathrm{psi}$ \\
\hline
\end{tabular}

Permeability's of the Montan Wax barriers is better than a typical barrier standard for permeability. Due to the high ratio of grout to soil it is possible that these results are not representative of what could be expected in other applications.

\subsubsection{Cost}

The cost of barrier construction is partially dependent upon the cost materials. The cost of materials can be calculated as follows:

Materials cost (\$)/quantity of barrier produced $\left(\mathrm{ft}^{2}\right)$ 
For this demonstration the cost of the Montan Wax was $\$ 48,000$. The volume of unformulated Montan Wax emulsion supplied was 30M3 $\left(1070 \mathrm{ft}^{3}\right)$. The wax was formulated with a bentonite suspension (in a 6:5, wax emulsion:bentonite, volume to volume ratio) to a total formulated wax volume of $1961 \mathrm{ft}^{3}$. Based on the assumed ratio of formulated wax grout to soil of 1:1 (by volume) the total barrier produced would be $3922 \mathrm{ft}^{3}$. For this demonstration, the barrier is one foot wide thus the volume of the barrier in cubic feet $\left(\mathrm{ft}^{3}\right)$ is equal to the area of the barrier in square feet $\left(\mathrm{ft}^{2}\right)$.

Thus the cost of Montan Wax in a optimal application with the SoilSaw ${ }^{\mathrm{TM}}$ will be:

$\$ 48,000 / 3,922 \mathrm{ft}^{2}=\$ 12.24 / \mathrm{ft}^{2}$

\subsubsection{Conclusions}

1. Montan Wax emulsions are compatible with SoilSaw ${ }^{\mathrm{TM}}$ equipment and the SoilSaw ${ }^{\mathrm{TM}}$ process.

2. Barrier quality met or exceed standard requirements for slurry wall barriers.

\subsection{SoilSaw' ${ }^{\top M}$ Depth Potential}

\subsubsection{Objective}

To use information from the SoilSaw ${ }^{\mathrm{TM}}$ Demonstration to estimate the depth potential of the SoilSaw ${ }^{\text {TM }}$ Barrier System.

\subsubsection{Considerations}

Theoretical considerations provide a framework for defining an upper limit to the maximum amount of soil that can be mixed with grout by hydraulic excavation (jetting). Of course any upper limit used will have the caveat attached that it is highly dependent upon soil type. As we have experienced during this project, hard cohesive clay will require more energy than free flowing non-cohesive materials. In any case, practical limitations turn out to define the depth potential without having to resort to specifying different potential depth for different soil types

Practical limitations to SoilSaw ${ }^{\top M}$ operating depth are, high pressure pumping capacity, bulk material supply rates (water, cement, bentonite), high pressure hose capacity, grout preparation equipment, SoilSaw ${ }^{\top M}$ stroking device, SoilSaw ${ }^{\top M}$ Beam friction in the hole and SoilSaw ${ }^{\mathrm{TM}}$ Beam strength.

As shown in Table 9, barrier depth and operating parameters such as jet size and number, beam length, grout density, pressure and flow, high pressure pump horsepower and pump capacity are highly related.

Thus, as shown in Figure 2 the maximum depth of the SoilSaw ${ }^{\mathrm{TM}}$ as currently configured, can be calculated based on given assumptions. Assumptions for the maximum depth potential calculation of the current SoilSaw ${ }^{\mathrm{TM}}$ are shown below. 
Assumptions:

1. Two 1,000 hp pumping units

a. Maximum flow rate of $15 \mathrm{bpm}(630 \mathrm{gpm})$

b. Maximum of 64 jets ( 0.078 " diameter)

c. Two 2" diameter flex hoses required

2. 5,000 psi grout pressure required

3. $500 \mathrm{hhp}$ available for stroking special Caterpillar D9 $\mathrm{H}$

4. 45 deg. operating angle

5. 12 foot long beam modules

6. 12 foot stroke length

7. 6 module long SoilSaw ${ }^{\mathrm{TM}}$ beam (72' long, 60 jets ( 10 jets/module))

\subsubsection{Depth Calculation}

72 ' beam $x(\sin 45$ deg. $)=51^{\prime}$ deep

Modifying SoilSaw ${ }^{\top M}$ equipment to operate at greater depth would should focus on extending the operating length of the beam without increasing the number of jets or increasing the amount of high pressure pumping horsepower required. With these guidelines, the maximum depth potential for a modified SoilSaw ${ }^{\top \mathrm{M}}$ can be calculated.

Modifications proposed to extend the SoilSaw ${ }^{\mathrm{TM}}$ operating depth:

1. 40 foot long beam modules

2. 40 foot stroke length

3. 7 module long SoilSaw ${ }^{\top M}$ beam (280' long)

4. $200,000 \mathrm{lbs}$ stroking force

5. 45 deg. operating angle

6. center pivot stroking machine

\subsubsection{Depth calculation}

$280^{\prime}$ length $x(\sin 45$ deg. $)=\mathbf{1 9 8}^{\prime}$ deep

With appropriate modifications the SoilSaw ${ }^{\mathrm{TM}}$ can be configured to operate deeper than any practical system being used today. However, improvements in the productivity should be addressed prior to attempting to extend the depth potential. 


\subsection{CONTINUING DEVELOPMENT}

Continued development of the SoilSaw ${ }^{\top M}$ will focus on increasing productivity and reducing spoils in hard soils.

Our early tests clearly showed that the SSBS technology could be successfully deployed on sandy sites. While the D9H had clearly solved all of the operational horsepower problems, the tests in Pasadena and Savannah River Site demonstrated that jetting efficiency had to be improved for the technology to be successful in tougher clays.

A development and testing plan was devised which would include laboratory and two field tests.

A series of bench scale tests were conducted to examine the cutting efficiency of our existing system and alternative jet arrangements. A variety of test specimens were used to simulate difficult clay cutting situations. The results of the tests suggested that cutting efficiency was suffering from reflected energy loss and turbulent grout flow within the beam spool. This loss of efficiency was reducing the depth of cut and increasing spoils volumes. The solution to this problems was flow straightening and angled patterns for the jets.

\subsection{Jet Configuration \#1}

The first of two pilot-scale tests of the solutions derived from the laboratory tests were conducted in Duncan, Oklahoma in the summer of 1994. A single beam section and spool with a redesigned jet sub-assembly was attached to a Gradall 880 for the test. Flow straighteners and an angled jet pattern were used.

The flow straighteners were only partially successful and the angle pattern failed to improve efficiency largely because the depth of cut was less than expected. The new jet pattern performed considerably better that the old pattern but the improvement could be attributed to the increase in total horsepower that resulted from the increase number of jets in the new pattern.

\subsection{Jet Configuration \#2}

The second pilot-scale test was conducted in December of 1994 in Duncan, Oklahoma. The test set-up was the same as the previous test but both the old jet pattern and the new jet pattern incorporated improved flow straightening. The jet flow was clearly less turbulent. The results of this test showed an increase in productivity for both new and old jet patterns. It appears, but has not been confirmed, that flow straightening of the grout path rather than jet pattern improvement may be making the largest contribution to improving performance.

\subsection{Market Advantages}

Conventional barrier walls are most often formed by the slurry trenching method. This is a two step process. First a back hoe excavates soil under a cover of lightweight bentonite (clay) slurry. The slurry supports the walls of the excavation. The excavated soil is mixed with bentonite, and sometimes cement or imported clay soil, to form a suitable backfill material. This backfill is pushed or pumped into the trench to displace the lightweight bentonite slurry and form the final wall. 
In some soils the lightweight bentonite slurry may not be heavy enough to keep the side walls of the trench from sloughing off. This may cause soil or rocks to fall to the bottom of the trench which may become a permeable inclusion under the backfill. If the backfill does not completely displace the bentonite slurry it may leave inclusions of liquid slurry in the wall. Excavating under a cement-based slurry which itself later solidifies into final wall, solves some quality problems but it generates large quantities of spoils.

As slurry trenches become deeper these problems increase in complexity and productivity is also slowed. Deeper wall construction generally requires that the wall be made wider (which is more expensive) to allow greater mechanical strength of the excavating equipment and to minimize the impact of poorer quality walls. In shallow walls productivity is generally less than 500 square feet per hour. Costs tend to go up exponentially with depth.

The vibrating beam method of wall construction utilizes a wide flange steel beam which is driven into the ground with a vibratory pile driving hammer. After it reaches full depth it is vibrated out of the hole while a grout mixture is pumped into the void left by extraction of the beam. Successive beam penetrations are overlapped to form the cutoff wall. This technique works best in saturated loose granular soils. The thickness of the wall is limited to the thickness of the web of the beam. Quality control issues include the potential for the soils to close up or "neck-in" as the beam is withdrawn, which can result in a thin or discontinuous wall in layers of softer soil. Trench wall continuity may also be affected by beam alignment or subsurface deflection which can result in gaps through the wall. A 10 percent overlap is required to help reduce the potential for gaps in the wall. Production rates of up to 1000 square feet per hour have been reported in wet soil which has no rocks.

Mixed-in-place walls have been formed using ganged multiple auger tools which inject a slurry while cutting and mixing the soil in situ. These systems produce high-quality product material since they do not rely on an "excavate and replace" approach. These systems must rely totally on precise mechanical positioning and minimizing subsurface deflection to achieve the overlap on each succeeding pass needed to maintain continuity of the wall. Like the other alternative technologies, verification of continuity must be performed in a secondary operation with some type of mechanical proving device. Productivity rates of up to 1000 square feet per hour have been reported in soft soil. Small rocks and debris are tolerated well.

Today's market price for shallow barriers ( 25 feet or less) is in the range of $\$ 5$ to $\$ 10$ per square foot depending on many factors such as performance requirements, the size of the project and obstructions. Project size is one of the more important factors is determining project unit costs. Certainly, large projects (greater than 500,000 square feet) can generally achieve the $\$ 5$ per square foot price. We believe that the SSBS can produce wall at a cost of $\$ 3$ to $\$ 4$ per square foot at these depths. In addition, the customer will save additional money with reduced waste disposal costs. As the depth of the barrier increases, this price/cost differential can grow because the conventional and alternative methods loss efficiency with depth while the SSBS does not. While the technology has been demonstrated to a depth of 50 feet, we believe that it can be extended even further.

The continuity and quality of the barrier is superior with the SSBS. While some customers will pay a premium for the assurance of a quality barrier, the SSBS can yield a price advantage on 
performance specification projects. The poor mix quality, inclusions and sloughing of conventional methods often results in walls failing specification and requiring rework. The selfproving nature of the SSBS eliminates the need for independent verification of barrier depth.

The SSBS has been developed to address the weaknesses of the conventional and alternative barrier wall construction techniques. It derives its market advantage from being capable of building barriers faster (and at less expense), of higher quality and with less waste. This final - characteristic is particularly important in the hazardous waste market. 


\subsection{PATENTS AND INTELLECTUAL PROPERTY}

Halliburton NUS has maintained the proprietary nature of this technology. In addition we have pursued patents (domestically and internationally) for the SoilSaw ${ }^{\mathrm{TM}}$ Barrier System and associated technologies. 


\subsection{CONCLUSIONS}

The SoilSaw ${ }^{\mathrm{TM}}$ Barrier System successfully achieved all project objectives. A prototype SoilSaw ${ }^{\mathrm{TM}}$ was developed, barriers were constructed to the targeted depth of 50 feet and barrier quality met or exceeded typical barrier performance specifications.

\subsection{Objectives}

SoilSaw ${ }^{\mathrm{TM}}$ project objectives and measures of success are shown below:

Objective

1. Determine feasibility of operating at fifty foot depths

2. Model the depth potential of the SoilSaw ${ }^{\top M}$

3. Establish productivity for the SoilSaw ${ }^{\mathrm{TM}}$

4. Quantify SoilSaw ${ }^{\mathrm{TM}}$ barrier quality

Compressive strength $1-140 \mathrm{psi}$.

5. Assess Montan Wax use in the SoilSaw ${ }^{\mathrm{TM}}$ Barrier System
Measure of Success (units)

50 ' deep barrier constructed

Max. depth calculated as $198 \mathrm{ft}$. deep

Ranged $13-140$ sq. ft./min.

Permeability $<1 \times 10-6 \mathrm{~cm} / \mathrm{sec}$.

Permeability $<1 \times 10-6 \mathrm{~cm} / \mathrm{sec}$.

Compressive strength $2-10 \mathrm{psi}$

Compatible with SoilSaw ${ }^{\mathrm{TM}}$ process and equipment

The SoilSaw ${ }^{\mathrm{TM}}$ Barrier System is a workable means of placing barrier walls in soils ranging from 0.5 to 4 tsf at depths to at least $50 \mathrm{ft}$. The performance of the system is affected dramatically by soil density and strength. The jet pattern and energy levels which worked well in loose to medium compacted sand at the Rush Springs, OK test site were much less efficient in the unexpectedly very stiff fine grained soils encountered at the Palestine and Savannah River test sites. During the Palestine, TX test it became apparent that the Gradall platform did not have enough power to stroke the jetting beam in clay soils. The telescoping boom would typically slow down and stall on the up stroke. The Gradall was capable of stroking about $18,000 \mathrm{lb}$. force at $2 \mathrm{ft} / \mathrm{sec}$. This limited the clay soil operating depth to about $24 \mathrm{ft}$. The SoilSaw ${ }^{\mathrm{TM}}$ Beam was transferred to a modified CAT D-9 machine capable of stroking the beam at up to $125,000 \mathrm{lb}$. force at $2 \mathrm{ft} / \mathrm{sec}$. The D-9 machine was used at Savannah River in clay soil at a depth of $50 \mathrm{ft}$ with no indication of power deficiencies. Theoretical calculations indicate in its present form, using $12 \mathrm{ft}$ sections with $13 \mathrm{ft}$ strokes, the machine should be capable of reaching at least $65 \mathrm{ft}$. 
The SoilSaw ${ }^{\mathrm{TM}}$ Barrier System will work in both non cohesive and cohesive soils but it clearly works faster and better in soft sands and soft to medium fine grained soils. Hard soils (very dense sands), rock layers and cohesive clay (strengths $>4.0$ tsf) reduced the production rates by as much as one fifth compared to the loose to medium dense sandy soils. Even at these reduced production rates the method is still faster and potentially more economical than most slurry wall methods. The field tests demonstrated that traditional soils investigation data may not be sufficient to predict productivity. When performing a standard site soil sampling survey, additional information such as unconfined compressive strength and cone penetrometer test data (cpt) may be beneficial in estimating or predicting SoilSaw ${ }^{\mathrm{TM}}$ production rates.

Productivity ranged from 140 sq. ft./min. during the Rush Springs feasibility test to 28 sq. $\mathrm{ft} . / \mathrm{min}$. in hard clays at Savannah River, SC. The productivity of the method is significantly higher than conventional methods but its true long term "up time" is not yet proven on a large project. The narrow but uniform thickness walls produced by the SoilSaw ${ }^{\top M}$ Barrier System serve to reduce the spoils volumes and the cost of materials for barrier walls. In loose noncohesive soils, the SoilSaw ${ }^{\top M}$ Barrier System can reduce spoils by as much as 80 percent. In hard cohesive soils the present system may not reduce the generation of spoils except by its ability to form a narrower wall than conventional methods. However, optimizing the jetting pattern should increase production rates and it appears likely that modifying the jetting blocks for dense or stiff soils should decrease spoils production. The SoilSaw ${ }^{\mathrm{TM}}$ has the potential to produce lower cost barriers than conventional methods, although the cost of the method was not established due to the less than optimum jetting pattern and the dependence of SoilSaw ${ }^{\top M}$ productivity on soil type. Full operation of the system should be planned to include two hours of preparation each day and two hour of clean-up each evening and about $4 \mathrm{hr}$ of productive work each day.

Quality of walls produced by this method appears to be excellent offering clear advantages in loose to medium dense sands overcoming the tendency of the soil to slough off into conventional slurry trenches. The mixing of soil and slurry in place produces a wall material from the start of construction that has a density large enough to prevent sloughing. The system also can work with many different types of grout materials. Montan Wax use was evaluated for use with the SoilSaw ${ }^{\top M}$ and found to be compatible with the equipment and the processes used. Montan Wax barrier quality exceeded standard specifications when used with the SoilSaw ${ }^{\mathrm{TM}}$.

Walls are uniformly 12 in. wide with smooth sides using the current jet block design. A new design of jetting nozzle layout, with multi-angled jets, may be needed to enhance cutting performance in cohesive soil. It is also possible to add jetting blocks to the beam which will form different width walls or walls with rough sides. Specifying walls more than 12 in. wide increases the cost significantly. Also certain slurry wall specifications, such as those requiring surface mixing of backfill, are inappropriate since the material is mixed in situ.

The SoilSaw ${ }^{\top M}$ Barrier System can produce barrier walls, through correct grout design, which meet or exceed permeability performance standards. Sample collection technique for cured in place barriers was a critical element in determining correct permeability's. 


\subsection{Advantages of the SoilSaw ${ }^{\mathrm{TM}}$ Method}

The energy to cut and mix the soil is transferred to the soil work face hydraulically by the reagent media itself. Energy transfer of up to 2,000 hydraulic horsepower can be supplied by oil field cement pumps to help achieve dramatic productivity rates up to 10 times faster than conventional methods.

The method forms a very uniform barrier wall with smooth sides and a homogeneous interior.

Barriers can be made thinner, thus reducing spoils disposal cost and raw materials cost while increasing the walls lateral flexibility for any given material. Barrier walls can be formed in soft wet sands or other unconsolidated formations without sloughing of the formation soils or rocks into the wall because the wall material is as dense as the soils and exerts a balanced hydrostatic force against the soil.

Long barriers can be formed to great depths at a potentially lower cost than other methods.

The continuity of the barrier is assured since the cutting hardware passes through 100 percent of the volume of the wall.

Fluidized material in the "trench" is generally too viscous to flow into cracks or natural fractures.

If pipelines or other underground structures must be tied to the barrier wall the SoilSaw ${ }^{\top M}$ Barrier System equipment can be used to support Jet Grouting of the tie-in.

The system can operate on long narrow right of ways, such as levee's, with slurry batch plants delivering slurry through a pipeline.

\subsection{Disadvantages of the Method}

The method has a high mobilization cost for the first days work, therefore, it may only be comparable economically with tracked backhoes on projects specifying a minimum of 30,000 40,000 sq. $\mathrm{ft}$. The economics depend on type of soil (dense to very dense sands or stiff to hard cohesive soils), depths (up to $100 \mathrm{ft}$ ), and special conditions including narrow right-of-ways, spoils management, trench stability and contaminated ground water.

The method's current productivity is reduced in hard cohesive soils ( $>4.0$ tsf) and is unsuitable for rock or shale.

The method may not be able to "key" into hard rock layers. The nose of the jetting beam can jet scour and bond the wall to a hard rock formation but it would not be able to cut a $3 \mathrm{ft}$. "key" into a hard rock without a significant loss of soil cutting efficiency.

Large rocks, more than $2 \mathrm{ft}$ in diameter, may have to be removed by conventional means. To date no loose rocks have been encountered which affected normal operation but it is anticipated that large hard rocks which are able to resist the crushing action of the jetting beam blade could be a problem. This estimate is based on the available stroking force and jetting beam weight. 


\subsection{Cost Model for SoilSaw ${ }^{\top \mathrm{M}}$ Production}

The following table represents the cost associated with the Savannah River Site demonstration and anticipated cost for future work to be performed with the SoilSaw ${ }^{\mathrm{TM}}$.

The Savannah River Site work could not be separated into cost per square footage due to the nature and number of the experiments performed. The work breakdown was assigned to four categories as represented in the following table. The most square footage available at the Savannah River Site was estimated at $63,000 \mathrm{sq} \mathrm{ft}$.

The models were assembled, starting at $63,000 \mathrm{sq} \mathrm{ft}$ and worked up to $168,000 \mathrm{sq} \mathrm{ft}$.. As represented in the model it can be determined that for a site with $63,000 \mathrm{sq} f \mathrm{ft}$. the mobilization and demobilization represents nearly half of the cost of the project or equal to the production cost. A site of $168,000 \mathrm{sq} \mathrm{ft}$. has a mobilization and demobilization cost of a quarter of the project and less than $30 \%$ of the cost of production. The size of a site has direct bearing on production cost with the SoilSaw ${ }^{T M}$ technology.

\begin{tabular}{|c|c|c|c|c|c|c|c|c|c|c|c|c|}
\hline \multicolumn{13}{|l|}{ SAVANNAH RIVER SITE } \\
\hline MORDEMOR & $\$ 148.803$ & $38 \%$ & & & & & & & & & & \\
\hline SIIE PREPARESTORATION & $\$ 22646$ & $6 \%$ & & & & & & & & & & \\
\hline SET UP \& INST ALLATION & 5137287 & $35 \%$ & & & & & & & & & & \\
\hline MATERIALS & $\$ 85.250$ & $22 \%$ & & & & & & & & & & \\
\hline BUDEET & $\$ 393.986$ & $100 \%$ & & & & & & & & & & \\
\hline PRODUCTION DAYS. & 4 & \multirow{2}{*}{$\begin{array}{l}\text { Cost } \\
\text { saft }\end{array}$} & \multirow{2}{*}{$\begin{array}{c}\% \\
\text { sqft }\end{array}$} & 7 & \multirow{2}{*}{$\begin{array}{l}\text { Cost } \\
\text { sqft }\end{array}$} & \multirow{2}{*}{$\begin{array}{c}\% \\
\text { sqft }\end{array}$} & 10 & \multirow{2}{*}{$\begin{array}{l}\text { Cost } \\
\text { saft }\end{array}$} & \multirow{2}{*}{$\begin{array}{c}\% \\
\text { sqfit }\end{array}$} & 11 & \multirow{2}{*}{$\begin{array}{l}\text { Cost } \\
\text { seft }\end{array}$} & \multirow{2}{*}{$\begin{array}{c}\% \\
\text { sqft }\end{array}$} \\
\hline SQUARE FOOTACE & 63000 & & & 100000 & & & 147000 & & & 168000 & & \\
\hline MOBAEMOA & $\$ 200.884$ & $\$ 3.19$ & $42 \%$ & $\$ 200.884$ & $\$ 2.01$ & $32 \%$ & $\$ 200.884$ & $\$ 1.37$ & $25 \%$ & $\$ 200.884$ & 5120 & $23 \%$ \\
\hline SIIE PREPARSTORATION & 530.572 & 50.49 & $6 \%$ & $\$ 30.572$ & 50.31 & $5 \%$ & $\$ 30.572$ & $\mathrm{SO2} 2 \mathrm{I}$ & $4 \%$ & $\$ 30.572$ & so.18 & $3 \%$ \\
\hline SEI UP \& INST ALLATION & $\$ 198.837$ & $\$ 3.16$ & $42 \%$ & $\$ 315615$ & $\$ 3.16$ & $51 \%$ & $\$ 463.954$ & $\$ 3.16$ & $58 \%$ & $\$ 530.233$ & $\$ 3.16$ & $60 \%$ \\
\hline $\begin{array}{l}\text { MATERIALS } \\
\text { IOTAL }\end{array}$ & $\$ 477881$ & $\$ 2.59$ & $100 \%$ & $\$ 622.607$ & 56.23 & $100 \%$ & 5806.448 & 5.5 .49 & $100 \%$ & $\$ 888,589$ & $\$ 5.29$ & $100 \%$ \\
\hline
\end{tabular}

\section{Figure 7 Cost Model SoilSaw ${ }^{\text {TM }}$}




\subsection{REFERENCES}

The following references were taken from an EPA technical report titled SLURRY TRENCH CONSTRUCTION FOR POLLUTION MIGRATION CONTROL.PB84-177831 Feb. 84.

Cavalli, N. J. ICOS Corporation of America. Personal Communication with P. A. Spooner of JRB Associates. December 1982.

Jefferis, S. A. Bentonite - Cement Slurries for Hydraulic Cut Offs. In: Proceedings of the Tenth International Conference on Soil Mechanics and Foundation Engineering, Stockholm June 15-19, 1981b. A. A. Balkema, Rotterdam. pp. 435-440.

Lager, D. C. Case International Co. Personal Communication with P. A. Spooner of JRB Associates. September 13, 1982.

Millet, R. A., and J. Y. Perez. Current USA Practice: Slurry Wall Specifications. J. Geot. Eng. Div. 107(8):1041-1056, 1981.

Xanthakos, P. P. Slurry Walls. McGraw-Hill Book Company, New York. 1979, 621 pp. 


\subsection{ACRONYMS}

$\begin{array}{ll}\text { ASTM } & \text { American Society Testing Materials } \\ \text { API } & \text { American Petroleum Institute } \\ \text { CPT } & \text { Cone Penetrometer Testing } \\ \text { DOE } & \text { U. S. Department of Energy } \\ \text { HDPE } & \text { High Density Polyethylene } \\ \text { PRDA } & \text { Program Research and Development Award } \\ \text { S/B } & \text { Soil Bentonite } \\ \text { S/C/B } & \text { Soil Cement Bentonite } \\ \text { SPT } & \text { Standard Penetrometer Testing } \\ \text { SRS } & \text { Savannah River Site } \\ \text { SSBS } & \text { SoilSaw TM Barrier System } \\ \text { QA/QC } & \text { Quality Assurance Quality Control } \\ \text { US.PTO } & \text { U. S. Patent Office } \\ \text { UCS } & \text { Unconfined Compressive Strength }\end{array}$




\section{APPENDIX A SOILSAWTM EQUIPMENT LIST}

\section{Material Storage Trailers}

$7 \quad 500 \mathrm{bbl}$. Baker tanks liquid storage.

$24000 \mathrm{cu} \mathrm{ft}$ storage tanks for dry cement and bentonite.

\section{Mixing Trailer}

Mixing system is mounted on a 40 foot double drop trailer, which consists of the following modular units.

1 Educator mixing $6 \times 8$ centrifugal pump driven by a 4-71 Detroit diesel engine.

1 Booster/roll $6 \times 8$ centrifugal pump driven by a 4-71 Detroit diesel engine.

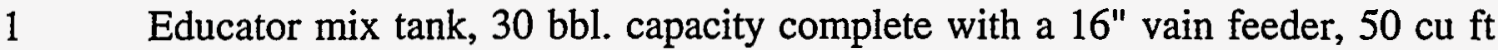
per min. feed rate.

12 " air diaphragm pump liquid additive, $15 \mathrm{gpm}$.

1 Diesel driven air compressor.

$130 \mathrm{bbl}$. surge tank, equipped with frame support for shaker screen.

1 Shaker screen.

1 Manifold system.

1 Instrumentation control group, to include 4 turbine flow meters, one radioactive densometer, one RPM shaft counter, five MC II display boxes and one TDRAD density monitor.

$1 \quad$ Scale tank.

1 Dust collector.

\section{Low Pressure System}

1 Booster $6 \times 8$ centrifugal pump driven by a Detroit diesel engine.

1 Low pressure slurry hose reel, trailer mounted.

1 Slurry tanker trailer, complete with a hydraulic power pack driven by a Cat diesel engine, two centrifugal pumps and control system.

2 Low pressure suction screens.

\section{High Pressure Systems}

2 Halliburton High pressure frac pumps, complete with suction and discharge pipe systems.

1 High pressure hose bundle, consists of wire rope bridle, $2^{\text {" high pressure hoses }}$ and restraining clamps.

1 Cat D9H dozer prime mover, modified to accept the SoilSaw ${ }^{\mathrm{TM}}$ tools.

1 Attachment device.

1 Reciprocating device. 


\section{Support Systems}

$40^{\prime}$ dry storage van complete with spare parts, tools and assorted components to support the system.

2 Portable generator sets.

1 High pressure washer.

1 Portable air compressor.

2 Air diaphragm pumps complete with hoses.

1 Forklift.

120 ton cherry picker crane.

1 Extended reach manlift.

1 JD 650 dozer.

1 Water transport tanker.

$120^{\prime}$ Conex tool/storage container, complete with tools and spare parts. 
APPENDIX B

OPERATING DATA 

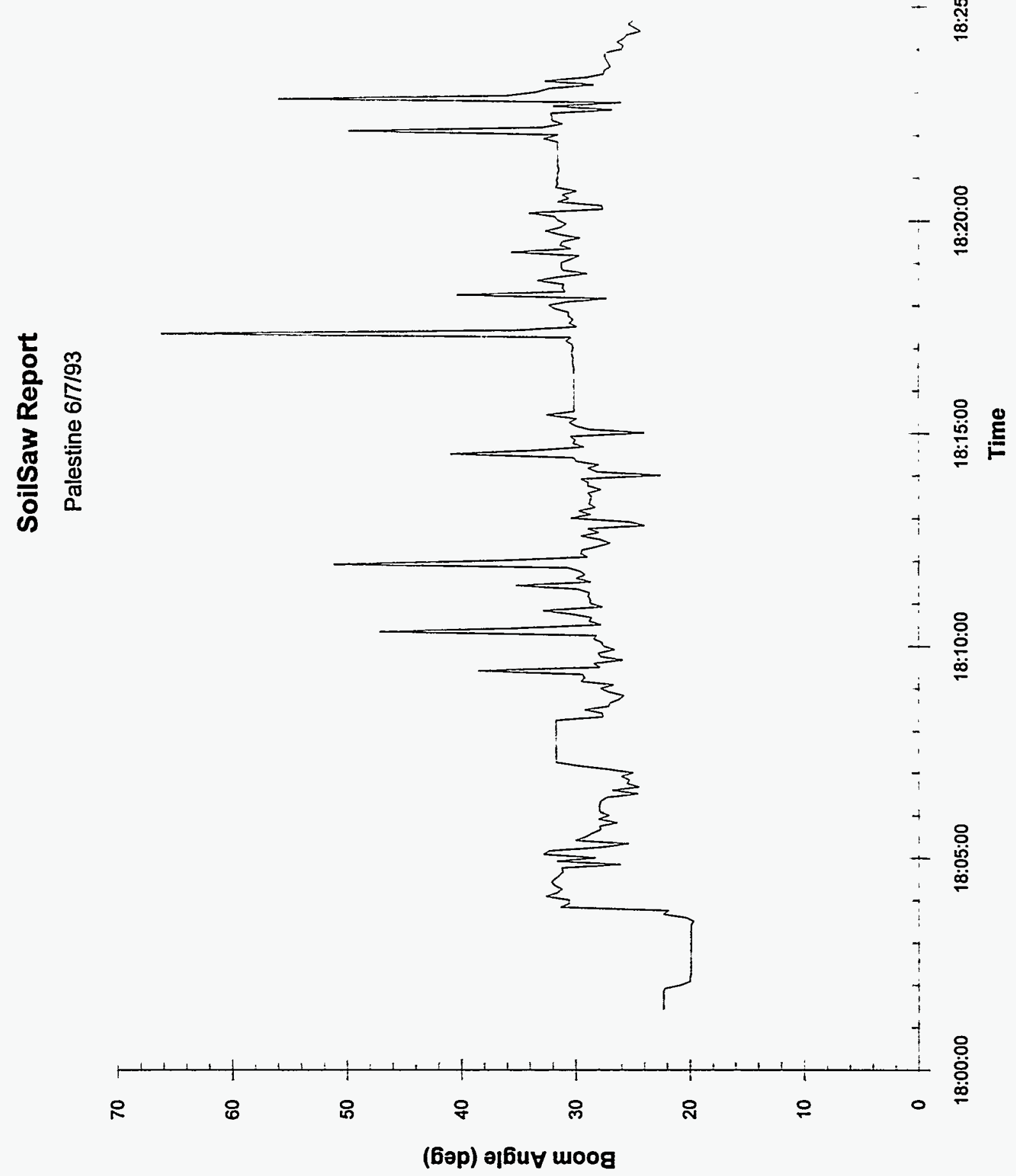

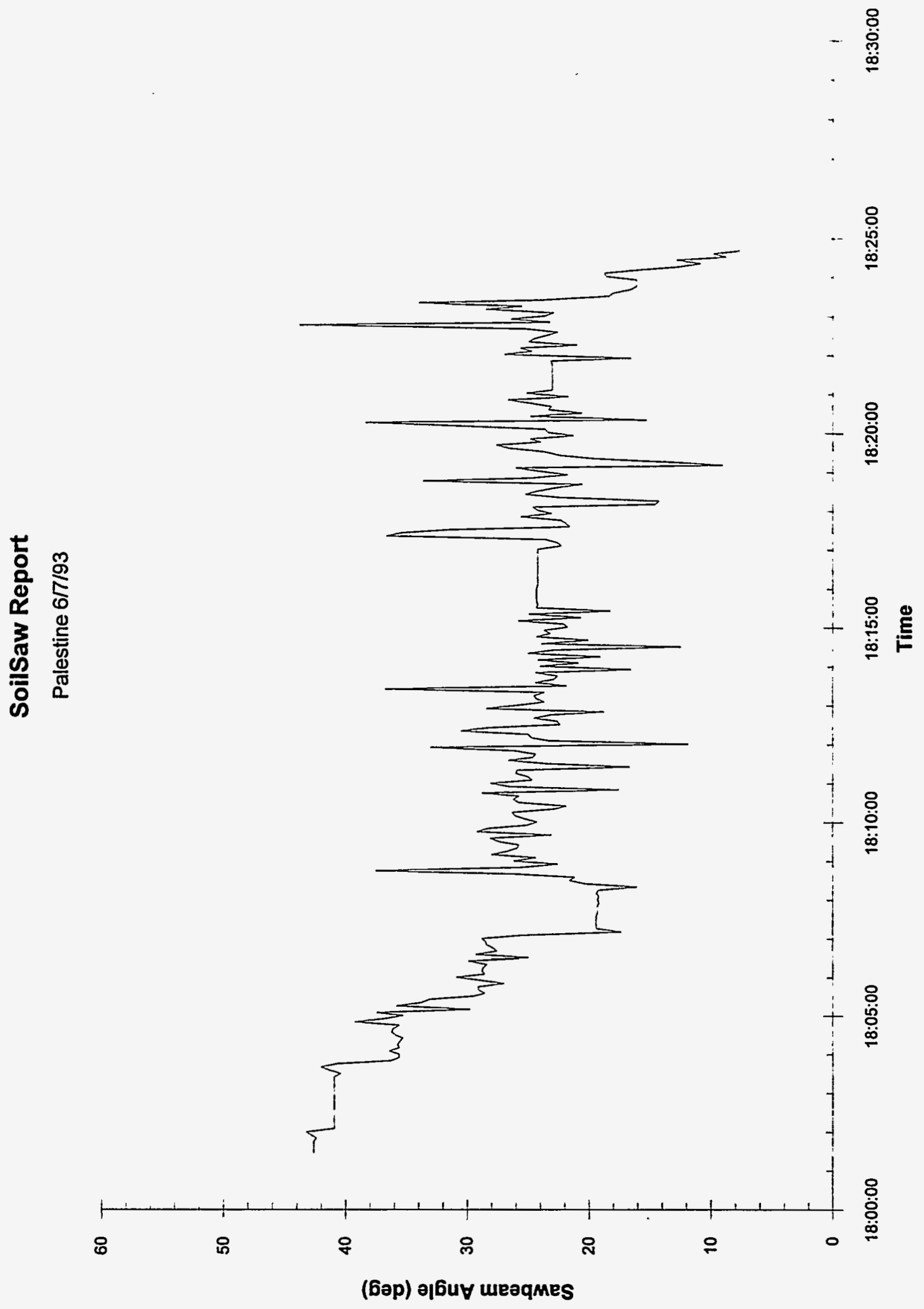


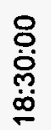

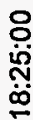
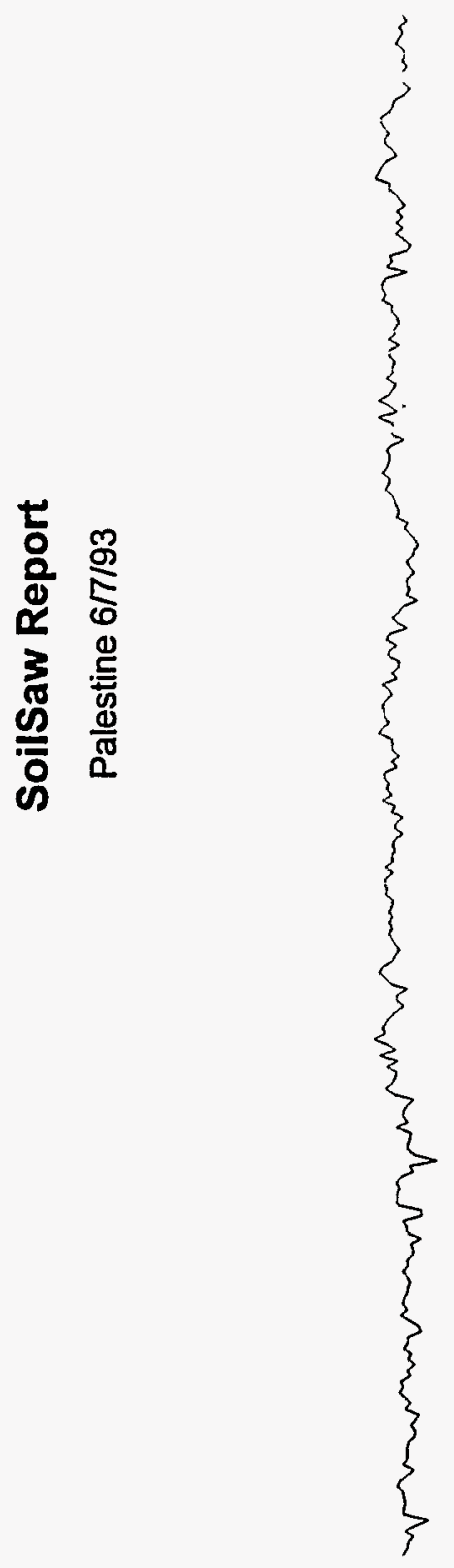

ס̊

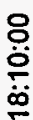

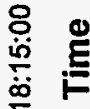

웅

8

ஸ்.

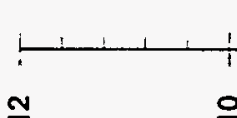

으

(|e6/q1) Kł!suəa RunIS 

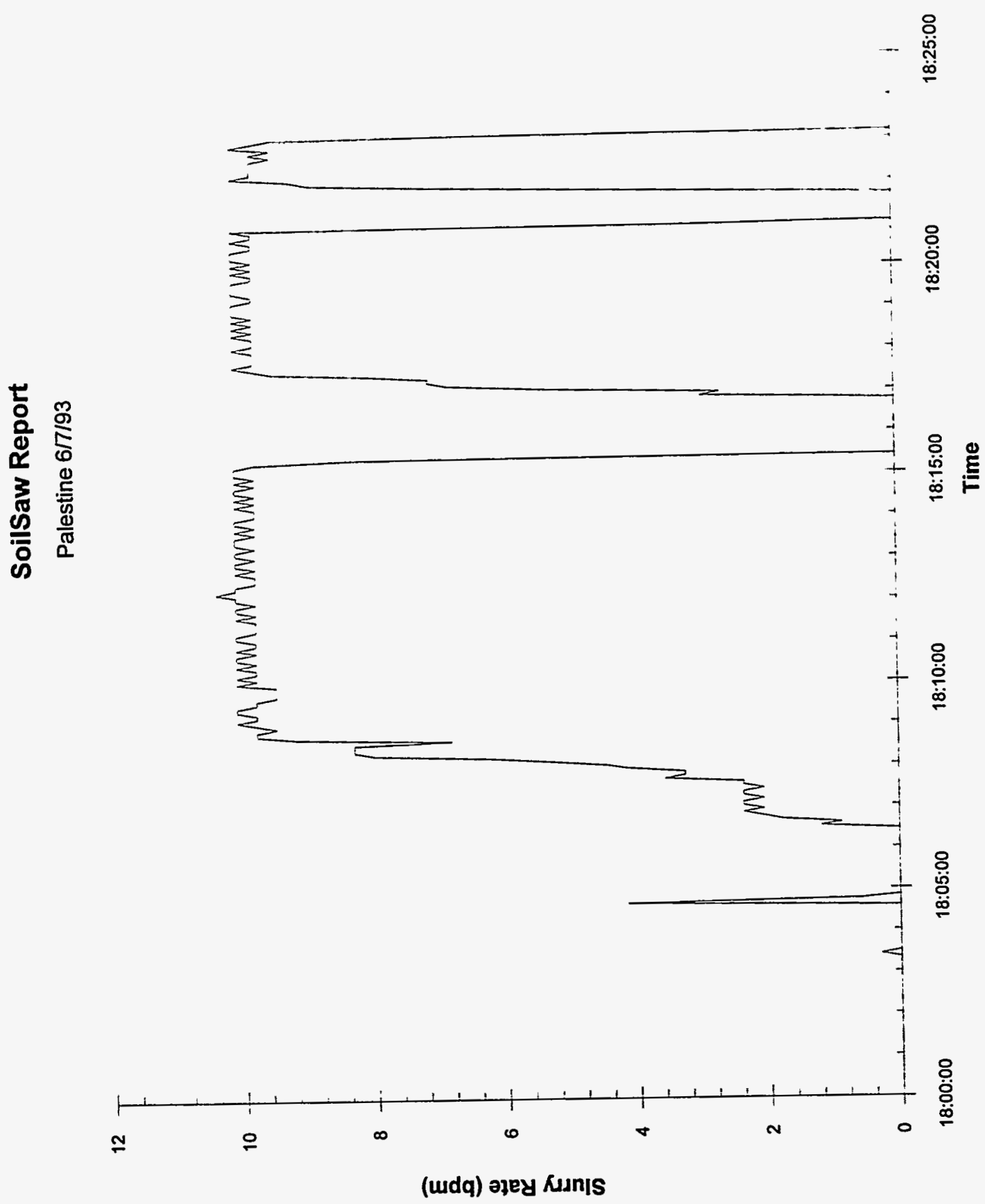


\section{SoilSaw Report}

Palestine 6/7/93

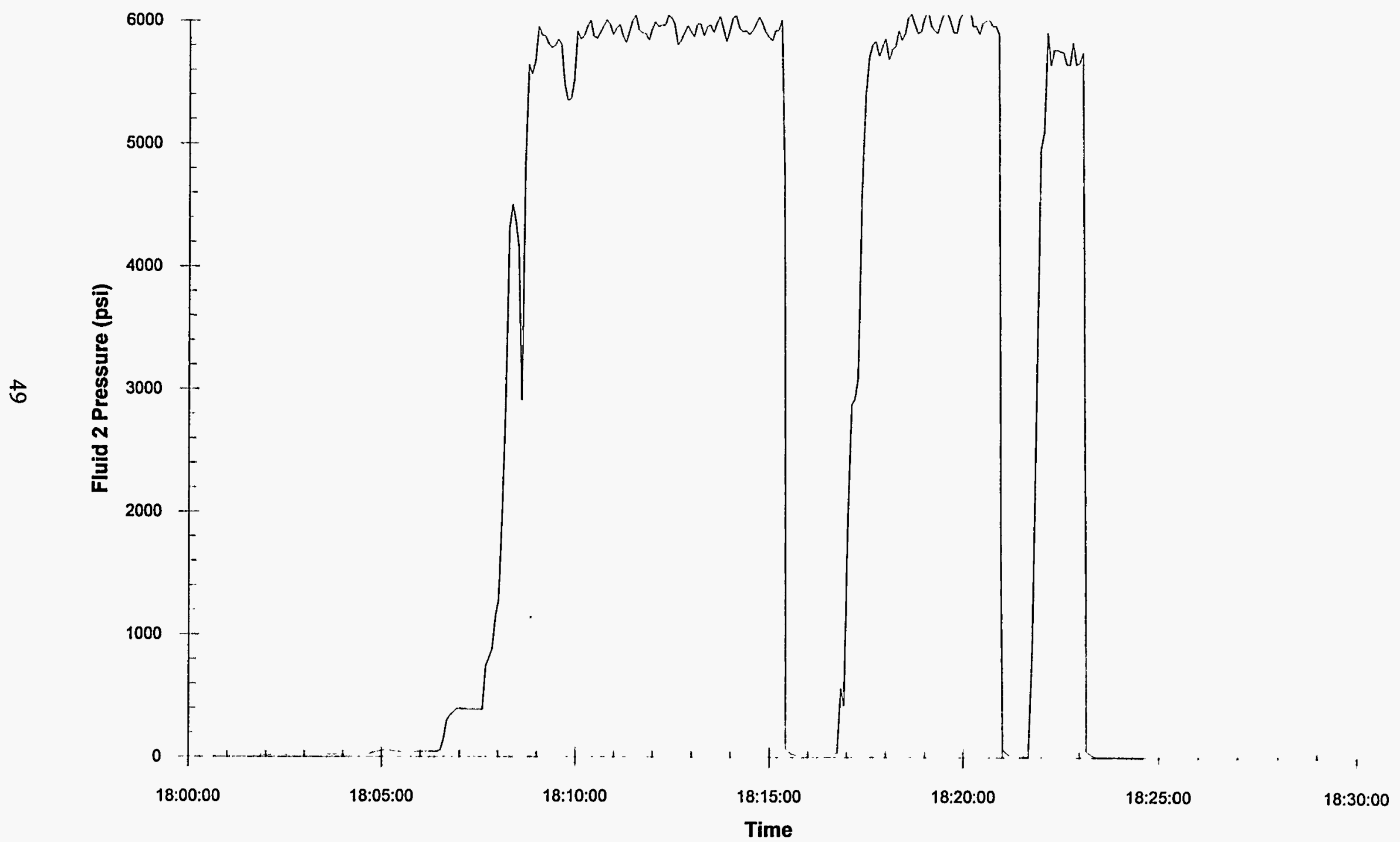


sollsaw Keport

Location: Palestine

Date: June 7, 1993

\begin{tabular}{|c|c|c|c|c|c|c|c|c|c|c|c|c|}
\hline \multirow[b]{2}{*}{ Time } & \multicolumn{2}{|c|}{ Tubing } & \multicolumn{3}{|c|}{ Gradall } & \multicolumn{3}{|c|}{ Slurry } & \multicolumn{4}{|c|}{ Fluid 2} \\
\hline & $\begin{array}{c}\text { Depth } \\
\text { ft }\end{array}$ & $\begin{array}{c}\text { Pressure } \\
\text { psi }\end{array}$ & $\begin{array}{c}\text { Speed } \\
\mathrm{ft} / \mathrm{min}\end{array}$ & $\begin{array}{l}\text { Boom } \\
\text { Angle }\end{array}$ & $\begin{array}{l}\text { Beam } \\
\text { Angle }\end{array}$ & $\begin{array}{c}\text { Density } \\
\text { lb/gal }\end{array}$ & $\begin{array}{l}\text { Rate } \\
\text { bpm }\end{array}$ & $\begin{array}{c}\text { Volume } \\
\text { bbl }\end{array}$ & $\begin{array}{c}\text { Pressure } \\
\text { psi }\end{array}$ & $\begin{array}{c}\text { Density } \\
\text { lb/gal }\end{array}$ & $\begin{array}{l}\text { Flow } \\
\text { bpm }\end{array}$ & $\begin{array}{c}\text { Volume } \\
\text { bbl }\end{array}$ \\
\hline $18: 01: 25$ & 0.0 & 71 & 0.0 & 22.3 & 42.6 & 9.79 & 0.00 & 0.0 & 15 & 8.65 & 0.03 & 0.0 \\
\hline 18:01:30 & 0.0 & 71 & 0.0 & 22.3 & 42.6 & 9.79 & 0.00 & 0.0 & 15 & 8.61 & 0.00 & 0.0 \\
\hline $18: 01: 35$ & 0.0 & 72 & 0.0 & 22.3 & 42.6 & 9.76 & 0.00 & 0.0 & 16 & 8.59 & 0.00 & 0.0 \\
\hline $18: 01: 40$ & 0.0 & 72 & 0.0 & 22.3 & 42.6 & 9.75 & 0.00 & 0.0 & 16 & 8.58 & 0.00 & 0.0 \\
\hline 18:01:45 & 0.0 & 72 & 0.0 & 22.3 & 42.6 & 9.70 & 0.00 & 0.0 & 15 & 8.58 & 0.00 & 0.0 \\
\hline 18:01:50 & 0.0 & 71 & 0.0 & 22.3 & 42.4 & 9.78 & 0.00 & 0.0 & 15 & 8.57 & 0.00 & 0.0 \\
\hline $18: 01: 55$ & 0.0 & 72 & 0.0 & 22.2 & 42.8 & 9.68 & 0.00 & 0.0 & 15 & 8.61 & 0.00 & 0.0 \\
\hline 18:02:00 & 0.0 & 71 & 0.0 & 20.8 & 43.2 & 9.56 & 0.00 & 0.0 & 15 & 8.59 & 0.00 & 0.0 \\
\hline 18:02:05 & 0.0 & 72 & 0.0 & 20.0 & 40.9 & 9.79 & 0.00 & 0.0 & 15 & 8.63 & 0.00 & 0.0 \\
\hline 18:02:10 & 0.0 & 71 & 0.0 & 20.0 & 40.9 & 9.79 & 0.00 & 0.0 & 15 & 8.64 & 0.00 & 0.0 \\
\hline 18:02:15 & 0.0 & 71 & 0.0 & 19.9 & 40.9 & 9.78 & 0.00 & 0.0 & 15 & 8.60 & 0.00 & 0.0 \\
\hline 18:02:20 & 0.0 & 71 & 0.0 & 19.9 & 40.9 & 9.79 & 0.00 & 0.0 & 15 & 8.61 & 0.00 & 0.0 \\
\hline 18:02:25 & 0.0 & 70 & 0.0 & 19.9 & 40.9 & 9.80 & 0.00 & 0.0 & 15 & 8.60 & 0.00 & 0.0 \\
\hline 18:02:30 & 0.0 & 71 & 0.0 & 19.9 & 40.9 & 9.85 & 0.00 & 0.0 & 15 & 8.59 & 0.00 & 0.0 \\
\hline 18:02:35 & 0.0 & 71 & 0.0 & 19.9 & 40.9 & 9.83 & 0.00 & 0.0 & 15 & 8.60 & 0.00 & 0.0 \\
\hline 18:02:40 & 0.0 & 72 & 0.0 & 19.9 & 40.9 & 9.76 & 0.00 & 0.0 & 16 & 8.62 & 0.00 & 0.0 \\
\hline $18: 02: 45$ & 0.0 & 72 & 0.0 & 19.9 & 40.9 & 9.70 & 0.00 & 0.0 & 16 & 8.63 & 0.00 & 0.0 \\
\hline 18:02:50 & 0.0 & 72 & 0.0 & 19.9 & 40.9 & 9.80 & 0.00 & 0.0 & 16 & 8.62 & 0.00 & 0.0 \\
\hline 18:02:55 & 0.0 & 73 & 0.0 & 19.9 & 40.9 & 9.76 & 0.00 & 0.0 & 16 & 8.63 & 0.00 & 0.0 \\
\hline 18:03:00 & 0.0 & 72 & 0.0 & 19.9 & 40.9 & 9.76 & 0.00 & 0.0 & 16 & 8.63 & 0.00 & 0.0 \\
\hline 18:03:05 & 0.0 & 73 & 0.0 & 19.9 & 40.9 & 9.76 & 0.00 & 0.0 & 16 & 8.63 & 0.00 & 0.0 \\
\hline $18: 03: 10$ & 0.0 & 73 & 0.0 & 19.9 & 40.9 & 9.75 & 0.00 & 0.0 & 16 & 8.66 & 0.00 & 0.0 \\
\hline 18:03:15 & 0.0 & 73 & 0.0 & 19.9 & 40.9 & 9.69 & 0.00 & 0.0 & 16 & 8.70 & 0.00 & 0.0 \\
\hline 18:03:20 & 0.0 & 72 & 0.0 & 19.9 & 40.9 & 9.68 & 0.00 & 0.0 & 16 & 8.70 & 0.00 & 0.0 \\
\hline 18:03:25 & 0.0 & 74 & 0.0 & 19.9 & 40.9 & 9.72 & 0.30 & 0.0 & 16 & 8.66 & 0.00 & 0.0 \\
\hline 18:03:30 & 0.0 & 76 & 0.0 & 19.7 & 40.4 & 9.68 & 0.00 & 0.0 & 16 & 8.66 & 0.00 & 0.0 \\
\hline 18:03:35 & 0.0 & 76 & 0.0 & 20.3 & 41.3 & 9.65 & 0.00 & 0.0 & 16 & 8.67 & 0.00 & 0.0 \\
\hline 18:03:40 & 0.0 & 75 & 0.0 & 22.3 & 42.0 & 9.78 & 0.00 & 0.0 & 16 & 8.64 & 0.00 & 0.0 \\
\hline 18:03:45 & 0.0 & 75 & 0.0 & 21.9 & 40.6 & 9.73 & 0.00 & 0.0 & 16 & 8.65 & 0.00 & 0.0 \\
\hline 18:03:50 & 0.0 & 77 & 0.0 & 31.3 & 36.3 & 9.78 & 0.00 & 0.0 & 17 & 8.66 & 0.00 & 0.0 \\
\hline 18:03:55 & 0.0 & 75 & 0.0 & 30.6 & 35.6 & 9.83 & 0.00 & 0.0 & 17 & 8.69 & 0.00 & 0.0 \\
\hline 18:04:00 & 0.0 & 75 & 0.0 & 30.6 & 35.6 & 9.80 & 0.00 & 0.0 & 17 & 8.66 & 0.00 & 0.0 \\
\hline $18: 04: 05$ & 0.0 & 76 & 0.0 & 32.6 & 36.4 & 9.82 & 0.00 & 0.0 & 17 & 8.64 & 0.00 & 0.0 \\
\hline $18: 04: 10$ & 0.0 & 74 & 0.0 & 31.6 & 35.6 & 9.73 & 0.00 & 0.0 & 17 & 8.64 & 0.00 & 0.0 \\
\hline $18: 04: 15$ & 0.0 & 77 & 0.0 & 31.2 & 35.7 & 9.76 & 0.00 & 0.0 & 17 & 8.63 & 0.00 & 0.0 \\
\hline $18: 04: 20$ & 0.0 & 76 & 0.0 & 31.8 & 35.5 & 9.69 & 0.00 & 0.0 & 17 & 8.63 & 0.00 & 0.0 \\
\hline $18: 04: 25$ & 0.0 & 77 & 0.0 & 32.1 & 35.3 & 9.75 & 0.00 & 0.0 & 17 & 8.64 & 0.00 & 0.0 \\
\hline
\end{tabular}

Date Printed: 08/24/94

Page : 1 


\section{SoilSaw Report}

Location: Palestine

Date: June 7, 1993

\begin{tabular}{|c|c|c|c|c|c|c|c|c|c|c|c|c|}
\hline \multirow[b]{2}{*}{ Time } & \multicolumn{2}{|c|}{ Tubing } & \multicolumn{3}{|c|}{ Gradall } & \multicolumn{3}{|c|}{ Slurry } & \multicolumn{4}{|c|}{ Fluid 2} \\
\hline & $\begin{array}{c}\text { Depth } \\
\mathrm{ft}\end{array}$ & $\begin{array}{c}\text { Pressure } \\
\text { psi }\end{array}$ & $\begin{array}{r}\text { Speed } \\
\mathrm{ft} / \mathrm{min}\end{array}$ & $\begin{array}{l}\text { Boom } \\
\text { Angle }\end{array}$ & $\begin{array}{l}\text { Beam } \\
\text { Angle }\end{array}$ & $\begin{array}{c}\text { Density } \\
\text { lb/gal }\end{array}$ & $\begin{array}{l}\text { Rate } \\
\text { bpm }\end{array}$ & $\begin{array}{c}\text { Volume } \\
\text { bbl }\end{array}$ & $\begin{array}{c}\text { Pressure } \\
\text { psi }\end{array}$ & $\begin{array}{c}\text { Density } \\
\text { Ib/gal }\end{array}$ & $\begin{array}{l}\text { Flow } \\
\text { bpm }\end{array}$ & $\begin{array}{c}\text { Volume } \\
\text { bbl }\end{array}$ \\
\hline $18: 04: 30$ & 0.0 & 77 & 0.0 & 31.8 & 35.9 & 9.72 & 0.00 & 0.0 & 17 & 8.64 & 0.00 & 0.0 \\
\hline $18: 04: 35$ & 0.0 & 75 & 0.0 & 31.4 & 36.2 & 9.79 & 0.00 & 0.0 & 18 & 8.66 & 0.00 & 0.0 \\
\hline 18:04:40 & 0.0 & 82 & 0.0 & 31.1 & 36.1 & 9.75 & 4.15 & 0.2 & 23 & 3.20 & 0.45 & 0.0 \\
\hline $18: 04: 45$ & 0.0 & 90 & 0.0 & 31.2 & 35.6 & 9.75 & 0.59 & 0.4 & 35 & 5.11 & 1.76 & 0.1 \\
\hline $18: 04: 50$ & 0.0 & 97 & 0.0 & 26.1 & 39.2 & 9.63 & 0.00 & 0.4 & 40 & 7.19 & 1.89 & 0.3 \\
\hline $18: 04: 55$ & 0.0 & 104 & 0.0 & 31.6 & 36.8 & 9.65 & 0.00 & 0.4 & 46 & 1.11 & 1.32 & 0.4 \\
\hline 18:05:00 & 0.0 & 111 & 0.0 & 28.3 & 35.3 & 9.73 & 0.00 & 0.4 & 52 & 0.57 & 0.99 & 0.5 \\
\hline 18:05:05 & 0.0 & 111 & 0.0 & 32.8 & 37.4 & 9.82 & 0.00 & 0.4 & 57 & 8.61 & 0.60 & 0.6 \\
\hline 18:05:10 & 0.0 & 105 & 0.0 & 32.3 & 29.8 & 9.76 & 0.00 & 0.4 & 55 & 8.61 & 0.24 & 0.6 \\
\hline 18:05:15 & 0.0 & 100 & 0.0 & 27.8 & 35.8 & 9.80 & 0.00 & 0.4 & 50 & 8.64 & 0.04 & 0.6 \\
\hline 18:05:20 & 0.0 & 98 & 0.0 & 25.4 & 33.8 & 9.79 & 0.00 & 0.4 & 44 & 8.63 & 0.00 & 0.6 \\
\hline $18: 05: 25$ & 0.0 & 96 & 0.0 & 30.0 & 33.1 & 9.76 & 0.00 & 0.4 & 41 & 8.65 & 0.00 & 0.6 \\
\hline 18:05:30 & 1.2 & 98 & 0.0 & 29.1 & 29.5 & 9.75 & 0.00 & 0.4 & 41 & 8.63 & 0.10 & 0.6 \\
\hline 18:05:35 & 1.3 & 99 & 0.0 & 28.6 & 28.6 & 9.73 & 0.00 & 0.4 & 41 & 8.56 & 0.10 & 0.6 \\
\hline 18:05:40 & 1.3 & 98 & 0.0 & 27.8 & 29.1 & 9.76 & 0.00 & 0.4 & 42 & 8.58 & 0.00 & 0.6 \\
\hline $18: 05: 45$ & 1.3 & 97 & 0.0 & 27.9 & 29.1 & 9.80 & 0.00 & 0.4 & 42 & 8.56 & 0.01 & 0.6 \\
\hline $18: 05: 50$ & 1.2 & 95 & -17.9 & 26.4 & 27.0 & 9.75 & 0.00 & 0.4 & 42 & 8.59 & 0.02 & 0.6 \\
\hline 18:05:55 & 1.8 & 99 & 0.3 & 28.0 & 28.9 & 9.76 & 0.00 & 0.4 & 42 & 8.62 & 0.01 & 0.6 \\
\hline 18:06:00 & 1.8 & 99 & 0.0 & 27.1 & 30.9 & 9.70 & 0.00 & 0.4 & 42 & 8.64 & 0.00 & 0.6 \\
\hline 18:06:05 & 1.8 & 105 & 0.0 & 27.9 & 28.6 & 9.70 & 0.00 & 0.4 & 43 & 8.63 & 0.00 & 0.6 \\
\hline 18:06:10 & 1.8 & 97 & 0.0 & 27.9 & 28.8 & 9.72 & 0.00 & 0.4 & 43 & 8.62 & 0.00 & 0.6 \\
\hline 18:06:15 & 1.8 & 96 & 0.0 & 27.9 & 28.7 & 9.63 & 0.00 & 0.4 & 43 & 8.64 & 0.00 & 0.6 \\
\hline 18:06:20 & 1.8 & 96 & 0.0 & 27.8 & 28.4 & 9.76 & 0.00 & 0.4 & 42 & 8.65 & 0.00 & 0.6 \\
\hline 18:06:25 & 1.8 & 98 & 0.0 & 27.3 & 29.9 & 9.76 & 0.00 & 0.4 & 43 & 8.65 & 0.10 & 0.6 \\
\hline $18: 06: 30$ & 1.8 & 139 & 0.0 & 24.6 & 25.0 & 9.80 & 1.19 & 0.4 & 57 & 8.35 & 0.94 & 0.7 \\
\hline 18:06:35 & 1.8 & 199 & 0.0 & 26.8 & 29.3 & 9.62 & 0.89 & 0.5 & 148 & 8.42 & 1.79 & 0.8 \\
\hline 18:06:40 & 1.8 & 318 & 0.0 & 24.5 & 27.6 & 9.62 & 1.78 & 0.7 & 299 & 8.54 & 2.03 & 1.0 \\
\hline 18:06:45 & 1.8 & 396 & 0.0 & 25.5 & 27.9 & 9.85 & 2.07 & 0.8 & 342 & 8.55 & 2.24 & 1.1 \\
\hline 18:06:50 & 1.8 & 394 & 0.0 & 25.3 & 28.4 & 9.85 & 2.37 & 1.1 & 365 & 8.60 & 2.33 & 1.3 \\
\hline 18:06:55 & 1.8 & 393 & 0.0 & 26.0 & 28.5 & 9.85 & 2.07 & 1.2 & 393 & 8.60 & 2.40 & 1.5 \\
\hline 18:07:00 & 1.8 & 402 & 0.0 & 25.0 & 28.8 & 9.83 & 2.37 & 1.4 & 395 & 8.63 & $2: 40$ & 1.7 \\
\hline 18:07:05 & 1.8 & 394 & 0.0 & 27.2 & 25.6 & 9.86 & 2.37 & 1.6 & 392 & 8.67 & 2.40 & 1.9 \\
\hline 18:07:10 & 1.8 & 395 & 0.0 & 29.8 & 17.4 & 9.82 & 2.07 & 1.8 & 389 & 8.66 & 2.41 & 2.1 \\
\hline 18:07:15 & 1.8 & 394 & 0.0 & 31.7 & 19.4 & 9.70 & 2.37 & 2.0 & 387 & 8.61 & 2.40 & 2.3 \\
\hline 18:07:20 & 1.8 & 388 & 0.0 & 31.7 & 19.4 & 9.73 & 2.37 & 2.2 & 386 & 8.63 & 2.40 & 2.5 \\
\hline 18:07:25 & 0.0 & 395 & 0.0 & 31.7 & 19.4 & 9.48 & 2.07 & 2.4 & 385 & 8.67 & 2.41 & 2.7 \\
\hline 18:07:30 & 0.0 & 397 & 0.0 & 31.7 & 19.4 & 9.68 & 2.37 & 2.6 & 388 & 8.65 & 2.41 & 2.9 \\
\hline
\end{tabular}


SollSaw Report

Location: Palestine

Date: June 7, 1993

\begin{tabular}{|c|c|c|c|c|c|c|c|c|c|c|c|c|}
\hline \multirow[b]{2}{*}{ Time } & \multirow{2}{*}{\multicolumn{2}{|c|}{\begin{tabular}{c|c}
\multicolumn{2}{c}{ Tubing } \\
Depth & Pressure \\
$\mathrm{ft}$ & psi
\end{tabular}}} & \multicolumn{3}{|c|}{ Gradall } & \multicolumn{3}{|c|}{ Slurry } & \multicolumn{4}{|c|}{ Fluid 2} \\
\hline & & & $\begin{array}{c}\text { Speed } \\
\mathrm{ft} / \mathrm{min}\end{array}$ & $\begin{array}{l}\text { Boom } \\
\text { Angle }\end{array}$ & $\begin{array}{l}\text { Beam } \\
\text { Angle }\end{array}$ & $\begin{array}{c}\text { Density } \\
\text { lb/gal }\end{array}$ & $\begin{array}{l}\text { Rate } \\
\text { bpm }\end{array}$ & $\begin{array}{c}\text { Volume } \\
\text { bbl }\end{array}$ & $\begin{array}{c}\text { Pressure } \\
\text { psi }\end{array}$ & $\begin{array}{c}\text { Density } \\
\text { lb/gal }\end{array}$ & $\begin{array}{l}\text { Flow } \\
\text { bpm }\end{array}$ & $\begin{array}{c}\text { Volume } \\
\text { bbl }\end{array}$ \\
\hline 18:07:35 & 0.0 & 396 & 0.0 & 31.7 & 19.4 & 9.75 & 2.37 & 2.8 & 388 & 8.64 & 2.42 & 3.1 \\
\hline $18: 07: 40$ & 0.0 & 719 & 0.0 & 31.7 & 19.3 & 9.75 & 3.56 & 3.1 & 739 & 8.68 & 2.83 & 3.4 \\
\hline 18:07:45 & 0.0 & 739 & 0.0 & 31.7 & 19.3 & 9.73 & 3.26 & 3.4 & 809 & 8.68 & 3.35 & 3.6 \\
\hline $18: 07: 50$ & 0.0 & 773 & 0.0 & 31.7 & 19.3 & 9.72 & 3.26 & 3.7 & 879 & 8.66 & 3.55 & 3.9 \\
\hline 18:07:55 & 0.0 & 1012 & 0.0 & 31.7 & 19.2 & 9.86 & 4.15 & 0.3 & 1157 & 8.65 & 3.85 & 0.3 \\
\hline 18:08:00 & 0.0 & 1218 & 0.0 & 31.7 & 19.3 & 9.75 & 4.45 & 0.7 & 1279 & 8.66 & 4.22 & 0.6 \\
\hline 18:08:05 & 0.0 & 1855 & 0.0 & 31.7 & 19.2 & 9.80 & 5.33 & 1.1 & 1940 & 8.62 & 4.56 & 1.0 \\
\hline 18:08:10 & 0.0 & 2589 & 0.0 & 31.7 & 19.4 & 9.79 & 6.22 & 1.6 & 2823 & 8.67 & 5.45 & 1.4 \\
\hline 18:08:15 & 0.0 & 3923 & 0.0 & 31.7 & 19.2 & 9.76 & 8.00 & 2.3 & 4305 & 8.67 & 6.85 & 2.0 \\
\hline 18:08:20 & 0.0 & 4071 & 0.0 & 27.6 & 16.1 & 9.70 & 8.30 & 3.0 & 4502 & 8.69 & 7.85 & 2.6 \\
\hline 18:08:25 & 0.0 & 3948 & 0.0 & 27.7 & 20.4 & 9.89 & 8.30 & 3.7 & 4379 & 8.71 & 8.18 & 3.3 \\
\hline 18:08:30 & 0.0 & 3845 & 0.0 & 29.2 & 21.6 & 9.96 & 8.30 & 4.4 & 4164 & 8.72 & 8.19 & 3.9 \\
\hline 18:08:35 & 0.0 & 2822 & 0.0 & 27.1 & 21.2 & 9.90 & 6.82 & 5.0 & 2910 & 8.74 & 7.78 & 4.6 \\
\hline 18:08:40 & 0.0 & 4299 & 0.0 & 27.0 & 26.0 & 9.87 & 9.19 & 5.7 & 4854 & 8.75 & 7.86 & 5.3 \\
\hline $18: 08: 45$ & 0.0 & 5420 & 0.0 & 26.2 & 37.5 & 9.86 & 9.78 & 6.5 & 5637 & 8.76 & 8.85 & 6.0 \\
\hline 18:08:50 & 0.0 & 5499 & 0.0 & 25.8 & 25.6 & 9.95 & 9.78 & 7.3 & 5566 & 8.74 & 9.35 & 6.7 \\
\hline $18: 08: 55$ & 0.0 & 5458 & 0.0 & 27.1 & 22.6 & 9.85 & 9.48 & 8.1 & 5672 & 8.74 & 9.38 & 7.5 \\
\hline 18:09:00 & 0.0 & 5775 & 0.0 & 27.8 & 26.2 & 10.02 & 9.78 & 9.0 & 5947 & 8.73 & 9.44 & 8.3 \\
\hline 18:09:05 & 0.0 & 5721 & 0.0 & 26.7 & 24.4 & 9.87 & 10.08 & 9.8 & 5881 & 8.72 & 9.51 & 9.1 \\
\hline 18:09:10 & 0.0 & 5763 & 0.0 & 29.5 & 28.0 & 9.95 & 9.78 & 10.6 & 5873 & 8.72 & 9.51 & 9.9 \\
\hline 18:09:15 & 0.0 & 5714 & 0.0 & 29.2 & 26.7 & 10.07 & 9.78 & 11.4 & 5808 & 8.75 & 9.52 & 10.7 \\
\hline $18: 09: 20$ & 0.0 & 5846 & 0.0 & 29.4 & 25.9 & 9.97 & 10.08 & 12.3 & 5776 & 8.74 & 9.54 & 11.5 \\
\hline 18:09:25 & 0.0 & 5772 & 0.0 & 38.5 & 25.8 & 9.99 & 10.08 & 13.1 & 5794 & 8.74 & 9.54 & 12.2 \\
\hline 18:09:30 & 0.0 & 5826 & 0.0 & 27.9 & 27.4 & 9.96 & 9.78 & 13.9 & 5844 & 8.75 & 9.54 & 13.0 \\
\hline 18:09:35 & 0.0 & 5808 & 0.0 & 28.4 & 28.1 & 9.92 & 9.78 & 14.8 & 5803 & 8.79 & 9.56 & 13.8 \\
\hline $18: 09: 40$ & 0.0 & 5200 & 0.0 & 25.9 & 23.1 & 9.86 & 9.48 & 15.6 & 5480 & 8.79 & 9.41 & 14.6 \\
\hline 18:09:45 & 0.0 & 5008 & 0.0 & 27.8 & 29.2 & 9.79 & 9.48 & 16.3 & 5350 & 8.79 & 9.14 & 15.4 \\
\hline 18:09:50 & 0.0 & 5123 & 0.0 & 28.0 & 28.3 & 9.86 & 9.48 & 17.1 & 5361 & 8.76 & 9.10 & 16.2 \\
\hline $18: 09: 55$ & 0.0 & 5179 & 0.0 & 26.6 & 25.1 & 9.85 & 9.48 & 17.9 & 5515 & 8.77 & 9.19 & 16.9 \\
\hline $18: 10: 00$ & 0.0 & 5916 & 0.0 & 27.6 & 24.3 & 9.76 & 10.08 & 18.7 & 5909 & 8.77 & 9.36 & 17.7 \\
\hline $18: 10: 05$ & 0.0 & 5945 & 0.0 & 27.7 & 25.3 & 9.92 & 9.78 & 19.6 & 5849 & 8.79 & 9.56 & 18.5 \\
\hline 18:10:10 & 0.0 & 5835 & 0.0 & 28.4 & 26.1 & 9.96 & 10.08 & 20.4 & 5876 & 8.85 & 9.59 & 19.3 \\
\hline $18: 10: 15$ & 0.0 & 5795 & 0.0 & 28.2 & 26.3 & 10.02 & 9.78 & 21.2 & 5950 & 8.85 & 9.57 & 20.1 \\
\hline $18: 10: 20$ & 0.0 & 5849 & 0.0 & 47.1 & 22.9 & 9.99 & 9.78 & 22.0 & 6000 & 8.81 & 9.57 & 20.9 \\
\hline $18: 10: 25$ & 0.0 & 5841 & 0.0 & 35.5 & 21.9 & 9.90 & 10.08 & 22.9 & 5872 & 8.82 & 9.58 & 21.7 \\
\hline $18: 10: 30$ & 0.0 & 5837 & 0.0 & 27.8 & 25.8 & 9.87 & 9.78 & 23.7 & 5855 & 8.84 & 9.57 & 22.5 \\
\hline 18:10:35 & 0.0 & 5883 & 0.0 & 28.8 & 26.2 & 9.83 & 10.08 & 24.5 & 5901 & 8.81 & 9.58 & 23.3 \\
\hline
\end{tabular}


SoilSaw Report

Location: Palestine

Date: June 7, 1993

\begin{tabular}{|c|c|c|c|c|c|c|c|c|c|c|c|c|}
\hline \multirow[b]{2}{*}{ Time } & \multicolumn{2}{|c|}{ Tubing } & \multicolumn{3}{|c|}{ Gradall } & \multicolumn{3}{|c|}{ Slurry } & \multicolumn{4}{|c|}{ Fluid 2} \\
\hline & $\begin{array}{c}\text { Depth } \\
\text { ft }\end{array}$ & $\begin{array}{c}\text { Pressure } \\
\text { psi }\end{array}$ & $\begin{array}{c}\text { Speed } \\
\mathrm{ft} / \mathrm{min}\end{array}$ & $\begin{array}{l}\text { Boom } \\
\text { Angle }\end{array}$ & $\begin{array}{l}\text { Beam } \\
\text { Angle }\end{array}$ & $\begin{array}{c}\text { Density } \\
\text { lb/gal }\end{array}$ & $\begin{array}{l}\text { Rate } \\
\text { bpm }\end{array}$ & $\begin{array}{c}\text { Volume } \\
\text { bbl }\end{array}$ & $\begin{array}{c}\text { Pressure } \\
\text { psi }\end{array}$ & $\begin{array}{c}\text { Density } \\
\text { |b/gal }\end{array}$ & $\begin{array}{l}\text { Flow } \\
\text { bpm }\end{array}$ & $\begin{array}{c}\text { Volume } \\
\text { bbl }\end{array}$ \\
\hline $18: 10: 40$ & 0.0 & 5839 & 0.0 & 28.6 & 25.8 & 9.87 & 10.08 & 25.4 & 5955 & 8.80 & 9.58 & 24.1 \\
\hline 18:10:45 & 0.0 & 5868 & 0.0 & 30.4 & 28.8 & 9.90 & 9.78 & 26.2 & 5999 & 8.82 & 9.59 & 24.9 \\
\hline 18:10:50 & 0.0 & 5932 & 0.0 & 32.8 & 17.6 & 9.93 & 10.08 & 27.0 & 5967 & 8.81 & 9.60 & 25.7 \\
\hline 18:10:55 & 0.0 & 5890 & 0.0 & 27.7 & 26.6 & 9.90 & 9.78 & 27.9 & 5886 & 8.86 & 9.60 & 26.5 \\
\hline 18:11:00 & 0.0 & 5917 & 0.0 & 28.7 & 28.1 & 9.93 & 9.78 & 28.7 & 5937 & 8.82 & 9.58 & 27.3 \\
\hline 18:11:05 & 0.0 & 5911 & 0.0 & 28.7 & 24.7 & 9.90 & 10.08 & 29.5 & 5964 & 8.87 & 9.60 & 28.1 \\
\hline 18:11:10 & 0.0 & 5946 & 0.0 & 28.9 & 25.0 & 9.93 & 10.08 & 30.4 & 5872 & 8.85 & 9.61 & 28.9 \\
\hline 18:11:15 & 0.0 & 5891 & 0.0 & 28.8 & 26.0 & 9.90 & 9.78 & 31.2 & 5823 & 8.84 & 9.60 & 29.7 \\
\hline 18:11:20 & 0.0 & 5875 & 0.0 & 29.8 & 25.9 & 9.89 & 9.78 & 32.0 & 5906 & 8.83 & 9.58 & 30.5 \\
\hline 18:11:25 & 0.0 & 5827 & 0.0 & 35.2 & 16.7 & 9.96 & 9.78 & 32.8 & 6001 & 8.84 & 9.58 & 31.3 \\
\hline 18:11:30 & 0.0 & 5893 & 0.0 & 28.7 & 23.5 & 9.95 & 9.78 & 33.6 & 6038 & 8.83 & 9.59 & 32.1 \\
\hline 18:11:35 & 0.0 & 5957 & 0.0 & 29.9 & 26.6 & 9.97 & 10.08 & 34.5 & 5924 & 8.78 & 9.61 & 32.9 \\
\hline $18: 11: 40$ & 0.0 & 5896 & 0.0 & 29.2 & 24.6 & 9.96 & 9.78 & 35.3 & 5896 & 8.81 & 9.62 & 33.7 \\
\hline 18:11:45 & 0.0 & 5863 & 0.0 & 29.6 & 24.4 & 9.89 & 10.08 & 36.1 & 5890 & 8.81 & 9.60 & 34.5 \\
\hline 18:11:50 & 0.0 & 5831 & 0.0 & 30.7 & 26.1 & 9.96 & 10.08 & 37.0 & 5843 & 8.81 & 9.58 & 35.3 \\
\hline 18:11:55 & 0.0 & 5888 & 0.0 & 51.1 & 33.0 & 9.89 & 9.78 & 37.8 & 5929 & 8.81 & 9.58 & 36.1 \\
\hline 18:12:00 & 0.0 & 5918 & 0.0 & 36.7 & 11.9 & 9.90 & 10.08 & 38.6 & 5986 & 8.83 & 9.59 & 36.9 \\
\hline 18:12:05 & 0.0 & 5865 & 0.0 & 29.0 & 23.3 & 9.87 & 10.08 & 39.5 & 5948 & 8.83 & 9.58 & 37.7 \\
\hline 18:12:10 & 0.0 & 5883 & 0.0 & 29.5 & 24.7 & 9.89 & 10.37 & 40.3 & 5959 & 8.82 & 9.59 & 38.5 \\
\hline 18:12:15 & 0.0 & 5932 & 0.0 & 29.4 & 25.0 & 9.87 & 10.08 & 41.1 & 5962 & 8.81 & 9.59 & 39.3 \\
\hline 18:12:20 & 0.0 & 5904 & 0.0 & 28.1 & 30.5 & 9.80 & 10.08 & 42.0 & 6038 & 8.79 & 9.60 & 40.1. \\
\hline $18: 12: 25$ & 0.0 & 5854 & 0.0 & 27.0 & 28.3 & 9.87 & 9.78 & 42.8 & 6021 & 8.79 & 9.60 & 40.9 \\
\hline 18:12:30 & 0.0 & 5929 & 0.0 & 27.8 & 22.4 & 9.86 & 9.78 & 43.6 & 5967 & 8.79 & 9.59 & 41.7 \\
\hline 18:12:35 & 0.0 & 5902 & 0.0 & 29.5 & 22.6 & 9.80 & 9.78 & 44.5 & 5801 & 8.80 & 9.58 & 42.5 \\
\hline $18: 12: 40$ & 0.0 & 5910 & 0.0 & 28.0 & 24.5 & 9.90 & 10.08 & 45.3 & 5843 & 8.79 & 9.58 & 43.3 \\
\hline $18: 12: 45$ & 0.0 & 5878 & 0.0 & 28.9 & 23.1 & 9.87 & 9.78 & 46.1 & 5903 & 8.80 & 9.59 & 44.1 \\
\hline $18: 12: 50$ & 0.1 & 5934 & 0.0 & 24.0 & 18.8 & 9.99 & 10.08 & 46.9 & 5953 & 8.78 & 9.59 & 44.9 \\
\hline 18:12:55 & 0.1 & 5948 & 0.0 & 25.2 & 28.4 & 9.90 & 10.08 & 47.8 & 5909 & 8.82 & 9.60 & 45.7 \\
\hline 18:13:00 & 0.1 & 5848 & 0.0 & 30.4 & 25.8 & 9.95 & 9.78 & 48.6 & 5869 & 8.79 & 9.60 & 46.5 \\
\hline 18:13:05 & 0.1 & 5887 & 0.0 & 28.7 & 23.7 & 9.93 & 10.08 & 49.4 & 5968 & 8.75 & 9.59 & 47.3 \\
\hline 18:13:10 & 0.1 & 5944 & 0.0 & 29.7 & 24.3 & 9.97 & 10.08 & 50.3 & 5967 & 8.74 & 9.60 & 48.1 \\
\hline 18:13:15 & 0.1 & 5926 & 0.0 & 28.3 & 24.5 & 9.97 & 9.78 & 51.1 & 5876 & 8.77 & 9.61 & 48.9 \\
\hline $18: 13: 20$ & 0.1 & 5917 & 0.0 & 28.8 & 23.7 & 9.85 & 10.08 & 51.9 & 5949 & 8.76 & 9.60 & 49.7 \\
\hline 18:13:25 & 0.1 & 5963 & 0.0 & 28.7 & 36.7 & 9.90 & 10.08 & 52.8 & 5960 & 8.75 & 9.61 & 50.5 \\
\hline 18:13:30 & 0.1 & 5897 & 0.0 & 28.6 & 21.9 & 9.83 & 10.08 & 53.6 & 5903 & 8.75 & 9.61 & 51.3 \\
\hline 18:13:35 & 0.1 & 5879 & 0.0 & 28.9 & 24.4 & 9.89 & 9.78 & 54.4 & 5974 & 8.72 & 9.60 & 52.1 \\
\hline 18:13:40 & 0.1 & 5918 & 0.0 & 27.8 & 22.9 & 9.89 & 10.08 & 55.3 & 6028 & 8.73 & 9.60 & 52.9 \\
\hline
\end{tabular}


SoilSaw Report

Location: Palestine

Date: June 7, 1993

\begin{tabular}{|c|c|c|c|c|c|c|c|c|c|c|c|c|}
\hline \multirow[b]{2}{*}{ Time } & \multicolumn{2}{|c|}{ Tubing } & \multicolumn{3}{|c|}{ Gradall } & \multicolumn{3}{|c|}{ Slurry } & \multicolumn{4}{|c|}{ Fluid 2} \\
\hline & $\begin{array}{c}\text { Depth } \\
\text { ft }\end{array}$ & $\begin{array}{c}\text { Pressure } \\
\text { psi }\end{array}$ & $\begin{array}{r}\text { Speed } \\
\mathrm{ft} / \mathrm{min}\end{array}$ & $\begin{array}{l}\text { Boom } \\
\text { Angle }\end{array}$ & $\begin{array}{l}\text { Beam } \\
\text { Angle }\end{array}$ & $\begin{array}{c}\text { Density } \\
\text { lb/gal }\end{array}$ & $\begin{array}{l}\text { Rate } \\
\text { bpm }\end{array}$ & $\begin{array}{c}\text { Volume } \\
\text { bbl }\end{array}$ & $\begin{array}{c}\text { Pressure } \\
\text { psi }\end{array}$ & $\begin{array}{c}\text { Density } \\
\text { Ib/gal }\end{array}$ & $\begin{array}{l}\text { Flow } \\
\text { bpm }\end{array}$ & $\begin{array}{c}\text { Volume } \\
\text { bbl }\end{array}$ \\
\hline $18: 13: 45$ & 0.1 & 5924 & 0.0 & 28.9 & 22.6 & 9.90 & 9.78 & 56.1 & 5929 & 8.79 & 9.60 & 53.7 \\
\hline 18:13:50 & 0.1 & 5930 & 0.0 & 28.9 & 24.4 & 10.02 & 10.08 & 56.9 & 5829 & 8.79 & 9.60 & 54.5 \\
\hline $18: 13: 55$ & 0.1 & 5931 & 0.0 & 29.5 & 16.6 & 9.99 & 10.08 & 57.8 & 5915 & 8.81 & 9.61 & 55.3 \\
\hline $18: 14: 00$ & 0.1 & 5945 & 0.0 & 22.6 & 24.0 & 9.93 & 9.78 & 58.6 & 6021 & 8.79 & 9.62 & 56.1 \\
\hline 18:14:05 & 0.1 & 5956 & 0.0 & 28.1 & 20.9 & 9.97 & 9.78 & 59.4 & 6035 & 8.80 & 9.62 & 56.9 \\
\hline $18: 14: 10$ & 0.1 & 5968 & 0.0 & 28.9 & 24.2 & 9.97 & 9.78 & 60.3 & 5937 & 8.79 & 9.62 & 57.7 \\
\hline $18: 14: 15$ & 0.1 & 5944 & 0.0 & 28.0 & 19.1 & 9.99 & 10.08 & 61.1 & 5905 & 8.80 & 9.62 & 58.5 \\
\hline $18: 14: 20$ & 0.1 & 5973 & 0.0 & 29.9 & 25.0 & 9.96 & 9.78 & 61.9 & 5912 & 8.80 & 9.62 & 59.3 \\
\hline $18: 14: 25$ & 0.1 & 5888 & 0.0 & 30.2 & 22.9 & 9.90 & 10.08 & 62.8 & 5885 & 8.78 & 9.61 & 60.1 \\
\hline $18: 14: 30$ & 0.1 & 5914 & 0.0 & 40.9 & 12.5 & 9.93 & 9.78 & 63.6 & 5915 & 8.85 & 9.60 & 60.9 \\
\hline $18: 14: 35$ & 0.1 & 5926 & 0.0 & 34.0 & 23.9 & 9.99 & 10.08 & 64.4 & 5973 & 8.80 & 9.60 & 61.7 \\
\hline $18: 14: 40$ & 0.1 & 5876 & 0.0 & 29.3 & 20.1 & 9.85 & 10.08 & 65.2 & 6022 & 8.79 & 9.59 & 62.5 \\
\hline 18:14:45 & 0.1 & 5915 & 0.0 & 30.2 & 24.3 & 9.90 & 9.78 & 66.1 & 5977 & 8.79 & 9.60 & 63.3 \\
\hline 18:14:50 & 0.1 & 5863 & 0.0 & 30.0 & 23.2 & 9.83 & 10.08 & 66.9 & 5903 & 8.81 & 9.60 & 64.1 \\
\hline $18: 14: 55$ & 0.1 & 5886 & 0.0 & 30.4 & 23.7 & 9.83 & 9.78 & 67.7 & 5858 & 8.79 & 9.59 & 64.9 \\
\hline 18:15:00 & 0.1 & 5960 & 0.0 & 24.0 & 21.8 & 9.93 & 10.08 & 68.6 & 5834 & 8.78 & 9.60 & 65.7 \\
\hline 18:15:05 & 0.1 & 5895 & 0.0 & 28.8 & 22.1 & 9.93 & 10.08 & 69.4 & 5913 & 8.77 & 9.61 & 66.5 \\
\hline 18:15:10 & 0.1 & 5880 & 0.0 & 30.0 & 25.8 & 9.86 & 10.08 & 70.2 & 5917 & 8.78 & 9.61 & 67.3 \\
\hline 18:15:15 & 0.1 & 5822 & 0.0 & 30.5 & 20.7 & 9.95 & 9.78 & 71.0 & 6002 & 8.80 & 9.60 & 68.1 \\
\hline 18:15:20 & 0.1 & 4283 & 0.0 & 29.9 & 24.9 & 9.93 & 8.30 & 71.8 & 4755 & 8.79 & 6.85 & 68.8 \\
\hline 18:15:25 & 0.1 & 102 & 0.0 & 32.5 & 18.3 & 9.76 & 0.00 & 71.9 & 71 & 8.75 & 1.43 & 69.0 \\
\hline $18: 15: 30$ & 0.1 & 82 & 0.0 & 30.1 & 24.3 & 9.85 & 0.00 & 71.9 & 44 & 8.71 & 0.96 & 69.1 \\
\hline 18:15:35 & 0.1 & 81 & 0.0 & 30.1 & 24.2 & 9.89 & 0.00 & 71.9 & 22 & 8.68 & 0.44 & 69.1 \\
\hline $18: 15: 40$ & 0.1 & 81 & 0.0 & 30.1 & 24.3 & 9.83 & 0.00 & 71.9 & 17 & 8.67 & 0.35 & 69.2 \\
\hline 18:15:45 & 0.1 & 79 & 0.0 & 30.1 & 24.3 & 9.80 & 0.00 & 71.9 & 18 & 8.67 & 0.37 & 69.2 \\
\hline 18:15:50 & 0.1 & 81 & 0.0 & 30.1 & 24.3 & 9.66 & 0.00 & 71.9 & 20 & 8.68 & 0.37 & 69.2 \\
\hline $18: 15: 55$ & 0.1 & 81 & 0.0 & 30.1 & 24.3 & 9.76 & 0.00 & 71.9 & 21 & 8.67 & 0.37 & 69.3 \\
\hline $18: 16: 00$ & 0.1 & 81 & 0.0 & 30.1 & 24.3 & 9.73 & 0.00 & 71.9 & 21 & 8.67 & 0.38 & 69.3 \\
\hline 18:16:05 & 0.1 & 82 & 0.0 & 30.1 & 24.2 & 9.76 & 0.00 & 71.9 & 22 & 8.68 & 0.36 & 69.3 \\
\hline 18:16:10 & 0.1 & 81 & 0.0 & 30.1 & 24.2 & 9.75 & 0.00 & 71.9 & 22 & 8.67 & 0.35 & 69.3 \\
\hline 18:16:15 & 0.0 & 84 & 0.0 & 30.1 & 24.2 & 9.69 & 0.00 & 71.9 & 23 & 8.63 & 0.36 & 69.4 \\
\hline 18:16:20 & 0.0 & 83 & 0.0 & 30.1 & 24.2 & 9.73 & 0.00 & 71.9 & 23 & 8.66 & 0.37 & 69.4 \\
\hline 18:16:25 & 0.0 & 84 & 0.0 & 30.1 & 24.2 & 9.76 & 0.00 & 71.9 & 23 & 8.68 & 0.37 & 69.4 \\
\hline 18:16:30 & 0.0 & 84 & 0.0 & 30.1 & 24.2 & 9.70 & 0.00 & 71.9 & 24 & 8.64 & 0.38 & 69.5 \\
\hline 18:16:35 & 0.0 & 94 & 0.0 & 30.2 & 24.2 & 9.69 & 0.00 & 71.9 & 28 & 8.64 & 0.44 & 69.5 \\
\hline $18: 16: 40$ & 0.0 & 94 & 0.0 & 30.2 & 24.2 & 9.65 & 0.00 & 71.9 & 33 & 8.63 & 0.52 & 69.5 \\
\hline $18: 16: 45$ & 0.0 & 96 & 0.0 & 30.2 & 24.2 & 9.68 & 0.00 & 71.9 & 36 & 8.65 & 0.55 & 69.6 \\
\hline
\end{tabular}


SoilSaw Report

Location: Palestine

Date: June 7, 1993

\begin{tabular}{|c|c|c|c|c|c|c|c|c|c|c|c|c|}
\hline \multirow[b]{2}{*}{ Time } & \multicolumn{2}{|c|}{ Tubing } & \multicolumn{3}{|c|}{ Gradall } & \multicolumn{3}{|c|}{ Slurry } & \multicolumn{4}{|c|}{ Fluid 2} \\
\hline & $\begin{array}{c}\text { Depth } \\
\mathrm{ft}\end{array}$ & $\begin{array}{c}\text { Pressure } \\
\text { psi }\end{array}$ & $\begin{array}{l}\text { Speed } \\
\mathrm{ft} / \mathrm{min}\end{array}$ & $\begin{array}{l}\text { Boom } \\
\text { Angle }\end{array}$ & $\begin{array}{l}\text { Beam } \\
\text { Angle }\end{array}$ & $\begin{array}{c}\text { Density } \\
\text { lb/gal }\end{array}$ & $\begin{array}{l}\text { Rate } \\
\text { bpm }\end{array}$ & $\begin{array}{c}\text { Volume } \\
\text { bbl }\end{array}$ & $\begin{array}{c}\text { Pressure } \\
\text { psi }\end{array}$ & $\begin{array}{c}\text { Density } \\
\text { lb/gal }\end{array}$ & $\begin{array}{l}\text { Flow } \\
\text { bpm }\end{array}$ & $\begin{array}{c}\text { Volume } \\
\text { bbl }\end{array}$ \\
\hline 18:16:50 & 0.0 & 486 & 0.0 & 30.3 & 24.2 & 9.73 & 2.96 & 72.0 & 566 & 8.63 & 2.88 & 69.7 \\
\hline $18: 16: 55$ & 0.0 & 411 & 0.0 & 30.3 & 24.2 & 9.78 & 2.67 & 72.3 & 426 & 8.63 & 3.23 & 70.0 \\
\hline 18:17:00 & 0.0 & 1441 & 0.0 & 30.2 & 24.2 & 9.75 & 5.33 & 72.6 & 1999 & 8.67 & 5.61 & 70.3 \\
\hline 18:17:05 & 0.0 & 2797 & 0.0 & 30.3 & 22.3 & 9.85 & 6.82 & 73.1 & 2874 & 8.71 & 6.66 & 70.8 \\
\hline 18:17:10 & 0.0 & 2773 & 0.0 & 30.8 & 22.6 & 9.83 & 7.11 & 73.7 & 2922 & 8.74 & 6.82 & 71.4 \\
\hline 18:17:15 & 0.0 & 2908 & 0.0 & 30.4 & 23.6 & 9.85 & 7.11 & 74.3 & 3090 & 8.74 & 6.80 & 71.9 \\
\hline $18: 17: 20$ & 0.0 & 3583 & 0.0 & 66.1 & 36.6 & 9.87 & 8.00 & 75.0 & 4557 & 8.77 & 7.42 & 72.5 \\
\hline $18: 17: 25$ & 0.0 & 5117 & 0.0 & 35.1 & 35.3 & 9.89 & 9.48 & 75.8 & 5397 & 8.76 & 9.31 & 73.3 \\
\hline $18: 17: 30$ & 0.0 & 5536 & 0.0 & 29.9 & 31.6 & 9.96 & 9.78 & 76.6 & 5699 & 8.77 & 9.34 & 74.1 \\
\hline $18: 17: 35$ & 0.0 & 5676 & 0.0 & 30.5 & 21.6 & 9.93 & 10.08 & 77.4 & 5799 & 8.75 & 9.41 & 74.9 \\
\hline $18: 17: 40$ & 0.0 & 5665 & 0.0 & 30.2 & 21.9 & 9.92 & 9.78 & 78.2 & 5826 & 8.75 & 9.46 & 75.7 \\
\hline $18: 17: 45$ & 0.0 & 5656 & 0.0 & 30.6 & 22.3 & 9.99 & 9.78 & 79.1 & 5711 & 8.78 & 9.47 & 76.5 \\
\hline $18: 17: 50$ & 0.0 & 5655 & 0.0 & 30.6 & 25.6 & 9.95 & 9.78 & 79.9 & 5787 & 8.79 & 9.47 & 77.2 \\
\hline 18:17:55 & 0.0 & 5597 & 0.0 & 31.8 & 23.1 & 9.93 & 9.78 & 80.7 & 5849 & 8.83 & 9.47 & 78.0 \\
\hline 18:18:00 & 0.0 & 5675 & 0.0 & 32.3 & 24.2 & 9.92 & 10.08 & 81.5 & 5682 & 8.82 & 9.48 & 78.8 \\
\hline 18:18:05 & 0.0 & 5641 & 0.0 & 30.7 & 24.6 & 9.95 & 9.78 & 82.3 & 5764 & 8.84 & 9.47 & 79.6 \\
\hline 18:18:10 & 0.0 & 5555 & 0.0 & 27.3 & 14.6 & 9.90 & 9.78 & 83.1 & 5788 & 8.82 & 9.47 & 80.4 \\
\hline 18:18:15 & 0.0 & 5927 & 0.0 & 40.3 & 14.3 & 9.79 & 9.78 & 84.0 & 5913 & 8.81 & 9.52 & 81.2 \\
\hline $18: 18: 20$ & 0.0 & 5874 & 0.0 & 30.9 & 22.4 & 9.90 & 10.08 & 84.8 & 5840 & 8.79 & 9.59 & 82.0 \\
\hline 18:18:25 & 0.0 & 5887 & 0.0 & 31.1 & 25.2 & 9.89 & 9.78 & 85.6 & 5895 & 8.81 & 9.62 & 82.8 \\
\hline $18: 18: 30$ & 0.0 & 5907 & 0.0 & 31.0 & 24.2 & 9.89 & 10.08 & 86.5 & 6023 & 8.81 & 9.62 & 83.6 \\
\hline $18: 18: 35$ & 0.0 & 5921 & 0.0 & 33.3 & 22.6 & 10.03 & 9.78 & 87.3 & 6046 & 8.79 & 9.62 & 84.4 \\
\hline 18:18:40 & 0.0 & 5959 & 0.0 & 31.6 & 20.6 & 9.85 & 10.08 & 88.1 & 5965 & 8.78 & 9.62 & 85.2 \\
\hline 18:18:45 & 0.0 & 5946 & 0.0 & 29.0 & 33.6 & 9.92 & 9.78 & 88.9 & 5892 & 8.78 & 9.62 & 86.0 \\
\hline 18:18:50 & 0.0 & 5922 & 0.0 & 31.1 & 24.8 & 10.02 & 10.08 & 89.8 & 5906 & 8.79 & 9.63 & 86.8 \\
\hline 18:18:55 & 0.0 & 5900 & 0.0 & 31.2 & 21.8 & 9.93 & 10.08 & 90.6 & 6020 & 8.80 & 9.62 & 87.6 \\
\hline 18:19:00 & 0.0 & 5925 & 0.0 & 31.2 & 24.0 & 9.89 & 10.08 & 91.4 & 6078 & 8.83 & 9.63 & 88.4 \\
\hline 18:19:05 & 0.0 & 5979 & 0.0 & 30.4 & 26.0 & 9.86 & 10.08 & 92.3 & 5954 & 8.84 & 9.63 & 89.2 \\
\hline $18: 19: 10$ & 0.0 & 5948 & 0.0 & 29.7 & 9.1 & 9.95 & 9.78 & 93.1 & 5916 & 8.83 & 9.63 & 90.0 \\
\hline $18: 19: 15$ & 0.0 & 5941 & 0.0 & 35.6 & 13.3 & 9.89 & 9.78 & 93.9 & 5895 & 8.86 & 9.63 & 90.8 \\
\hline $18: 19: 20$ & 0.0 & 5951 & 0.0 & 30.4 & 19.7 & 9.89 & 10.08 & 94.8 & 5986 & 8.85 & 9.62 & 91.6 \\
\hline 18:19:25 & 0.0 & 6000 & 0.0 & 31.3 & 22.4 & 9.87 & 10.08 & 95.6 & 6061 & 8.84 & 9.63 & 92.4 \\
\hline 18:19:30 & 0.0 & 5888 & 0.0 & 31.1 & 23.7 & 9.92 & 10.08 & 96.4 & 6059 & 8.87 & 9.63 & 93.2 \\
\hline $18: 19: 35$ & 0.0 & 5951 & 0.0 & 29.6 & 26.5 & 9.93 & 10.08 & 97.3 & 5987 & 8.86 & 9.62 & 94.0 \\
\hline 18:19:40 & 0.0 & 5920 & 0.0 & 31.4 & 27.6 & 9.83 & 9.78 & 98.1 & 5900 & 8.83 & 9.62 & 94.8 \\
\hline $18: 19: 45$ & 0.0 & 5963 & 0.0 & 32.6 & 24.0 & 9.93 & 9.78 & 98.9 & 5896 & 8.84 & 9.63 & 95.6 \\
\hline $18: 19: 50$ & 0.0 & 5963 & 0.0 & 31.3 & 24.8 & 9.87 & 10.08 & 99.8 & 6020 & 8.83 & 9.62 & 96.4 \\
\hline
\end{tabular}

Date Printed: 08/24/94

Page : 6 
SollSaw Report

Location: Palestine

Date: June 7, 1993

\begin{tabular}{|c|c|c|c|c|c|c|c|c|c|c|c|c|}
\hline \multirow[b]{2}{*}{ Time } & \multicolumn{2}{|c|}{ Tubing } & \multicolumn{3}{|c|}{ Gradall } & \multicolumn{3}{|c|}{ Slurry } & \multicolumn{4}{|c|}{ Fluid 2} \\
\hline & $\begin{array}{c}\text { Depth } \\
\text { ft }\end{array}$ & $\begin{array}{c}\text { Pressure } \\
\text { psi }\end{array}$ & $\begin{array}{r}\text { Speed } \\
\mathrm{ft} / \mathrm{min}\end{array}$ & $\begin{array}{l}\text { Boom } \\
\text { Angle }\end{array}$ & $\begin{array}{l}\text { Beam } \\
\text { Angle }\end{array}$ & $\begin{array}{c}\text { Density } \\
\text { Ib/gal }\end{array}$ & $\begin{array}{l}\text { Rate } \\
\text { bpm }\end{array}$ & $\begin{array}{c}\text { Volume } \\
\text { bbl }\end{array}$ & $\begin{array}{c}\text { Pressure } \\
\text { psi }\end{array}$ & $\begin{array}{c}\text { Density } \\
\text { Ib/gal }\end{array}$ & $\begin{array}{l}\text { Flow } \\
\text { bpm }\end{array}$ & $\begin{array}{c}\text { Volume } \\
\text { bbl }\end{array}$ \\
\hline 18:19:55 & 0.0 & 5945 & 0.0 & 30.8 & 21.3 & 9.87 & 9.78 & 100.6 & 6059 & 8.79 & 9.62 & 97.2 \\
\hline 18:20:00 & 0.0 & 5956 & 0.0 & 31.5 & 23.4 & 9.83 & 10.08 & 101.4 & 6062 & 8.85 & 9.63 & 98.0 \\
\hline 18:20:05 & 0.0 & 6030 & 0.0 & 31.8 & 23.6 & 9.85 & 9.78 & 102.2 & 6111 & 8.84 & 9.65 & 98.8 \\
\hline $18: 20: 10$ & 0.0 & 6029 & 0.0 & 34.0 & 30.5 & 9.90 & 10.08 & 103.1 & 5950 & 8.84 & 9.67 & 99.6 \\
\hline $18: 20: 15$ & 0.0 & 6043 & 0.0 & 27.6 & 38.3 & 9.90 & 10.08 & 103.9 & 5952 & 8.83 & 9.67 & 100.4 \\
\hline $18: 20: 20$ & 0.0 & 5924 & 0.0 & 27.7 & 15.3 & 9.99 & 10.08 & 104.7 & 5889 & 8.86 & 9.65 & 101.2 \\
\hline 18:20:25 & 0.0 & 5961 & 0.0 & 31.5 & 24.8 & 9.96 & 9.78 & 105.6 & 5973 & 8.81 & 9.63 & 102.0 \\
\hline 18:20:30 & 0.0 & 5945 & 0.0 & 30.6 & 20.6 & 9.99 & 9.78 & 106.4 & 5994 & 8.80 & 9.63 & 102.9 \\
\hline 18:20:35 & 0.0 & 6050 & 0.0 & 31.1 & 23.3 & 9.99 & 10.08 & 107.2 & 5997 & 8.79 & 9.65 & 103.7 \\
\hline $18: 20: 40$ & 0.0 & 6053 & 0.0 & 29.9 & 23.1 & 9.95 & 9.78 & 108.1 & 5949 & 8.81 & 9.67 & 104.5 \\
\hline $18: 20: 45$ & 0.0 & 5854 & 0.0 & 31.7 & 24.8 & 9.76 & 9.78 & 108.9 & 5953 & 8.81 & 9.63 & 105.3 \\
\hline $18: 20: 50$ & 0.0 & 5695 & 0.0 & 31.5 & 26.6 & 9.95 & 10.08 & 109.7 & 5886 & 8.82 & 9.55 & 106.1 \\
\hline $18: 20: 55$ & 0.0 & 831 & 0.0 & 31.6 & 21.7 & 9.90 & 3.56 & 110.4 & 1872 & 8.76 & 3.17 & 106.8 \\
\hline $18: 21: 00$ & 0.0 & 91 & 0.0 & 31.5 & 25.1 & 9.92 & 0.00 & 110.5 & 66 & 8.74 & 1.08 & 106.9 \\
\hline 18:21:05 & 0.0 & 78 & 0.0 & 31.5 & 23.0 & 9.75 & 0.00 & 110.5 & 44 & 8.66 & 0.50 & 106.9 \\
\hline 18:21:10 & 0.0 & 74 & 0.0 & 31.4 & 23.0 & 9.72 & 0.00 & 110.5 & 19 & 8.60 & 0.06 & 107.0 \\
\hline 18:21:15 & 0.0 & 75 & 0.0 & 31.5 & 23.0 & 9.79 & 0.00 & 110.5 & 15 & 8.59 & 0.00 & 107.0 \\
\hline 18:21:20 & 0.0 & 75 & 0.0 & 31.5 & 23.0 & 9.86 & 0.00 & 110.5 & 16 & 8.61 & 0.00 & 107.0 \\
\hline $18: 21: 25$ & 0.0 & 71 & 0.0 & 31.5 & 23.0 & 9.80 & 0.00 & 110.5 & 15 & 8.61 & 0.00 & 107.0 \\
\hline 18:21:30 & 0.0 & 70 & 0.0 & 31.5 & 23.0 & 9.85 & 0.00 & 110.5 & 12 & 8.46 & 0.00 & 107.0 \\
\hline 18:21:35 & 0.0 & 64 & 0.0 & 31.5 & 23.0 & 9.80 & 0.00 & 110.5 & 10 & 8.51 & 0.00 & 107.0 \\
\hline $18: 21: 40$ & 0.0 & 71 & 0.0 & 31.5 & 23.0 & 9.85 & 0.00 & 110.5 & 10 & 8.55 & 0.00 & 107.0 \\
\hline $18: 21: 45$ & 0.0 & 812 & 0.0 & 31.5 & 23.0 & 9.78 & 4.15 & 110.6 & 936 & 8.63 & 3.31 & 107.1 \\
\hline $18: 21: 50$ & 0.0 & 2928 & 0.0 & 31.5 & 23.1 & 9.82 & 7.11 & 111.2 & 3070 & 8.66 & 6.85 & 107.6 \\
\hline 18:21:55 & 0.0 & 4277 & 0.0 & 32.7 & 16.6 & 9.85 & 8.89 & 111.9 & 4955 & 8.69 & 7.66 & 108.2 \\
\hline 18:22:00 & 0.0 & 4784 & 0.0 & 31.5 & 26.9 & 9.93 & 9.19 & 112.6 & 5094 & 8.69 & 8.59 & 108.9 \\
\hline $18: 22: 05$ & 0.0 & 5910 & 0.0 & 49.8 & 24.7 & 9.92 & 10.08 & 113.4 & 5899 & 8.72 & 9.12 & 109.6 \\
\hline 18:22:10 & 0.0 & 5443 & 0.0 & 32.9 & 25.6 & 10.06 & 9.78 & 114.3 & 5638 & 8.73 & 9.39 & 110.4 \\
\hline 18:22:15 & 0.0 & 5558 & 0.0 & 31.1 & 21.0 & 10.03 & 9.78 & 115.1 & 5758 & 8.75 & 9.41 & 111.2 \\
\hline $18: 22: 20$ & 0.0 & 5470 & 0.0 & 32.0 & 24.9 & 10.00 & 9.78 & 115.9 & 5756 & 8.74 & 9.41 & 112.0 \\
\hline $18: 22: 25$ & 0.0 & 5514 & 0.0 & 32.0 & 24.5 & 9.96 & 9.78 & 116.7 & 5745 & 8.75 & 9.39 & 112.7 \\
\hline $18: 22: 30$ & 0.0 & 5562 & 0.0 & 32.1 & 23.5 & 9.86 & 9.78 & 117.5 & 5736 & 8.76 & 9.40 & 113.5 \\
\hline $18: 22: 35$ & 0.0 & 5521 & 0.0 & 26.8 & 22.6 & 9.89 & 9.48 & 118.3 & 5640 & 8.77 & 9.42 & 114.3 \\
\hline $18: 22: 40$ & 0.0 & 5484 & 0.0 & 31.9 & 25.2 & 9.96 & 9.78 & 119.1 & 5637 & 8.80 & 9.42 & 115.1 \\
\hline $18: 22: 45$ & 0.0 & 5524 & 0.0 & 26.0 & 43.7 & 9.97 & 9.48 & 119.9 & 5817 & 8.80 & 9.41 & 115.9 \\
\hline $18: 22: 50$ & 0.0 & 5546 & 0.0 & 55.9 & 23.2 & 9.93 & 10.08 & 120.8 & 5638 & 8.77 & 9.41 & 116.7 \\
\hline $18: 22: 55$ & 0.0 & 5550 & 0.0 & 36.1 & 26.4 & 9.97 & 9.78 & 121.6 & 5652 & 8.80 & 9.42 & 117.4 \\
\hline
\end{tabular}


Sollsaw Report

Location: Palestine

Date: June 7, 1993

\begin{tabular}{|c|c|c|c|c|c|c|c|c|c|c|c|c|}
\hline \multirow[b]{2}{*}{ Time } & \multicolumn{2}{|c|}{ Tubing } & \multicolumn{3}{|c|}{ Gradall } & \multicolumn{3}{|c|}{ Slurry } & \multicolumn{4}{|c|}{ Fluid 2} \\
\hline & $\begin{array}{c}\text { Depth } \\
\mathrm{ft}\end{array}$ & $\begin{array}{c}\text { Pressure } \\
\text { psi }\end{array}$ & $\begin{array}{r}\text { Speed } \\
\mathrm{ft} / \mathrm{min}\end{array}$ & $\begin{array}{l}\text { Boom } \\
\text { Angle }\end{array}$ & $\begin{array}{l}\text { Beam } \\
\text { Angle }\end{array}$ & $\begin{array}{c}\text { Density } \\
\text { Ib/gal }\end{array}$ & $\begin{array}{l}\text { Rate } \\
\text { bpm }\end{array}$ & $\begin{array}{c}\text { Volume } \\
\text { bbl }\end{array}$ & $\begin{array}{c}\text { Pressure } \\
\text { psi }\end{array}$ & $\begin{array}{c}\text { Density } \\
\text { lb/gal }\end{array}$ & $\begin{array}{l}\text { Flow } \\
\text { bpm }\end{array}$ & $\begin{array}{c}\text { Volume } \\
\text { bbl }\end{array}$ \\
\hline $18: 23: 00$ & 0.0 & 5497 & 0.0 & 33.4 & 23.6 & 10.00 & 9.48 & 122.4 & 5734 & 8.75 & 9.42 & 118.2 \\
\hline 18:23:05 & 0.0 & 2593 & 0.0 & 32.3 & 22.9 & 10.00 & 5.93 & 123.1 & 2763 & 8.76 & 5.30 & 118.9 \\
\hline 18:23:10 & 0.0 & 86 & 0.0 & 28.4 & 28.4 & 9.92 & 0.00 & 123.2 & 51 & 8.70 & 1.24 & 119.1 \\
\hline $18: 23: 15$ & 0.0 & 73 & 0.0 & 32.6 & 25.5 & 9.89 & 0.00 & 123.2 & 31 & 8.66 & 0.78 & 119.2 \\
\hline 18:23:20 & 0.0 & 68 & 0.0 & 29.0 & 33.9 & 9.87 & 0.00 & 123.2 & 14 & 8.62 & 0.16 & 119.2 \\
\hline 18:23:25 & 0.0 & 66 & 0.0 & 27.5 & 23.8 & 9.78 & 0.00 & 123.2 & 7 & 8.61 & 0.00 & 119.2 \\
\hline 18:23:30 & 0.0 & 65 & 0.0 & 27.4 & 18.4 & 9.73 & 0.00 & 123.2 & 4 & 8.58 & 0.00 & 119.2 \\
\hline 18:23:35 & 0.0 & 64 & 0.0 & 26.9 & 18.0 & 9.79 & 0.00 & 123.2 & 3 & 8.62 & 0.00 & 119.2 \\
\hline $18: 23: 40$ & 0.0 & 64 & 0.0 & 27.1 & 16.6 & 9.79 & 0.00 & 123.2 & 2 & 8.61 & 0.00 & 119.2 \\
\hline $18: 23: 45$ & 0.0 & 63 & 0.0 & 27.3 & 16.1 & 9.79 & 0.00 & 123.2 & 2 & 8.60 & 0.00 & 119.2 \\
\hline $18: 23: 50$ & 0.0 & 64 & 0.0 & 27.4 & 16.1 & 9.76 & 0.00 & 123.2 & 2 & 8.57 & 0.00 & 119.2 \\
\hline 18:23:55 & 0.0 & 65 & 0.0 & 27.3 & 16.1 & 9.80 & 0.00 & 123.2 & 2 & 8.56 & 0.00 & 119.2 \\
\hline $18: 24: 00$ & 0.0 & 64 & 0.0 & 25.9 & 18.6 & 9.78 & 0.00 & 123.2 & 2 & 8.56 & 0.00 & 119.2 \\
\hline 18:24:05 & 0.0 & 63 & 0.0 & 25.8 & 18.7 & 9.79 & 0.00 & 123.2 & 3 & 8.57 & 0.00 & 119.2 \\
\hline $18: 24: 10$ & 0.0 & 64 & 0.0 & 26.3 & 16.0 & 9.86 & 0.00 & 123.2 & 3 & 8.56 & 0.00 & 119.2 \\
\hline $18: 24: 15$ & 0.0 & 65 & 0.0 & 25.7 & 12.7 & 9.83 & 0.00 & 123.2 & 3 & 8.55 & 0.00 & 119.2 \\
\hline $18: 24: 20$ & 0.0 & 66 & 0.0 & 25.5 & 10.9 & 9.80 & 0.00 & 123.2 & 3 & 8.61 & 0.00 & 119.2 \\
\hline $18: 24: 25$ & 0.0 & 65 & 0.0 & 24.3 & 12.8 & 9.83 & 0.00 & 123.2 & 3 & 8.61 & 0.00 & 119.2 \\
\hline $18: 24: 30$ & 0.0 & 66 & 0.0 & 24.8 & 8.8 & 9.76 & 0.00 & 123.2 & 4 & 8.60 & 0.00 & 119.2 \\
\hline 18:24:35 & 0.0 & 66 & 0.0 & 25.3 & 9.8 & 9.80 & 0.00 & 123.2 & 4 & 8.57 & 0.00 & 119.2 \\
\hline $18: 24: 40$ & 0.0 & 65 & 0.0 & 24.9 & 7.6 & 9.80 & 0.00 & 123.2 & 4 & 8.57 & 0.00 & 119.2 \\
\hline
\end{tabular}


APPENDIX C

SOIL ANALYSIS, PALESTINE, TX 


\section{GEOTECHNICAL SERVICES \\ SOIL SAW DEMONSTRATION TEST \\ PALESTINE, TEXAS}

\section{Introductory Summary}

The project consists of a subsurface investigation, associated geotechnical laboratory testing, and data report for a demonstration test area within the Alcoa facility located near Palestine, Texas. Presented herein is a summary of our field investigation and laboratory testing. This work was authorized by you on April 28, 1993 under the Master Service Agreement Number 5200-0000-M007176, Work Order Number 23403040-S2501.

\section{Project Description}

The project consists of performing geotechnical borings in the demonstration test area and laboratory tests on selected soil samples from the borings. The area is located adjacent to State Highway 79 northeast of the City of Palestine, Texas as. shown on Figure 1.

\section{Scope of Work}

We drilled six 35-ft and one 54-ft deep exploratory soil borings at the location shown on Figure 2 to investigate subsurface stratigraphy and groundwater conditions. Composite bulk soil samples were obtained from each 15 -ft interval of soil stratigraphy explored, to a maximum depth of 35-ft. The composite samples were transported to Hull Airport as requested by Mr. Ernie Carter. We performed soil mechanics laboratory tests on selected soil samples recovered from the borings to measure selected physical and engineering properties.

\section{Field Exploration}

The field exploration for this project began on April 29, 1993 and was completed on May 3, 1993. One boring, B-4, was drilled to a depth of $54 \mathrm{ft}$ and six borings B-I through B-3 and B-5 through B-7) were drilled to depths of $35 \mathrm{ft}$ below existing ground surface. The boring locations were specified by Brown \& Root Environmental and elevations at the boring locations were not surveyed. A truck mounted rig was used on borings B-1 through B-6 and a buggy-mounted rig was used on B-7, with both rigs having hydraulic draw down. The approximate boring locations are shown on Figure 2.

Soil Sampling. Soil samples were taken at continual 2.5-ft intervals to a depth of $35 \mathrm{ft}$. Samples were not obtained in boring B-4 from the 35-ft to 54-ft depth. The borings were 
initially dry augured to explore for perched or free-water, and continued by the wet rotary method to the boring depths of 35 to $54 \mathrm{ft}$.

Cohesive soil samples were generally obtained by hydraulically pushing a 3-in. diameter thin-walled Shelby tube in a single stroke (ASTM D 1587). Samples were extruded in the field, visually classified, and a strength estimate obtained with a pocket penetrometer. Penetrometer readings are shown on the boring logs. Representative portions of the samples were wrapped and sealed for transport to our laboratory.

Cohesionless and semi-cohesionless soils were sampled with the Standard Penetration Test (SPT) sampler driven 18 in. by blows from a 140 pound hammer falling 30 in. (ASTM D 1586). The number of blows required to advance the sampler three consecutive 6 in. depths are recorded for each corresponding sample on the boring logs. The $(\mathrm{N})$ value, in blows per foot, is obtained from SPT by adding the last two blow count numbers. Samples obtained from the split barrel sampler were visually classified and placed in glass jars with screw top caps and transported to our laboratory.

Groundwater Observations. The project borings were initially dry augured to depths of $13.5 \mathrm{ft}$ to $18.5 \mathrm{ft}$ where free water was encountered and continued with the wet rotary method. Groundwater levels measured in open boreholes may not be accurate and should be considered approximate. The borings were filled with soil cuttings from each borehole after groundwater levels were noted and as directed. 


\section{Boring Logs}

Our interpretations of the general soil conditions at the boring locations are included on the boring logs presented at the end of this report. A key to the terms and symbols used on the boring logs is also attached.

\section{Laboratory Testing}

We performed soil mechanics laboratory tests on selected soil samples recovered from the project borings to measure specific physical and engineering properties. The laboratory tests performed on cohesive and cohesionless soils were specified by Halliburton NUS. The laboratory tests consisted of the following:

Natural Moisture Content: ASTM D 2216 - This test provides a measure of water in the soil. Test results are expressed as the weight of water as a percentage of the weight of sample solids.

Percent Finer Than The No. 200 Sieve: ASTM D 1140 - This gradation test is primarily a classification tool for cohesionless soils. The test results are presented as the percent of silt and clay sizes by weight in the sample. The percentage of fines can also provide an indication of the soil permeability.

Atterberg Limits: ASTM D 4318 - This test is primarily a classification tool and is used to distinguish different soil types. When considered in conjunction with natural moisture content it provides an indication of volume change potential.

Unconfined Compression: ASTM D 2166 - Compression tests on unconfined cylindrical samples were performed on cohesive soils. The compressive strength of each sample, determined as twice the undrained shear strength, is given at the sample depth on the boring logs.

Unconsolidated Undrained Triaxial Compression: ASTM D 2850 - Compression tests were performed on confined cohesive cylindrical samples. The samples were subjected to lateral cell pressures representative of the in situ overburden pressure corresponding to the sample depth. The compressive strength of each sample, determined as twice the undrained shear strength, is given at the sample depth on the boring logs.

The results of the laboratory tests are shown on the boring logs presented at the end of the report. A total of 26 cohesionless samples were tested for the percent 
passing a No. 100 sieve. The sieve results are shown in Table I at the end of this report.

\section{Subsurface Conditions}

The subsurface conditions were explored with seven borings drilled to depths of $35 \mathrm{ft}$ and $54 \mathrm{ft}$ at the approximate locations shown in Figure 2. The generalized stratigraphy based on conditions at the boring locations is shown on Figure 3.

Soil Stratiqraphy. The generalized soil stratigraphy, interpreted from the project borings. is tabulated as follows:

\begin{tabular}{|c|c|l|}
\hline Layer & $\begin{array}{c}\text { Typical Depth } \\
\text { interval }(\mathrm{ft})\end{array}$ & \multicolumn{1}{|c|}{ Soil Description \& Classification } \\
\hline 1 & $0-4$ & $\begin{array}{l}\text { Firm to very stiff SANDY CLAY FILL [ the upper O to 7 ft in } \\
\text { boring B-4 and O to 3.5 } \mathrm{ft} \text { in boring CB-5 consisted of } \\
\text { SILTY FINE SAND FILL] }\end{array}$ \\
\hline 2 & $4-10$ & Very stiff SANDY and SILTY CLAY (CL) \\
\hline 3 & $10-35+$ & $\begin{array}{l}\text { Predominantly firm to very dense FINE SAND (SM), } \\
\text { occasional SANDY and SILTY CLAY (CL) }\end{array}$ \\
\hline 4 & $50-?$ & CLAY (CH) \\
\hline
\end{tabular}

Detailed descriptions of the soils encountered are presented on the boring logs at the end of this report.

Soil Properties. We measured undrained shear strengths ranging from $1,240 \mathrm{psf}$ to $5,010 \mathrm{psf}$ on the cohesive soil samples recovered from the 0.5 to $19 \mathrm{ft}$ depths. Apparent shear strengths of the recovered cohesive soil samples, based on converted pocket penetrometer readings, were generally between 1,000 psf and more than 3,000 psf. Most values were greater than 2660 psf. Total unit weights of the recovered soil samples ranged from 104 pcf to 129 pcf, with a median value of 117 pcf.

Standard Penetration Test $\mathrm{N}$-values within cohesionless and semicohesionless soils ranged from 1 to more than 50 blows per foot, indicative of loose to very dense conditions. The loose consistency was measured at the 15.5 - $\mathrm{ft}$ depth in boring B-5. Fines contents of the clayey sands and silty sands ranged from 6 to $67 \%$. 
Groundwater Levels. The project borings were initially dry augured from $12.5-\mathrm{ft}$ to $35-\mathrm{ft}$ depths. Free water was encountered in B-2 through B-4 at a depth of $13.5 \mathrm{ft}$ to $18.5 \mathrm{ft}$. The borings were continued with the wet rotary method below those depths. Static groundwater levels were measured at a depth of $12.8 \mathrm{ft}$ in B-2, after an observation time period of about 15 minutes, and at a depth of $6.9 \mathrm{ft}$ in B-4 approximately two hours after the boring was completed. The static groundwater reading in B-4 was not obtained at the time free water was encountered because the boring caved at $12 \mathrm{ft}$. The groundwater observations are shown on the boring logs.

Groundwater levels may fluctuate with climatic and seasonal variations and should be verified just before construction.

\section{Limitations}

Reasonable variations from the subsurface information presented in this report should be assumed . 


\begin{tabular}{|c|c|c|}
\hline & \multicolumn{2}{|c|}{ TABLE 1 } \\
\hline BORING NO. & BORING DEPTH (FT) & $\begin{array}{c}\text { PERCENT PASSING } \\
\text { NO. 100 SIEVE }\end{array}$ \\
\hline B-1 & $6-7.5$ & 93 \\
\hline B-1 & $18.5-20$ & 71 \\
\hline B-2 & $18.5-20$ & 91 \\
\hline B-3 & $16-17.5$ & 92 \\
\hline B-5 & $10.5-12$ & 70 \\
\hline B-5 & $15.5-17$ & 71 \\
\hline B-5 & $20.5-22$ & 76 \\
\hline B-5 & $25.5-27$ & 76 \\
\hline B-5 & $30.5-32$ & 18 \\
\hline B-6 & $10-12.5$ & 92 \\
\hline B-6 & $16-17.5$ & 45 \\
\hline B-6 & $18.5-20$ & 67 \\
\hline B-6 & $21-22.5$ & 56 \\
\hline B-6 & $23.5-25$ & 75 \\
\hline B-6 & $26-27.5$ & 61 \\
\hline B-6 & $28.5-30$ & 62 \\
\hline B-6 & $33.5-35$ & 47 \\
\hline B-7 & $1-2.5$ & 98 \\
\hline B-7 & $3.5-5$ & 90 \\
\hline B-7 & $8-10$ & 52 \\
\hline B-7 & $13.5-15$ & 77 \\
\hline B-7 & $16-17.5$ & 86 \\
\hline B-7 & $18.5-20$ & 50 \\
\hline B-7 & $23.5-25$ & 74 \\
\hline B-7 & $26-27.5$ & 69 \\
\hline B-7 & $31-32.5$ & \\
\hline & & 77 \\
\hline & & 70 \\
\hline
\end{tabular}




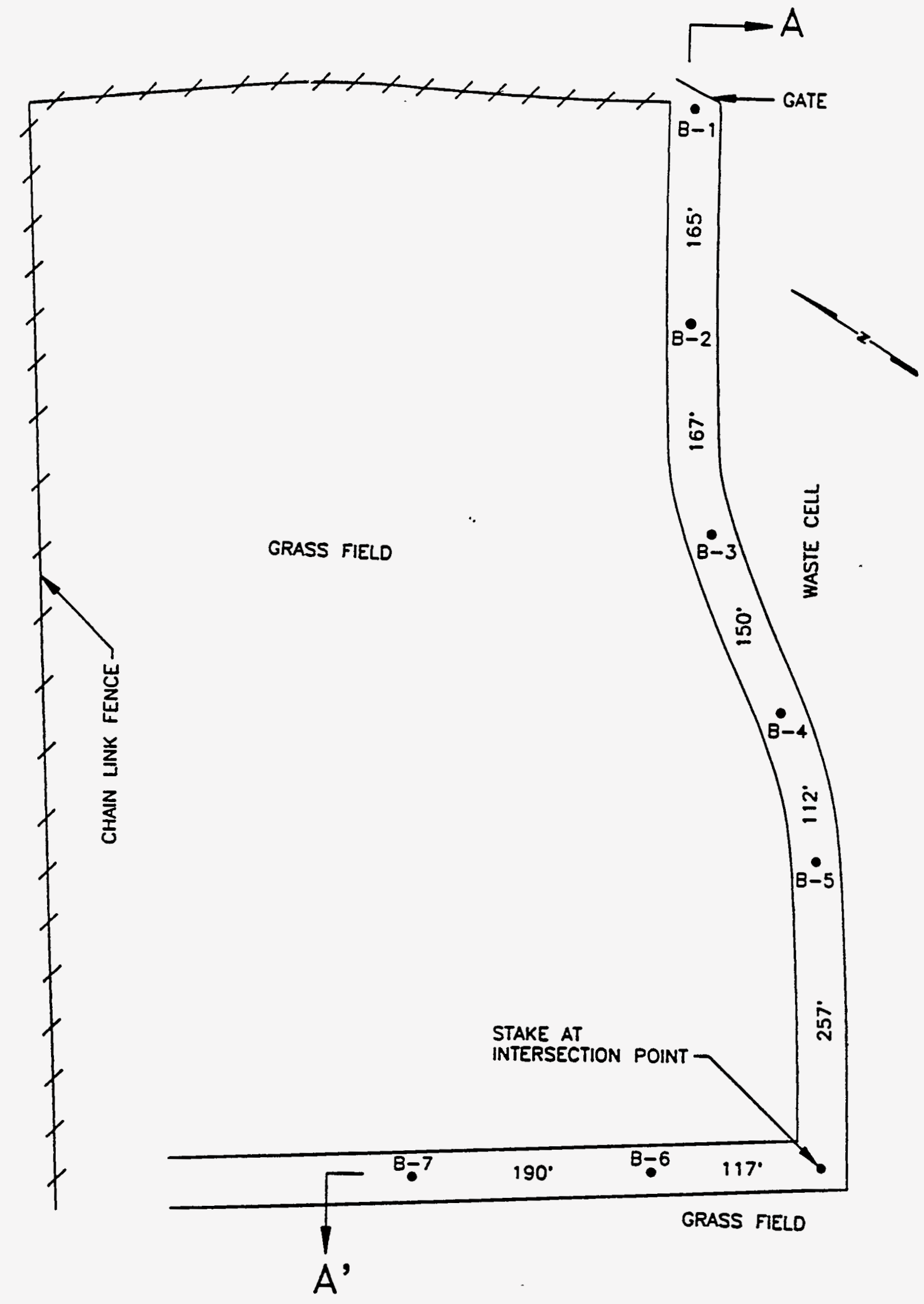




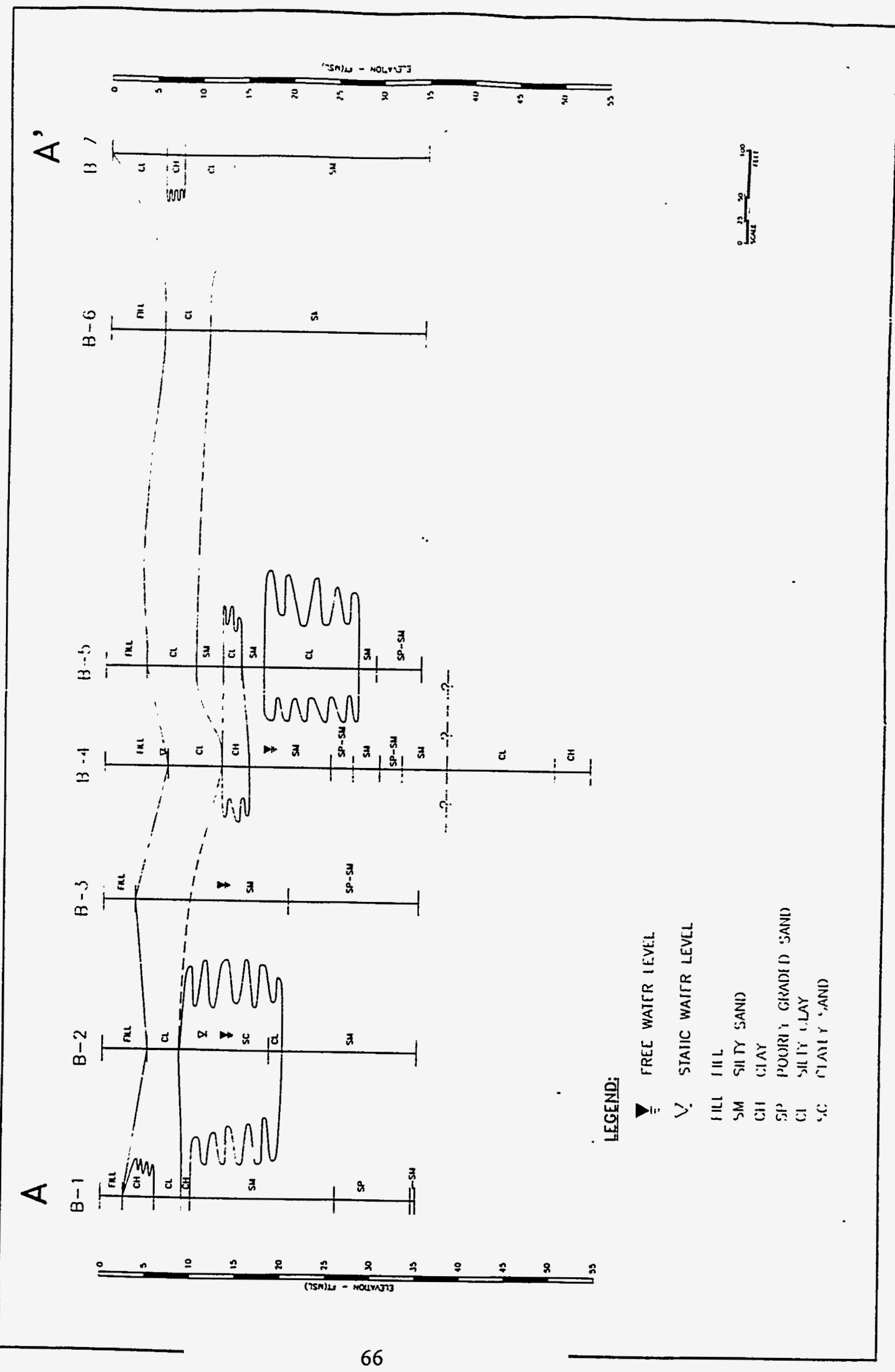




\section{LOG OF BORING}

Project : Soil Saw Demonstration

Palestine. Texas

Client : Brown \& Root Environmental

Houston. Texas

Dry Augered 0 to $12.5 \mathrm{ft}$. Water at Wash Bored 12.5 to $35 \mathrm{ft}$. Water at
Boring No. : $8-1$

File No.: 93-0190

Date : 5-3-93

Elevation : feet: Caving at 10.5 ft. after

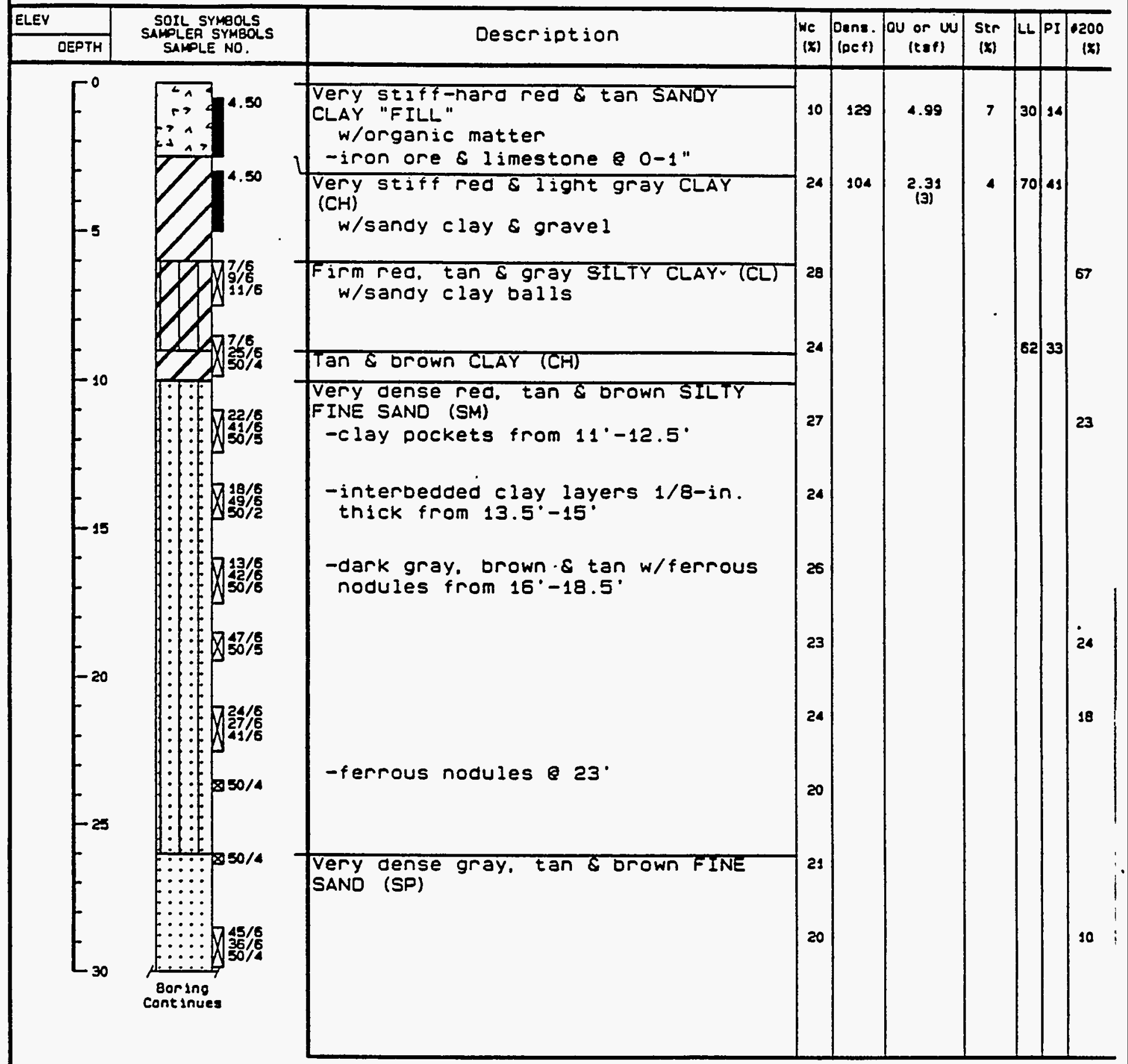

Bottom $935^{\circ}$ 


\section{LOG OF BORING}

Project : Soil Saw Demonstration

Palestine, Texas

Client : Brown $\&$ Root Environmental

Houston. Texas

Dry Augered 0 to $12.5 \mathrm{ft}$. Water at

Wash Bored 12.5 to $35 \mathrm{ft}$. Water at

Boring No. : $\mathrm{B}-1$

File No.: 93-0190

Date : 5-3-93

Elevation : -

feet: Caving at 10.5 $f t$ ft. after

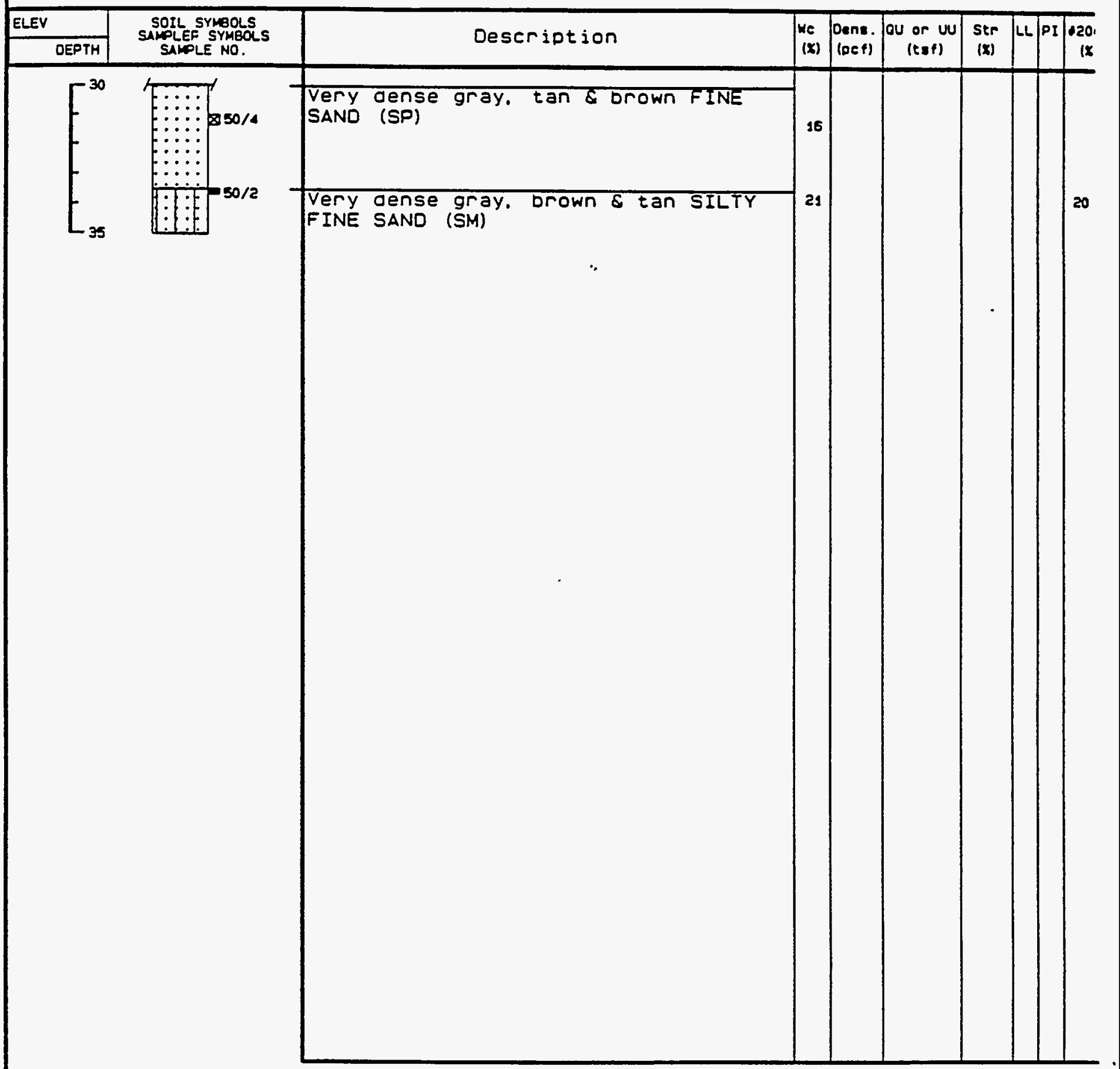

Bottom $35^{\circ}$ 


\section{LOG OF BORING}

Project : Soil Saw Demonstration

Palestine. Texas

Client : Brown \& Root Environmental

Houston, Texas

Dry Augered 0 to 15 Wash Bored 15 to $35 \mathrm{ft}$. Water at 12.8

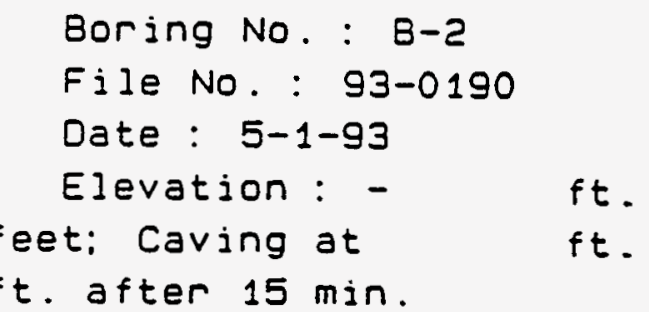




\section{LOG OF BORING}

Project : Soil Saw Demonstration

Palestine. Texas

Client : Brown \& Root Environmental

Houston, Texas

Dry Augered 0 to 15

ft. Water at 14

Wash Bored
15 to 35

ft. Water at 12.8
Boring No. : $8-2$

File No.: 93-0190

Date : 5-1-93

Ejevation : -

feet; Caving at

$f t$.

$f t$.

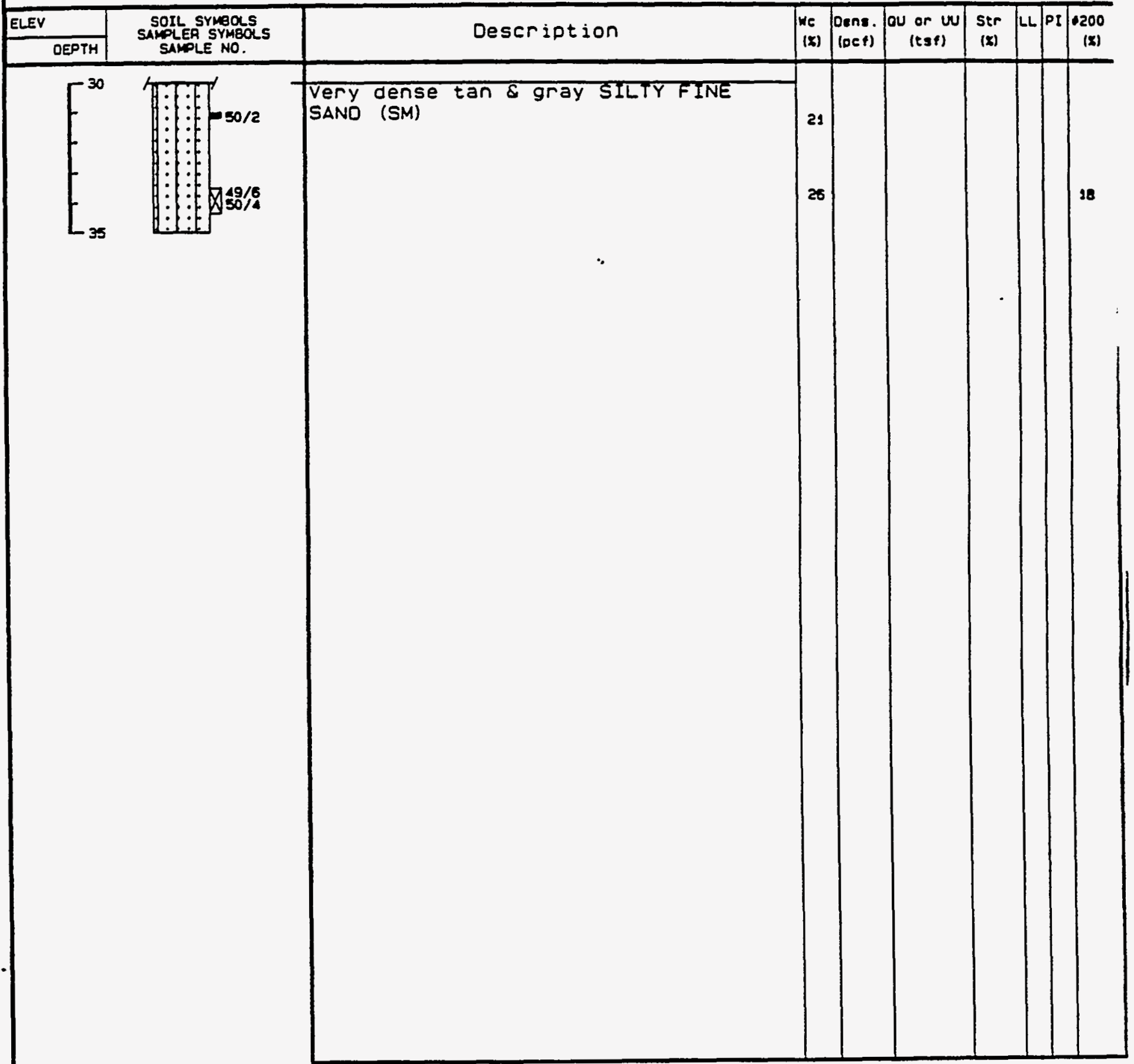




\section{LOG OF BORING}

Project : Soil Saw Demonstration.

Palestine, Texas

Client : Brown $\&$ Root Environmental Houston, Texas
Boring No. : $\mathrm{B}-3$

File No. : 93-0190

Date : 4-30-93

Elevation : -

Dry Augered 0 to $15 \mathrm{ft}$. Water at 13.5 feet: Caving at 12 Wash Bored 15 to $35 \mathrm{ft}$. Water at ft. after

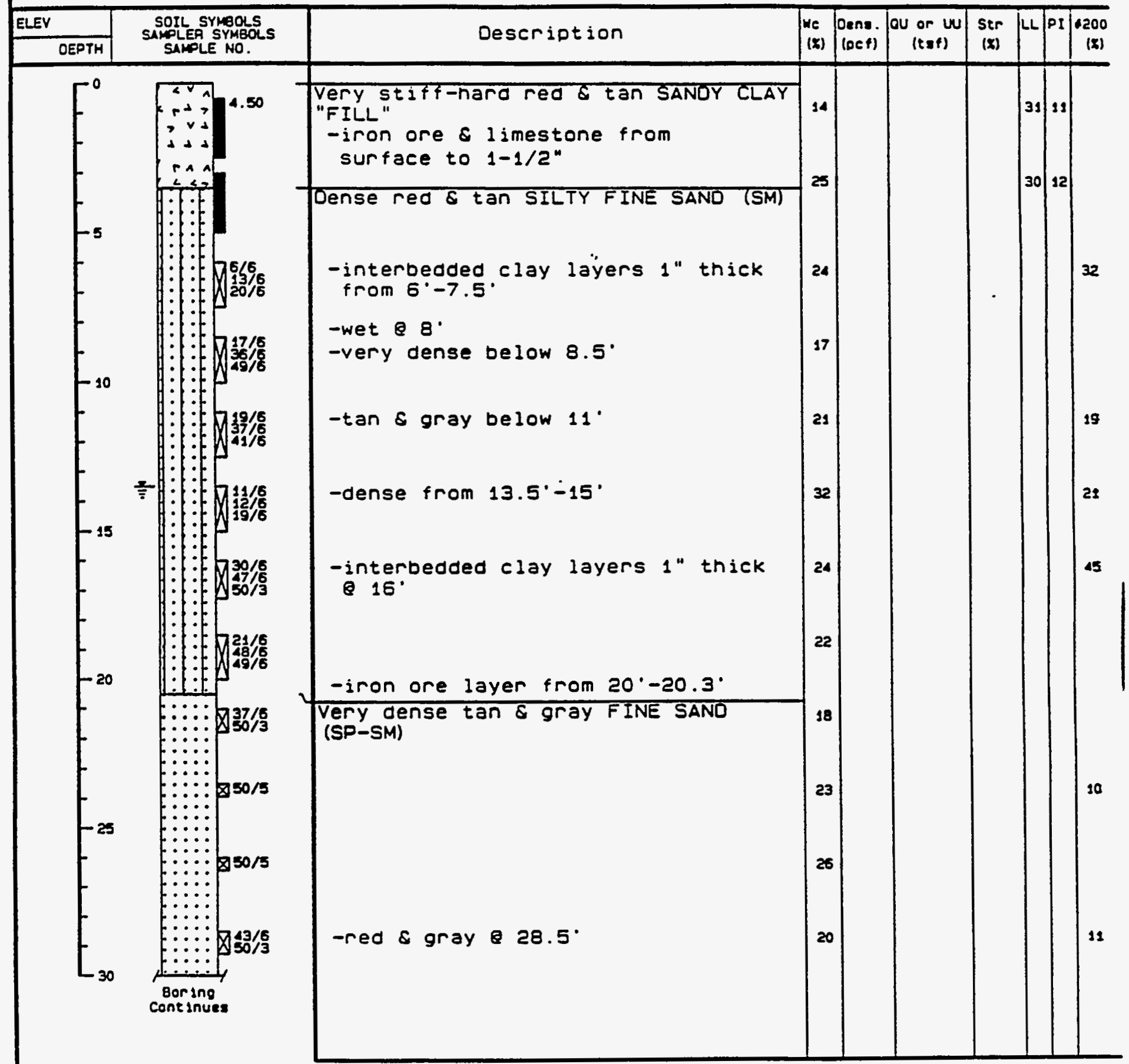




\section{LOG OF BORING}

Project : Soil Saw Demonstration

Palestine, Texas

Client : Brown \& Root Environmental

Houston. Texas

Dry Augered 0 to 15 Wash Bored 15 to 35 ft. Water at 13.5

ft. Water at
Boring No. : $\mathrm{B}-3$

File No.: 93-0190

Date : 4-30-93

Elevation : -

feet; Caving at 12 ft. after

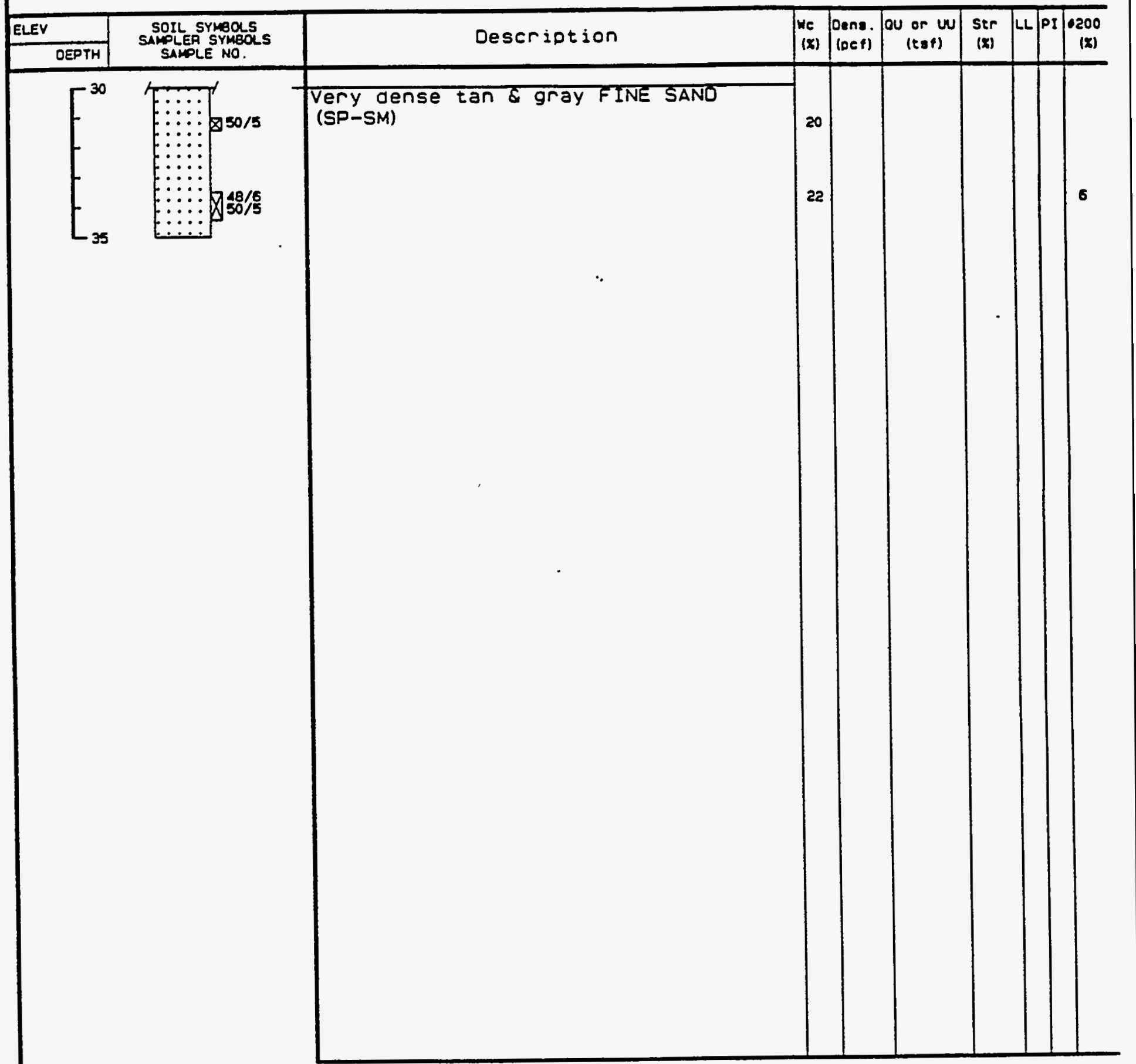




\section{LOG OF BORING}

Project : Soil Saw Demonstration

$$
\text { Palestine. Texas }
$$

Client : Brown $\&$ Root Environmental

Houston, Texas

Dry Augered 0 to 20 Wash Bored 20 to $54 \mathrm{ft}$. Water at 6.9
Boring No. : $8-4$

File No.: 93-0190

Date : 4-29-93

Elevation : -

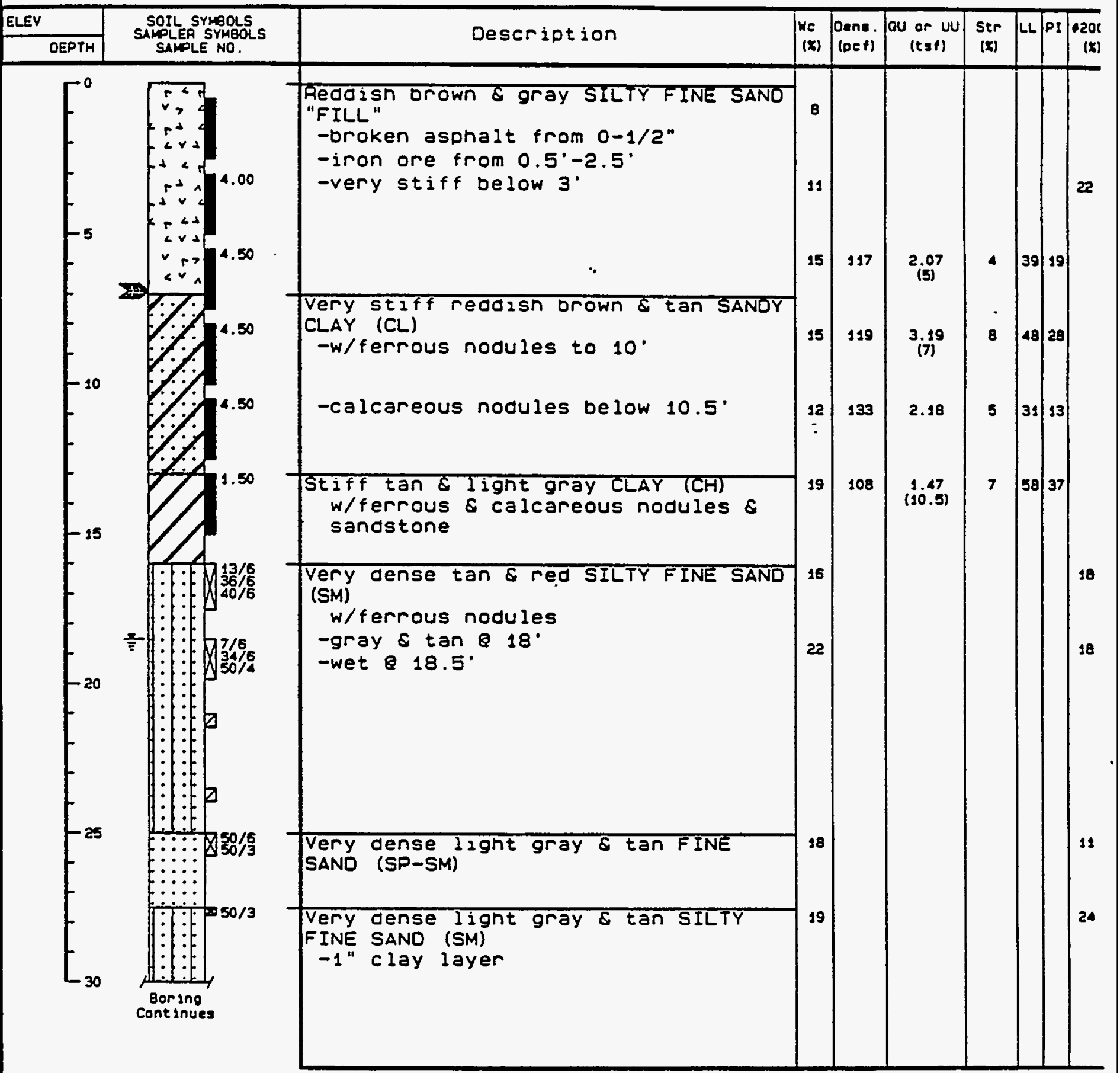

Bottom $@ 54^{\circ}$ 


\section{LOG OF BORING}

Project : Soil Saw Demonstration

Palestine, Texas

Client : Brown \& Root Environmental

Houston, Texas
Boring No. : $B-4$

File No.: 93-0190

Date : 4-29-93

Elevation : -

$\begin{array}{lllll}\text { Dry Augered } 0 & \text { to } 20 \mathrm{ft} \text {. Water at } 18.5 \text { feet: Caving at } 15 \\ \text { Wash Bored } 20 & \text { to } 54 & \mathrm{ft} \text {. Water at } 6.9 \mathrm{ft} \text {. after } 7 \mathrm{hrs} .\end{array}$

$\begin{array}{llllll}\text { Dry Augered } 0 & \text { to } 20 & \mathrm{ft} . & \text { Water at } 18.5 & \text { feet: Caving at } \\ \text { Wash Bored } 20 & \text { to } 54 & \mathrm{ft} \text {. Water at } 6.9 & \mathrm{ft} \text { after } 7 \text { hrs. }\end{array}$

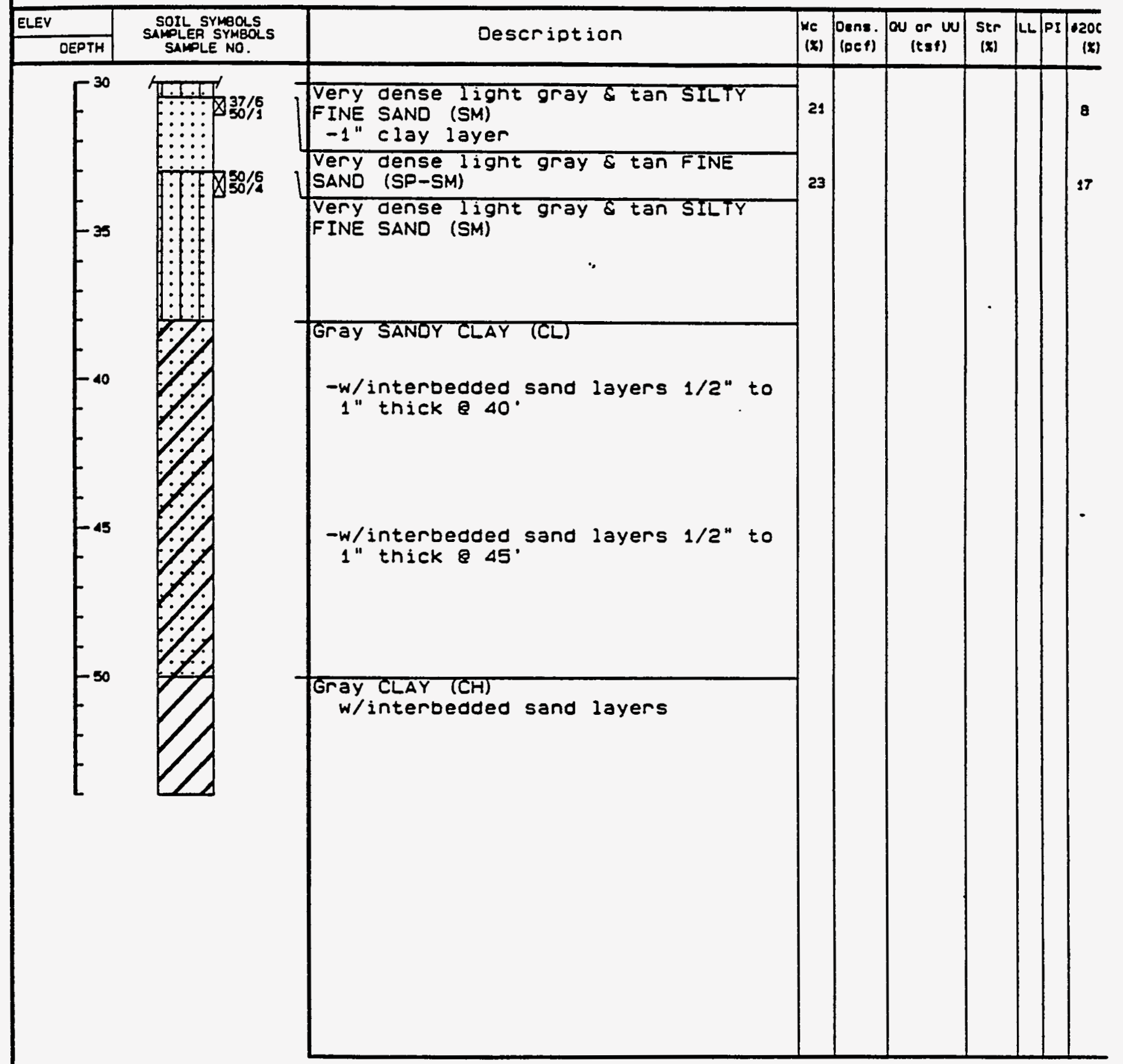




\section{LOG OF, BORING}

Project : Sojl Saw Demonstration

Palestine, Texas

Client : Brown \& Root Environmental

Houston. Texas

Dry Augered 0 to $35 \mathrm{ft}$. Water at

Wash Bored to $\mathrm{ft}$. Water at
Boring No. : $B-5$

File No.: 93-0190

Date : 4-29-93

Elevation : -

feet; Caving at

ft. after

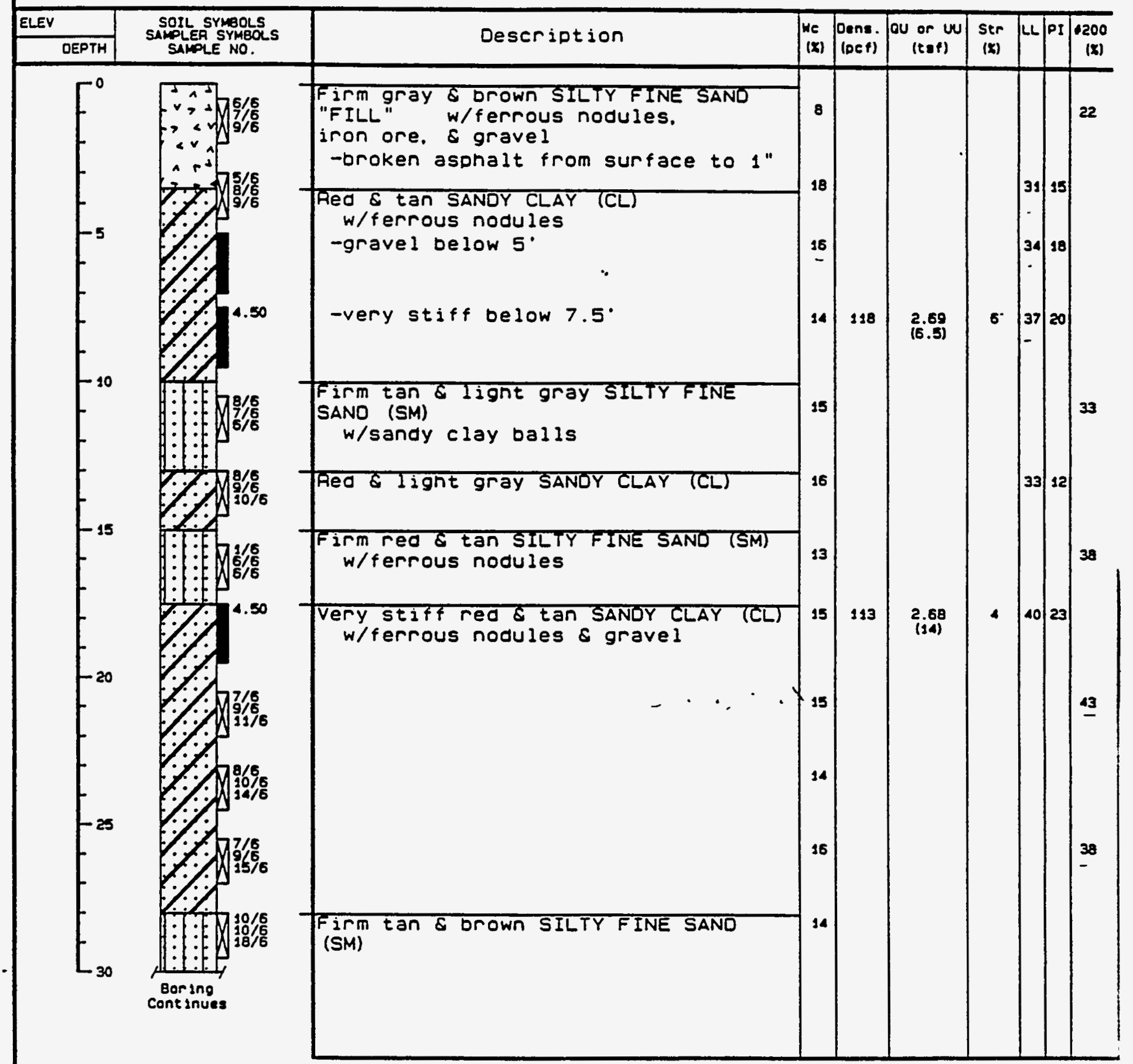

Bottom $35^{\circ}$ 


\section{LOG OF BORING}

Project : Soil Saw Demonstration Palestine. Texas

Client : Brown \& Root Environmental Houston. Texas

Dry Augered 0 to 35 Wash Bored

ft. Water at
Boring No. : $B-5$

File No. : 93-0190

Date : 4-29-93

Elevation : $f t$. feet: Caving at ft.

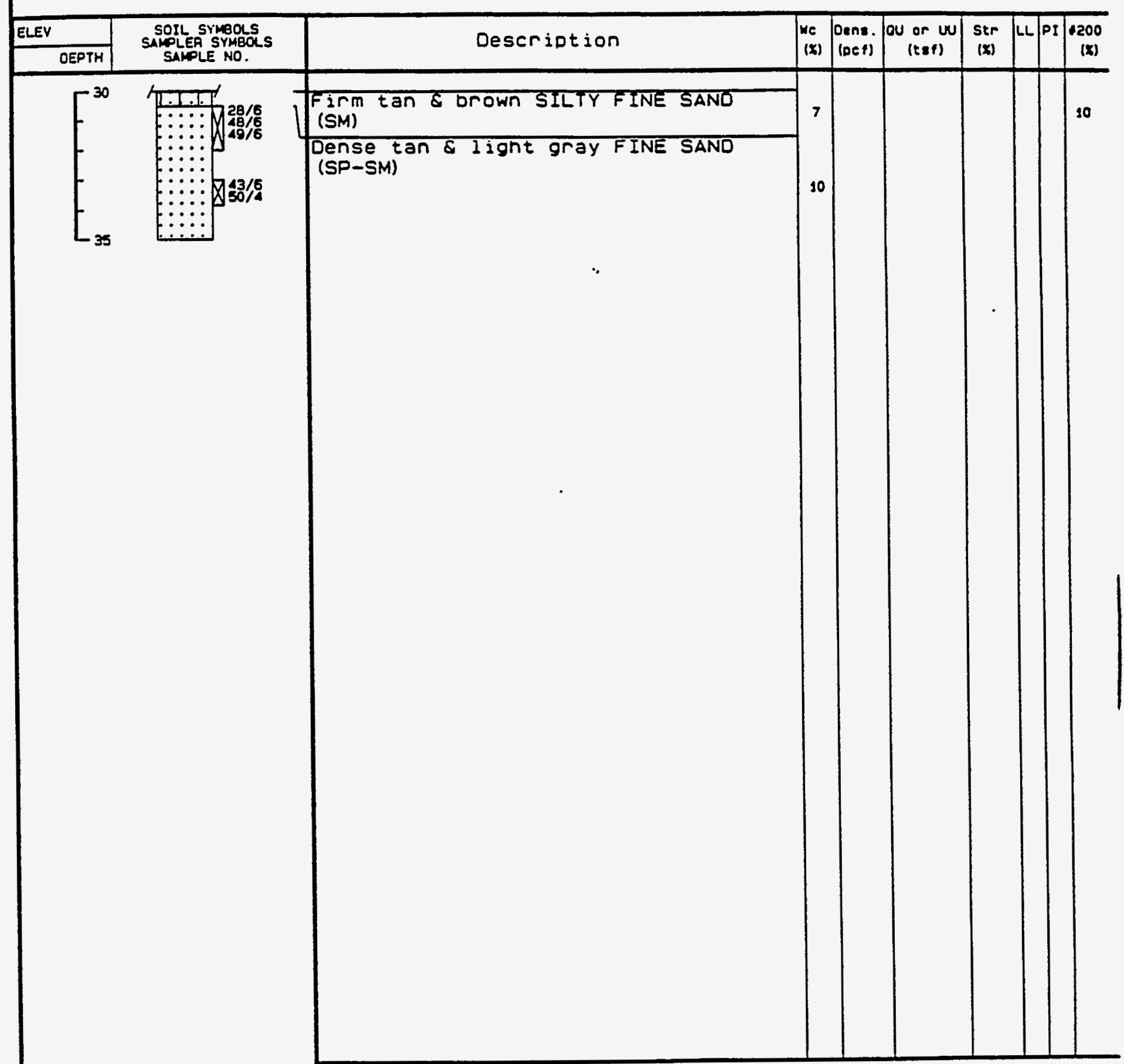




\section{LOG OF BORING}

Project : Soil Saw Demonstration

Palestine. Texas

Client : Brown \& Root Environmental

Boring No. : B-6

Houston, Texas

Dry Augered 0 to $35 \mathrm{ft}$. Water at

Wash Bored

to ft. Water at

File No.: 93-0190

Date : $4-30-93$

Elevation : -

feet: Caving at

ft.

ft. after

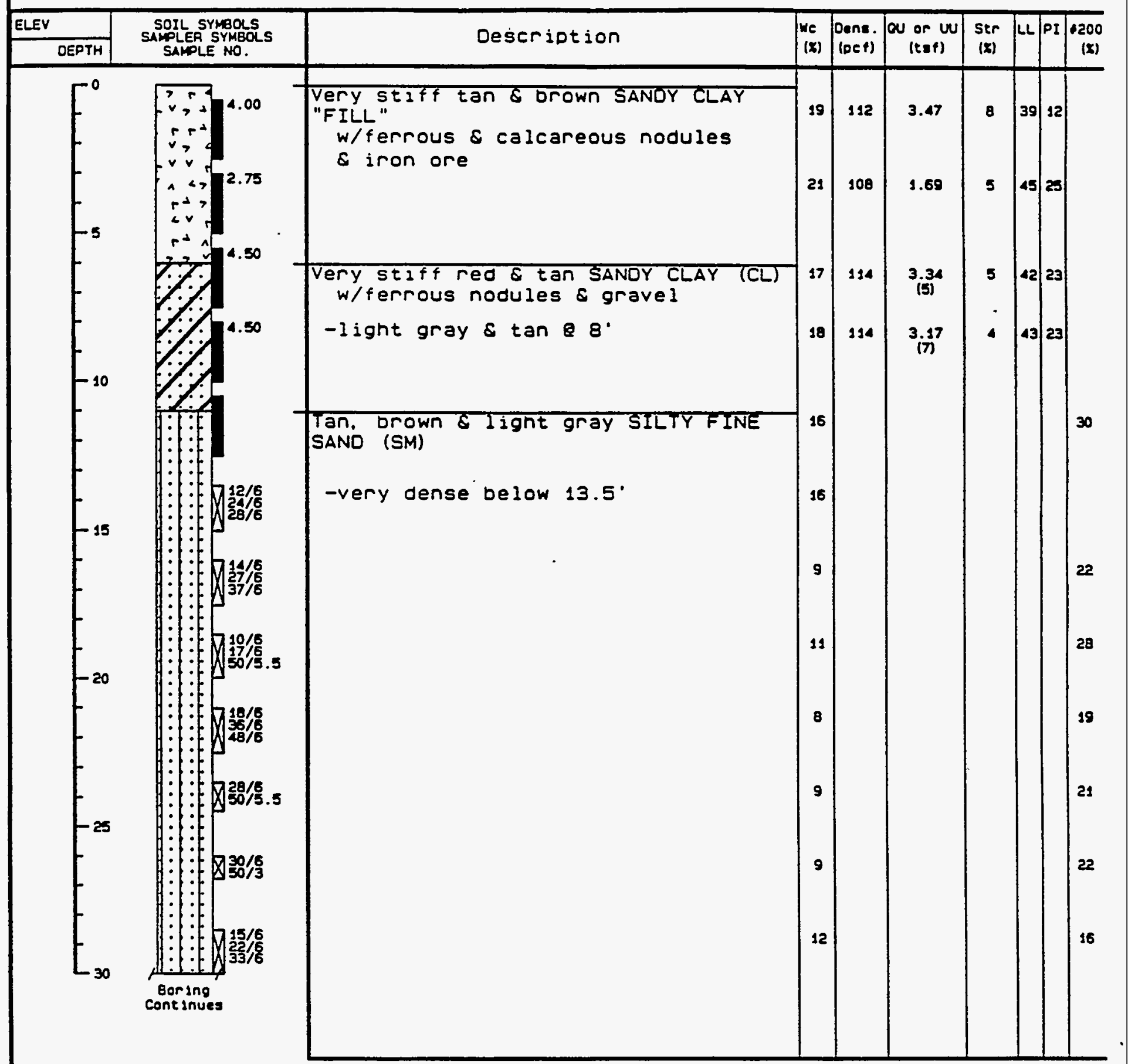

Bottom $83^{\circ}$ 


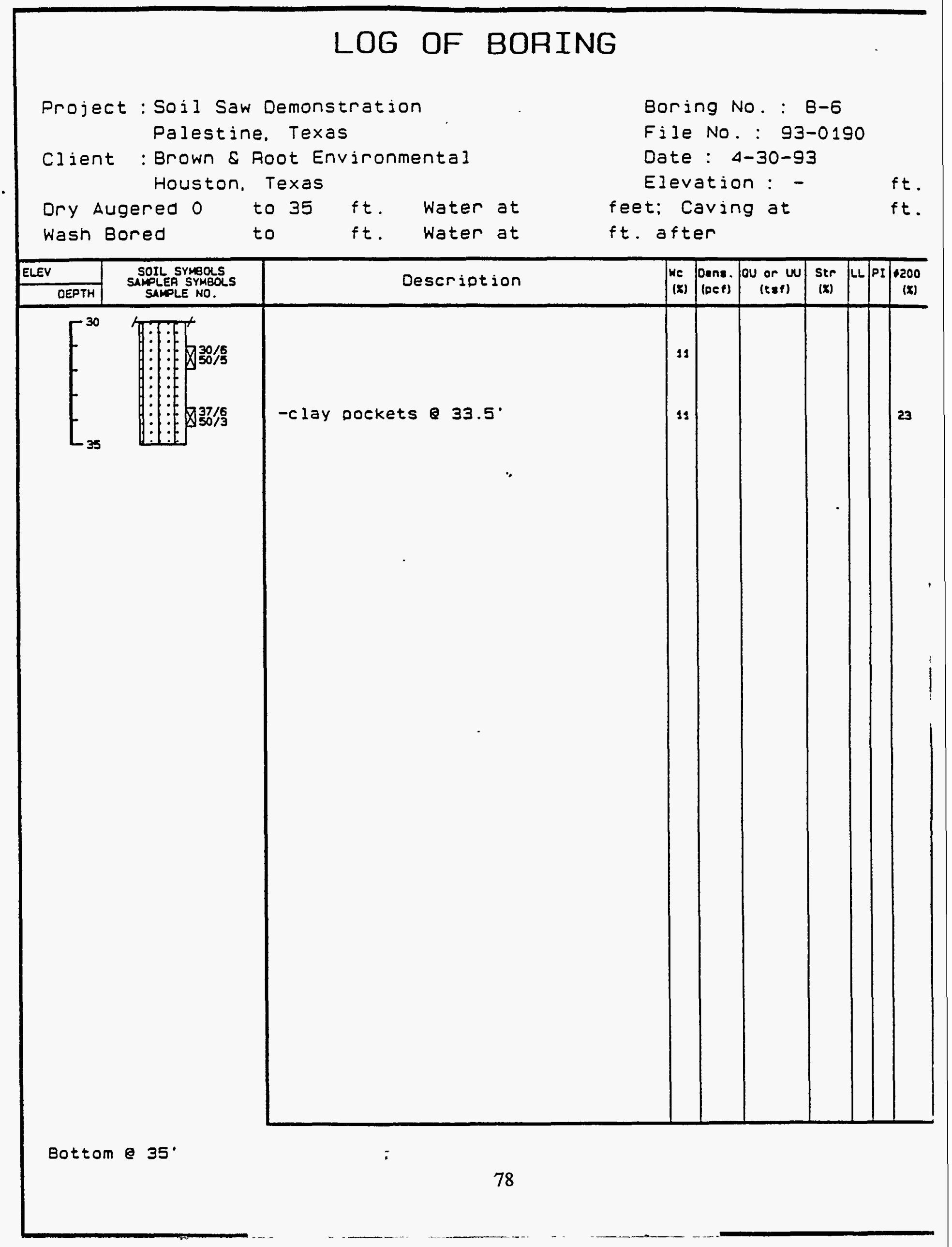




\section{LOG OF BORING}

Project : Sojl Saw Demonstration

Palestine, Texas

Client : Brown \& Root Environmental

Houston. Texas

Dry Augered 0 to $35 \mathrm{ft}$. Water at

Wash Bored to $f t$. Water at
Boring No. : $8-7$

File No.: 93-0190

Date : 5-3-93

Elevation : -

feet: Caving at

ft. after

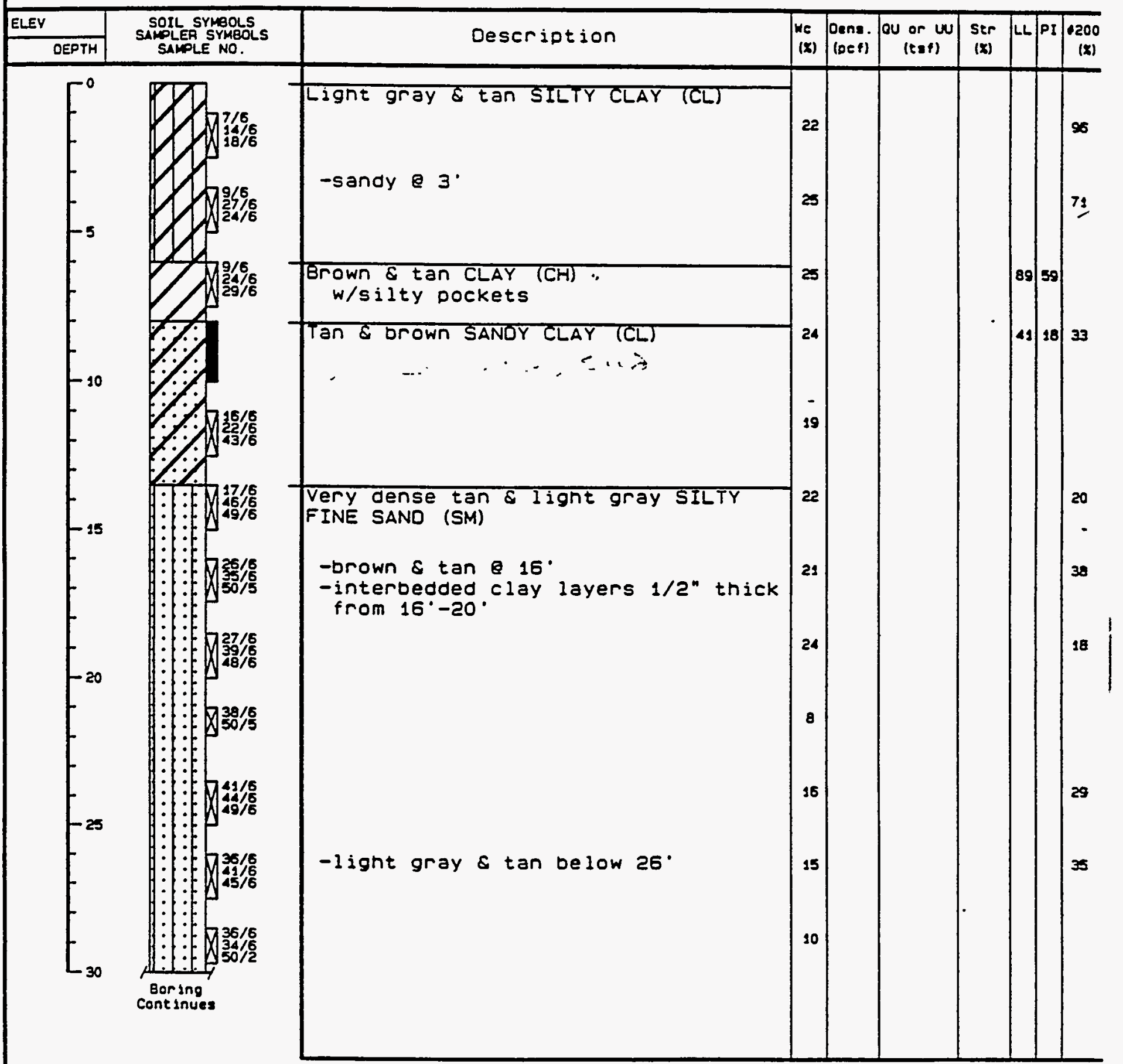

Bottom $85^{\circ}$ 


\section{LOG OF BORING}

Project : Soil Saw Demonstration

$$
\text { Palestine. Texas }
$$

Client : Brown \& Root Environmental

Houston. Texas

Dry Augered 0 to $35 \mathrm{ft}$. Water at

Wash Bored to ft. Water at
Boring No. : $B-7$

File No.: 93-0190

Date : 5-3-93

Elevation : -

feet: Caving at

$f t$. after

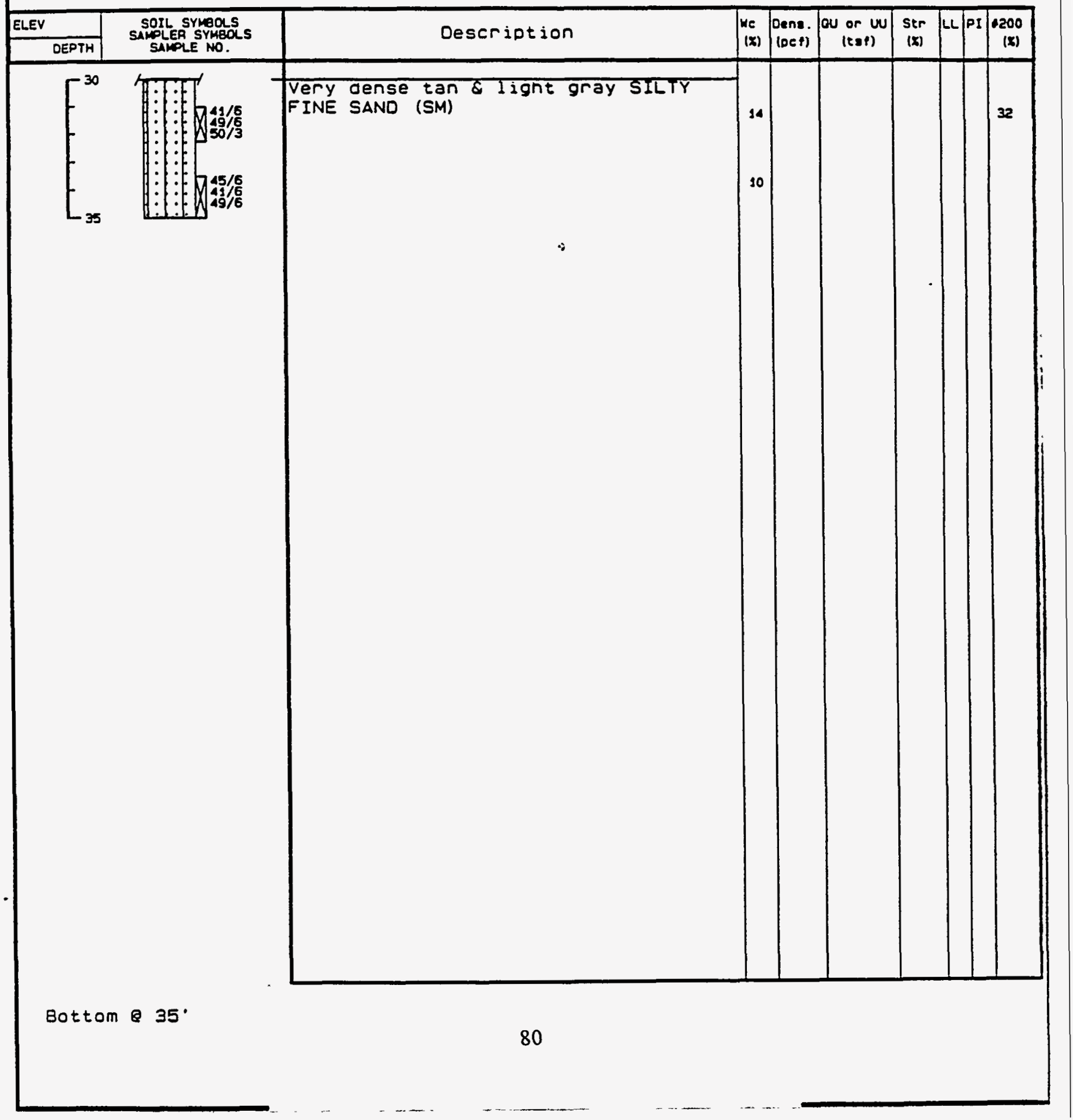




\section{SYMBOLS AND TERMS USED ON BORING LOGS}

Unified Soil Classification System Symbols

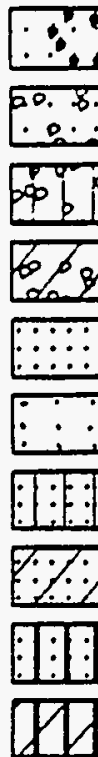

TाTा

ind
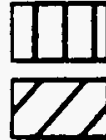

F.8.
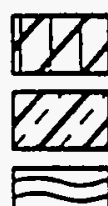

$\square$

174

$\wedge>2$

\begin{tabular}{|c|c|}
\hline GW & Well-graded Gravel \\
\hline GP & Poorly-graded Gravel \\
\hline GM & Silty Gravel \\
\hline GC & Clayey Gravel \\
\hline SW & Well-graded Sand \\
\hline$S P$ & Poorly-graded Sand \\
\hline$S M$ & Silty Sand \\
\hline $\mathrm{SC}$ & Clayey Sand \\
\hline$M L$ & Sandy Silt \\
\hline$M L$ & Claycy Silt \\
\hline OL & Organic Silt \\
\hline MH & Inorganic Silt \\
\hline $\mathrm{CH}$ & Clay \\
\hline CL & Sandy Clay \\
\hline $\mathrm{CL}$ & Silty Clay \\
\hline $\mathrm{OH}$ & Organic Clay \\
\hline PT & Peat \\
\hline FILL & Fill \\
\hline
\end{tabular}

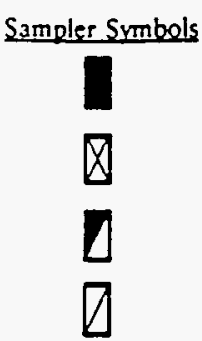

Ficld Test Data

2.50

$8 / 6$

$\frac{2}{5}$

$E$

Laboratory Test Data

$w_{c}(\%)$

Dens (psf)

Q (tsf)

UU (tsf)

Str (\%)

LL

PI

\#200 (\%)

( )

-

$*$

\author{
Meaning \\ Depth of thin-walled tube sample \\ Depth of Standard Penetration Test (SPT) \\ Depth of auger sample \\ Depth of sampling attempt unth no recovery
}

Pocket penetrometer reading in tons per square foot

Blow count per G-in. interval of the Standard Penetration Test

Observed free-water level during drilling

Observed static-water level

Moisture content in percent

Dry unit weight in pounds per square foot

Unconfined compressive strength in tons per square foot

Compressive strength under confining pressure in tons per square foot

Strain at failure in percent

Liquid limit in percent

Plasticity index

Percent passing the no. 200 mesh sieve

Confining pressure in pounds per square inch

Slickensided failure

Did not fail COHESIONLESS \& SEMI-COHESIVE SOILS

The following descriptive terms for telative density apply to cohesionless soils such as gravels, silty fine sands, and fine sands as well as semicohesive soils such as sandy silts, clayey silts, and clayey sands.

$\begin{array}{cc} & \begin{array}{r}\text { Typical } \\ \text { SPT } \mathrm{N}^{*} \\ \text { Value }\end{array} \\ \text { Relative } & \text { Range" } \\ \text { Densicy } & \\ & 0-4 \\ \text { Very Loose } & 5-10 \\ \text { Loose } & 11-30 \\ \text { Medium Dense } & 31-50 \\ \text { Dense } & \text { Over } 50 \\ \text { Very Derse } & \end{array}$

- $\quad \mathrm{N}$ ' is the aumber of blows from a $140-\mathrm{lb}$ weight having a free fall of 30 in. required to penetrate the final 12 in. of an 18 -in. sample interval. The density designations cortespond to a SPT " $N$ " value range based on an effective overburden pressure of 1 tsf. Densiv descriptors may be modified because of variations in the effective overburden pressure.
The following descriptive terms for consistency apply to cohesive soils such as clays, sandy clays, and silty clays.

$$
\begin{aligned}
& \text { Typical } \\
& \text { Unconiuned } \\
& \text { Compressive } \\
& \text { Strengih } \\
& \text { U1sD }
\end{aligned}
$$

$q<0.25$

$0.25 \leq q<0.50$

$0.50 \leq q<1.00$

$1.00 \leq q<2.00$

$2.00 \leq q_{1}<4.00$

q $\geq 4.00$

$\begin{array}{cc} & \begin{array}{c}\text { Typical } \\ \text { SPT } N^{-} \\ \text {Value } \\ \text { Range }\end{array} \\ \text { Consistency }\end{array}$

$\begin{array}{cc}\text { Very Soft } & \leq 2 \\ \text { Soft } & 3.4 \\ \text { Firm } & 5.8 \\ \text { Stiff } & 9.15 \\ \text { Very Stiff } & 16-30 \\ \text { Very Stiff-Hard } & \geq 31^{\circ}\end{array}$

- An " $\mathrm{N}$ " value of 31 or greater corresponds to a hard consistency. The corrclation of consistency with a typical SPT " $\mathrm{N}$ " value range is approximate. 
PERMEABILITY, STRENGTH, SOIL AND FORMULATION DATA 


\begin{tabular}{|c|c|c|c|c|c|c|c|c|c|c|c|c|}
\hline PERMEAB & ITY TABLE & & & & & & & & & & & \\
\hline \multicolumn{13}{|c|}{ Barriers formed by Soil5aw in June 1993 PRDA Demonstration } \\
\hline \multicolumn{13}{|c|}{ PRDA-ALCOA } \\
\hline \multicolumn{13}{|c|}{ PALESTINETX } \\
\hline & & & & & & & & & & & Unconfined & \\
\hline & & & & & & & & & & Perm & Compressive & \\
\hline & & Barrier & Deplh & Sample & Placement & Sampling & Lab Test & Age & Slumy & Rate & Strength & \\
\hline Station & Sample & Type & (ft.) & Type & Date & Dale & Date & Daya & \# & $\mathrm{C}$ nr/Sec & (psi) & Remarks \\
\hline \multirow[t]{2}{*}{$0+20$} & B1.1 & $S / B$ & $10^{\prime}$ & Bulk & $06107 / 93$ & $06 / 07 / 93$ & $07 / 02 / 93$ & 25 & 1 & $9.1 \times 10-9$ & 0.94 & Strength. test on $\mathbf{B 1 - 2}$ \\
\hline & B1-4 & S/B & $10^{\circ}$ & Bulk & $06 / 07 / 93$ & $06 / 07 / 93$ & $07 / 10293$ & 25 & 1 & $1.6 \times 10-8$ & 0.45 & Strength. test on $\mathrm{B1}-6$ \\
\hline \multirow{2}{*}{$0+20$} & B2.3 & $\mathrm{S} / \mathrm{B}$ & $19^{4}$ & Bulk & $06107 / 93$ & $0507 / 93$ & $07 / 08 / 93$ & 31 & 2 & $1.1 \times 10-8$ & 1.38 & Strength. test on $\mathbf{B 2 - 1}$ \\
\hline & B2-4 & $S / B$ & $19^{\circ}$ & Bulk & $06 / 07 / 93$ & $05 / 07 / 93$ & $07108 / 93$ & 31 & 2 & $5.6 \times 10-9$ & 1.03 & strength. test on $\mathrm{B2}-6$ \\
\hline & & & & & & & & & & & & \\
\hline $0+95$ & B7-2 & S/C/B & 3' & Bulk & $06 / 08 / 93$ & $06 / 08 / 93$ & $06 / 22 / 93$ & 14 & 2 & $6.4 \times 10-7$ & 53.47 & \\
\hline \multirow[b]{2}{*}{$0+95$} & & & & & & & & & & & & \\
\hline & BA-1 & $S / C / B$ & 12.5' & Bulk & $06 / 08 / 93$ & $05 / 08 / 93$ & $06 / 17 / 93$ & 9 & 2 & $1.1 \times 10-6$ & 12.50 & \\
\hline $1+45$ & B5-1 & S/C/B & $13^{\circ}$ & Bulk & $0 6 \longdiv { 0 8 / 9 3 }$ & $06708 \sqrt{93}$ & $06 / 17 / 93$ & 9 & 2 & $8.6 \times 10-7$ & 41.67 & Strength test on B5-4 \\
\hline $1+45$ & 884 & $\overline{S / C B B}$ & 51 & Bulk & $0608 / 93$ & $0608 / 93$ & $06 / 25 / 93$ & 17 & 2 & $42 \times 10.5$ & 5694 & \\
\hline & & & & & & & & & & & & \\
\hline $1+80$ & H6 & S/C/B & $10^{\circ}$ & Core & $06 / 28 / 93$ & $07108 / 93$ & $07 / 23 / 93$ & 45 & 3 & $7.6 \times 10-6$ & 52.78 & \\
\hline & $\mathrm{H} \cdot \mathbf{7}$ & & $10^{\circ}$ & Core & $06 / 08 / 93$ & $07 / 08 / 93$ & $07 / 23 / 93$ & 45 & 3 & $2.5 \times 10-5$ & 26.39 & \\
\hline & $H \cdot 10$ & & 8 & Shelby & $06 / 08 / 93$ & $07 / 08 / 93$ & $07 / 30 / 93$ & 52 & 3 & $6.6 \times 10-7$ & 45.83 & No vert. control for shelby tube \\
\hline & $\mathrm{H}-11$ & & 8 & Shelby & $0 6 \longdiv { 0 8 / 9 3 }$ & $07 / 08 / 93$ & $07 / 30 / 93$ & 52 & 3 & $1.1 \times 10-6$ & 76.39 & From same tube as $\mathrm{H} 10$ \\
\hline & H.8 & & $20^{\prime}$ & Core & $0 6 \longdiv { 0 8 / 9 3 }$ & $07 / 08 / 93$ & $07 / 23 / 93$ & 45 & 3 & $9.1 \times 10-6$ & 54.86 & \\
\hline & $\mathrm{H}-\mathrm{9}$ & & $20^{\prime}$ & core & $06 / 08 / 93$ & $07 / 08 / 93$ & $07 / 23 / 93$ & 45 & 3 & $2.9 \times 10-6$ & 56.25 & \\
\hline & & & & & & & & & & & & \\
\hline $1+95$ & $86-3$ & S/C/B & $\mathbf{4}^{\circ}$ & Bulk & $06 / 08 / 93$ & $0 6 \longdiv { 0 8 / 9 3 }$ & $06 / 17 / 93$ & 9 & 2 & $1.6 \times 10-6$ & 29.17 & \\
\hline & $86-5$ & & $4^{\circ}$ & Bulk & $06 / 08 / 93$ & $0 6 \longdiv { 0 8 / 9 3 }$ & $06 / 12 / 93$ & 4 & 2 & $4.1 \times 10-6$ & 27.78 & \\
\hline & & & & & & & & & & & & \\
\hline $1+95$ & 89-2 & $S / C / B$ & $10^{\prime}$ & Bulk & $06 / 08 / 93$ & $06 / 08 / 93$ & $06 / 17 / 93$ & 9 & 2 & $1.2 \times 10-7$ & 54.86 & \\
\hline & $89-4$ & & $10^{\prime}$ & Bulk & $06 / 08 / 93$ & $06109 / 93$ & $06 / 12 / 93$ & 4 & 3 & $6.8 \times 10-6$ & 54.17 & \\
\hline & & & & & & & & & & & & \\
\hline $2+55$ & B10-1 & S/C/B & $10^{\prime}$ & Bulk & $06 / 09 / 93$ & $06 / 09 / 93$ & $06 / 17 / 93$ & 8 & 3 & $2.9 \times 10.7$ & 48.61 & \\
\hline & $B 10-2$ & & $10^{\prime}$ & Bulk & $06 / 09 / 93$ & $06 / 09 / 93$ & $06 / 25 / 93$ & 16 & 3 & $1.2 \times 10-7$ & 49.31 & \\
\hline & $B 10-3$ & & $10^{\prime}$ & Bulk & $06 / 09 / 93$ & $06 / 09 / 93$ & $07 / 19293$ & 33 & 3 & $5.8 \times 10-8$ & 31.25 & \\
\hline & & & & & & & & & & & & \\
\hline $3+\infty$ & H-2 & S/C/B & $8^{\circ}$ & core & $06,09 / 93$ & $07 / 08 / 93$ & $07 / 24 / 93$ & 45 & 3 & $4.9 \times 10-6$ & 37.50 & \\
\hline & $\mathrm{H} \cdot 3$ & & $8^{\circ}$ & Core & $06 / 09 / 93$ & $07 / 08 / 93$ & $07 / 23 / 93$ & 44 & 3 & $1.6 \times 10-6$ & 25.00 & \\
\hline & $\mathrm{H}-4$ & & $12^{\prime}$ & Core & $06 / 09 / 93$ & $07 / 08 / 93$ & $07 / 24 / 93$ & 45 & 3 & $3.9 \times 10-6$ & 21.53 & \\
\hline & $\mathrm{H} \cdot \mathrm{5}$ & & $12^{\prime}$ & Core & $06 / 09 / 93$ & $07108 / 93$ & $07 / 24 / 93$ & 45 & 3 & $7.2 \times 10-6$ & 40.28 & \\
\hline & & & & & & & & & & & & \\
\hline $3+15$ & B11-4 & $S / C / B$ & $\mathbf{4}^{*}$ & Bulk & $06 / 09 / 93$ & $06 / 09 / 93$ & $06 / 2293$ & 13 & 3 & $5.2 \times 10-7$ & 22.92 & \\
\hline & 811.5 & & $4^{\circ}$ & Bulk & $06 / 09 / 93$ & $06 / 09 / 93$ & $06 \sqrt{30 / 93}$ & 21 & 3 & $4.4 \times 10-7$ & 28.47 & \\
\hline & B11-6 & & $4^{*}$ & Bulk & $06 / 09 / 93$ & $06 / 09 / 93$ & $07 / 12 / 93$ & 33 & 3 & $1.9 \times 10-7$ & 53.47 & \\
\hline & & & & & & & & & & & & \\
\hline Typical Sp & iffeation & & & & & & & & & $1 \times 10-6$ & 0.500 & \\
\hline & & & & & & & & & & & & \\
\hline SOIL TYPE & & & & & & & & & & & & \\
\hline & & & & & & & & & & Sumple m & sthods: & \\
\hline Typlacal De & & Soll Descript & on \& Classificat & & & SPT Blow C & gunts & & & & & \\
\hline $0.6^{\prime}$ & & Firm to very & stiff SANDY CLA & FLL & & $9-15$ & & & & Bulk sam & oles are taken & om freshly \\
\hline $4-10^{\prime}$ & & Very stiff SA & JOY and SILTYC & AY ICD & & $16-30$ & & & & formede & amler and cur & din plastic molds. \\
\hline $10-35^{\prime}+$ & & Predominan & Iy firm to very & dense FINE SA & VD (SM) & $>50$ & & & & & & \\
\hline & & & & & & & & & & Core sam & ples are taken & Y a mechankal \\
\hline & & & & & & & & & & drill unit & from the aure & bartier. \\
\hline Grout Form & Iation at the $A$ & COA SITE & & & & & & & & & & \\
\hline & & & & & & & & & & Shelby sa & mples were ta & en from the cured barfler \\
\hline & & & & Additlive & & & & & & by press & ig the shedby & tbe into the bartier. \\
\hline Slumy & Bentonite & Water & Cement & Llgnosite & Density & Barrier & & & & & & \\
\hline 1 & \% total wt. & \% total wt. & $\%$ total wt. & \% total wt. & lb/Gal & Type & & & & & & \\
\hline 1 & $5.91 \%$ & $94.09 \%$ & & & 8.60 & $5 / B$ & & & & & & \\
\hline 2 & $4.21 \%$ & $66.97 \%$ & $28.68 \%$ & $0.14 \%$ & 10.80 & S/C/B & & & & & & \\
\hline 3 & $4.65 \%$ & $74.05 \%$ & $21.14 \%$ & $0.16 \%$ & 10.10 & $S / C / B$ & & & & & & \\
\hline & & & & & & & & & & & & \\
\hline
\end{tabular}




\begin{tabular}{|c|c|c|c|c|c|c|c|c|c|c|c|c|}
\hline & & & & & & & & & & & & \\
\hline \multicolumn{13}{|c|}{ PERMEABILITY TABLE } \\
\hline \multicolumn{13}{|c|}{ Barriers formed by Soilsaw In February 1994 PRDA Demonstration } \\
\hline \multirow{2}{*}{\multicolumn{13}{|c|}{\begin{tabular}{|l|l|l|} 
PRDA-SAVANNAH RIVER SITE & & \\
\end{tabular}}} \\
\hline & & & & & & & & & & & & \\
\hline Barrier & & & & & & & & & & & Unconfined & \\
\hline \multirow[t]{2}{*}{$\mathbf{A}$} & & & & & & & & & & Perm & Compressive & \\
\hline & & Barrier & Depth & Sample & Placement & Sampling & Lab Test & Age & Slury & Rale & Strength & \\
\hline \multirow[t]{2}{*}{ Station } & Sample : & Type & (ft.) & Type & Dale & Date & Date & Days & 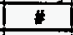 & $\mathrm{Cor} / \mathrm{Sec}$ & (psi) & Remarks \\
\hline & & & & & & & & & & & & \\
\hline \multirow[t]{2}{*}{$0+50$} & A50-10A & S/B & $10^{\prime}$ & Bulk & $02 / 09 / 94$ & $02 / 09 / 94$ & $04 / 07 / 94$ & 57 & 1 & $1.4 \times 10-8$ & 2.4 & \\
\hline & $A 50-10 B$ & $S / B$ & $10^{4}$ & Bulk & $02 / 09 / 94$ & $02 / 09 / 94$ & $04 / 11 / 94$ & 61 & 1 & $1.1 \times 10-8$ & 2.6 & \\
\hline & & & & & & & & & & & & \\
\hline \multirow[t]{2}{*}{$0+60$} & $A+60-1$ & S/B & $10^{\prime}$ & TRIM & $02 / 09 / 94$ & $04 / 11 / 94$ & $05 / 06 / 94$ & 86 & 1 & $3.2 \times 10-8$ & 1.2 & \\
\hline & $A \cdot 60-2$ & S/B & $10^{\prime}$ & TRIM & $02 / 09 / 94$ & $04 / 11 / 94$ & $05 / 13 / 94$ & 93 & 1 & $2.0 \times 10-8$ & 1.6 & \\
\hline & & & & & & & & & & & & \\
\hline \multirow[t]{2}{*}{$0+140$} & A140-20A & S/C/B & $20^{\circ}$ & Bulk & $02 / 10 / 94$ & $02 / 10 / 94$ & $03 / 29 / 94$ & 47 & $3 A$ & $1.9 \times 10-7$ & 45.2 & \\
\hline & $\mathrm{A} 140-20 \mathrm{~B}$ & $S / C / B$ & $20^{\prime}$ & Bulk & $02 / 10 / 94$ & $02 / 10 / 94$ & $03 / 29 / 94$ & 47 & $3 A$ & $2.6 \times 10-7$ & 40 & \\
\hline & & & & & & & & & & & & \\
\hline \multirow[t]{2}{*}{$0+140$} & A140 & $\mathrm{S} / \mathrm{C} / \mathrm{B}$ & $8^{\prime}$ & Trim & $02 / 10 / 94$ & $04 / 11 / 94$ & $05 / 13 / 94$ & 92 & $3 A$ & $9.3 \times 10-7$ & 7.1 & Transition from \\
\hline & & & & & & & & & & & & S/B TO C/B Wall \\
\hline \multirow[t]{2}{*}{$0+150$} & $A-150-1$ & $S / C / B$ & 8 & Trim & $02 / 10 / 94$ & $04 / 11 / 94$ & $05 / 16 / 94$ & 95 & $3 A$ & $7.5 \times 10.7$ & 30.6 & \\
\hline & $A \cdot 150-2$ & $S / C / B$ & $14^{\prime}$ & Tr!m & $02 / 10 / 94$ & $04 / 11 / 94$ & $05 / 16 / 94$ & 95 & $3 A$ & $7.5 \times 10-7$ & 31.7 & \\
\hline & & & & & & & & & & & & \\
\hline $0+170$ & $\frac{A 170-10 \mathrm{~A}}{\mathrm{~A} 170-10 \mathrm{~B}}$ & $\frac{S / C / B}{S / C / B}$ & $\frac{10^{\prime}}{10^{\prime}}$ & $\frac{\text { Bulk }}{\text { Bulk }}$ & $\frac{02 / 10 / 94}{02 / 10 / 94}$ & $\frac{02 / 10 / 94}{02 / 10 / 94}$ & \begin{tabular}{l|}
$03 / 29 / 94$ \\
$03 / 29 / 94$
\end{tabular} & $\frac{47}{47}$ & $\frac{3 A}{3 A}$ & $\frac{3.1 \times 10-7}{29 \times 10.7}$ & 49.8 & \\
\hline & & & & & & & & & & & & \\
\hline Barrier & & & & & & & & & & & Unconfined & \\
\hline $\mathbf{B}$ & & & & & & & & & & Perm & Compressive & \\
\hline & & Barrier & Depth & Sample & Placement & Sampling & Lab Test & Age & Slurry & Rale & Strength & \\
\hline Station & Sample & Type & (ft.) & Type & Date & Date & Date & Daye & 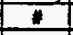 & $\mathrm{Cm} / \mathrm{Sec}$ & (psi) & Remarks \\
\hline $0+100$ & B100-10A & $S / C / B$ & $10^{\circ}$ & Bulk & $02 / 14 / 94$ & $02 / 14 / 94$ & $03 / 29 / 94$ & 431 & $3 A$ & $2.8 \times 10-7$ & 91 & \\
\hline & B100-108 & $S / C / B$ & $10^{\circ}$ & Bulk & $02 / 14 / 94$ & $02 / 14 / 94$ & $03 / 29 / 94$ & 43 & $3 \hat{A}$ & $4.0 \times 10-7$ & 12.8 & \\
\hline & & & & & & & & & & & & \\
\hline $0+190$ & B.190-1 & S/BNW & 8 & Grab & $02 / 14 / 94$ & $04 / 11 / 94$ & $05 / 06 / 94$ & 811 & 4 & $7.3 \times 10-8$ & 2.7 & Montan Wax Barrler \\
\hline & B.190-2 & S/BNW & $10^{\circ}$ & Grab & $02 / 14 / 94$ & $04 / 11 / 94$ & $05 / 06 / 94$ & 81 & 4 & $8.1 \times 10-8$ & 2 & \\
\hline $0+200$ & & SDNM & $10^{\circ}$ & Bulk & & & 0010710 & & & & & \\
\hline $0+200$ & $\frac{8200-10 \mathrm{~A}}{\mathrm{~B} 200-10 \mathrm{~B}}$ & $\frac{S / B N W}{S / B N W}$ & $\frac{10^{\circ}}{10^{\circ}}$ & $\frac{\text { Bulk }}{\text { Bulk }}$ & $\frac{02 / 14 / 94}{02 / 14 / 94}$ & \begin{tabular}{c|}
$02 / 15 / 94$ \\
$02 / 15 / 94$
\end{tabular} & $\frac{04 / 07 / 94}{04 / 11 / 94}$ & $\frac{52}{56}$ & $\frac{4}{4}$ & $\frac{1.1 \times 10-7}{1.0 \times 10.7}$ & $\frac{2.9}{2.8}$ & \\
\hline & & & & & & & & & & & & \\
\hline $0+250$ & 8250-10A & S/BN & $10^{\circ}$ & Bulk & $02 / 14 / 94$ & $02 / 15 / 94$ & $04 / 06 / 94$ & 51 & 4 & $6.0 \times 10-8$ & 4.6 & \\
\hline & $B 250-10 B$ & S/BM & $10^{\circ}$ & Bulk & $02 / 14 / 94$ & $02 / 15 / 94$ & $04 / 03 / 94$ & 48 & 4 & $1.7 \times 10-7$ & 27 & \\
\hline & & & & & & & & & & & & \\
\hline Typical Spe & ificallon & & & & & & & & & $1 \times 10-6$ & 0.500 & \\
\hline & & & & & & & & & & & & \\
\hline SOIL TYPE & & & & & & & & & & & & \\
\hline & & & & & & & & & & Samplemet & bodn: & \\
\hline Typlcal De & & Soll Descriptic & n \& Classificat & Ion & CPT Blow COU & & & & & & & \\
\hline $0-10^{\circ}$ & & Clay with fine & gravel & & $>90$ & & & & & Bulk samp & es are collected & from the freshly \\
\hline $10-20^{\circ}$ & & CL Sllt & & & $20-60$ & & & & & formed ba & rier and cured & In plastic molds. \\
\hline $20-37^{\circ}$ & & Sand $\mathrm{MlX}$ & & & $10-30$ & & & & & & & \\
\hline $37-40^{\prime}$ & & Sandy FC & & & $10-20$ & & & & & Trim samp & es taken from & he cured bartier as \\
\hline $40-65^{\prime}$ & & CL Slit, Clay, Se & ndy FC, CL SIIt & & $10-20$ & & & & & 10 inct df & meter cyinders & and taken to \\
\hline & & & & & & & & & & the tab in & ealed 5 galion t & uckets. Samples \\
\hline & & & & & & & & & & lare sculpt & d to ftnal size $f$ & ir testing. \\
\hline Grout Form & dation at the " & SAVANNAH RI & VER SIIE" Den & gonutration & & & & & & This proce & Jure appears to & avold surface \\
\hline & & & & Additlve & Additlve & & & & & damage to & the more fragi & e samples. \\
\hline Slurry & Bentonite & water & Cement & Lignosite & Montan Wax & Density & Barrler & & & & & \\
\hline 1 & $\%$ total wt. & $\%$ total wt. & $\%$ total wt. & $\%$ total wt. & \% total wt. & $\mathrm{Ib} / \mathrm{Gal}$ & Type & & & Grab samp & es are taken fro & m soft moldable \\
\hline 1 & $8.25 \%$ & $91.75 \%$ & $0.00 \%$ & & & 8.8 & $S / B$ & & & wall mater & als which are re & moldable even \\
\hline$\overline{1 A}$ & $6.67 \%$ & $93.33 \%$ & $0.00 \%$ & & & 8.7 & $\mathrm{~S} / \mathrm{B}$ & & & after curin & & \\
\hline $3 A$ & $5.82 \%$ & $80.38 \%$ & $12.00 \%$ & $1.80 \%$ & & 9.56 & $\mathrm{~S} / \mathrm{C} / \mathrm{B}$ & & & & & \\
\hline 4 & $2.00 \%$ & $87.00 \%$ & & & $11.00 \%$ & 8.5 & $S / B M$ & & & & & \\
\hline 5 & $4.30 \%$ & $95.70 \%$ & & & & 8.6 & $S / B$ & & & & & \\
\hline $5 A$ & $6.66 \%$ & $91.54 \%$ & $0.00 \%$ & $1.80 \%$ & & 8.7 & $5 / B$ & & & & & \\
\hline & & & & & & & & & & & & \\
\hline
\end{tabular}




\begin{tabular}{|c|c|c|c|c|c|c|c|c|c|c|c|c|}
\hline & & & & & & & & & & - & & \\
\hline PERMEA & ILITY TAI & & & & & & & & & & & \\
\hline Barrier lor & med by Soril & aw $\ln$ August & 1992 company fund & Sed research & & & & & & & & \\
\hline PRDA spo & sered exan & titon/sumpling & it Rush Springs, 0 & klahoms Tes & Sile & & & & & & & \\
\hline & & & & & & & & & & & & \\
\hline \begin{tabular}{|l|} 
Barrier \\
\end{tabular} & & & & & & & & & & & Unconfined & \\
\hline$A$ & & & & & & & & & & Perm & Compressive & \\
\hline & & Barrier & Depth & Sample & Placement & Sampling & Lab Test & Age & Slurry & Rale & Strength & \\
\hline \begin{tabular}{|l} 
Station \\
\end{tabular} & Sample & Type & (fit) & Type & Dale & Date & Date & Dayz & 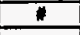 & $\mathrm{Cr} / \mathrm{Sec}$ & (psi) & Remarks \\
\hline & & & & & & & & & & & & \\
\hline 2 & $W-1-2$ & S/FA/C & $8-10^{\circ}$ & Shelby & $08 / 06 / 92$ & $07 / 20193$ & $08 / 12 / 93$ & 371 & 1 & $1.2 \times 10-5$ & 6.9 & Barrier placed on 8/6/92 \\
\hline 3 & W.1.3 & S/FA/C & $8^{\prime}$ & $\overline{G r a b}$ & $08 / 06 / 92$ & $07 / 21 / 93$ & $08 / 12 / 93$ & 371 & 1 & $\mid 1.5 \times 10-6$ & 10.4 & \\
\hline & & & & & & & & & & & & \\
\hline 7 & W.1.7 & SFAIC & $5^{\prime}$ & Core & $08106 / 92$ & 07720193 & $07 / 29193$ & 357 & 1 & $3.1 \times 10-6$ & 25 & \\
\hline 8 & W-1.8 & S/FA/C & $7^{\prime}$ & Shelby & $08 / 06 / 92$ & $07 / 21 / 93$ & 07129193 & 357 & $t$ & $5.0 \times 10-6$ & 43.7 & \\
\hline & & & & & & & & & & & & \\
\hline 10 & $W-1-10$ & S/FA/C & $5^{\prime}$ & Core & $08 / 06 / 92$ & $0721 / 93$ & $07 / 29193$ & 357 & $I$ & $1.9 \times 10-6$ & 44.4 & \\
\hline Barrier & & & & & & & & & & & Unconfined & \\
\hline B & & & & & & & & - & & Perm & $\begin{array}{l}\text { Uncoustaned } \\
\text { Comprestive }\end{array}$ & \\
\hline & & Barrier & Depth & Sample & Placement & Sampling & Lab Teat & Age & Slurry & Bate & Strength & \\
\hline \begin{tabular}{|l|} 
Station \\
\end{tabular} & Samplet & Type & (ft.) & Type & Date & Date & Date & Days & 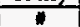 & $\mathrm{Cm}_{\mathrm{m} / \mathrm{Sec}}$ & Sortengat & In \\
\hline & & & & & & & & & & & & Kemarses \\
\hline 1 & W-2-1 & S/FA/C & $5^{\prime}$ & Corefblock & $08 / 07 / 92$ & $07 / 20193$ & $0729 / 93$ & 356 & 1 & $7.3 \times 10-6$ & 1007 & Wall placed on $877 / 92$ \\
\hline & & & & & & & & & & & & Standing sections of this wall \\
\hline 2 & W-2.2 & S/FA/C & 5 & Corefblock & $08 / 07 / 92$ & $07 / 20 / 93$ & $07 / 29193$ & 356 & 1 & $2.0 \times 10-6$ & 22.9 & were exeavated and phoographed \\
\hline & & & & & & & & & & & & \\
\hline 5 & W.2.5 & S/FA/C & $5^{\prime}$ & Coreßlock & $08877 / 92$ & $07 / 21 / 93$ & 0729993 & 356 & 1 & $5.6 \times 10-6$ & 22.9 & \\
\hline & & & & & & & & & & & & \\
\hline 6 & H-2.6 & S/FA/C & $5^{\prime}$ & Coreßblock & $08807 / 92$ & $07 / 21 / 93$ & $07 / 29193$ & 356 & 1 & $4.1 \times 10-6$ & 153.4 & \\
\hline Typleal S & secification & & & & 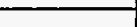 & & - & - & - & $2 \times 10-6$ & $0-500$ & \\
\hline ers & & & & & & & & & & & & \\
\hline & & & & & & & & & & & & \\
\hline SOIL.TYI & & & & & & & & & & & & \\
\hline & & & & & & & & & & Sample tone & thode: & \\
\hline Typical De & plh & Soli Descripti & on \& Clarsification & & SPT Blow Count & & & & & & & \\
\hline $0.10^{\circ}$ & & Sandy & & & $0-15$ & & & & & Stalby satsp & les were uked fro & 2 the cured barrier \\
\hline $10-30^{\circ}$ & & Sandy & & & $0-15$ & & & & & by presesing & the stelby tobo inco & the burvier. \\
\hline & & & & & & & & & & & & \\
\hline & & & & & & & & & & Grab sample & s are weren front so & it moldabio \\
\hline Groul for & mulation at & he Rush Spri & ngs Feadability $\mathrm{T}$ & & & & & & & barrier maxe & rials which are rems & oldable ever \\
\hline & & & & & & & & & & after curing. & & \\
\hline Slurty & Class $F$ ash & Water & Class H Cement & Density & Burier & & & & & & & \\
\hline$I$ & $\Rightarrow$ cotat wt. & \begin{tabular}{|l|l|}
$5 \operatorname{loc} 21$ \\
$\mathrm{w}$
\end{tabular} & St cotal wt. & $\mid \mathrm{b} / \mathrm{G} \mathrm{al}^{\mathrm{a}}$ & Type & & & & & Core sumpic & 5 were taken by $a t$ & nechanioal \\
\hline 1 & $25.00 \%$ & $50.00 \%$ & $25.00 \pi$ & 12 & S/FAC & & & & & drilf uait tro & wa the cured barriex & \\
\hline & & & & & & & & & & & & \\
\hline & & & & & & & & & & Conebloct: & comples were taken & froms 28 excaysect \\
\hline & & & & & & & & & & dritt pniti & 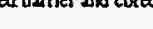 & 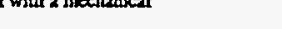 \\
\hline & & & & & & & & & & & & \\
\hline
\end{tabular}


APPENDIX E

CONSTRUCTION AND BARRIER EXCAVATION PHOTOGRAPHS 


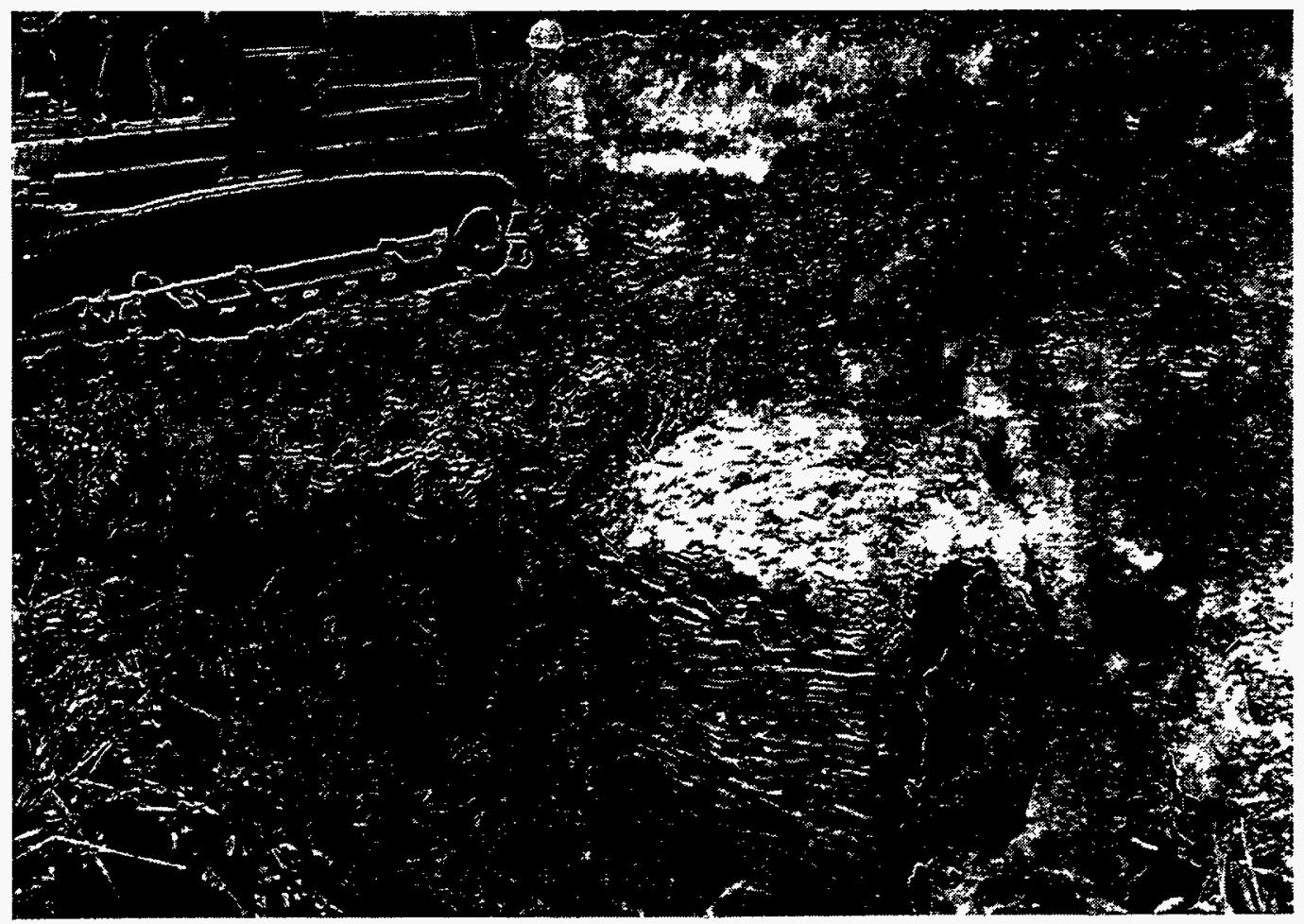

Photograph \# 1 Rush Springs, OK

Barrier excavation, both parallel to and across the barrier sections. Note, two barriers placed parallel to each other.

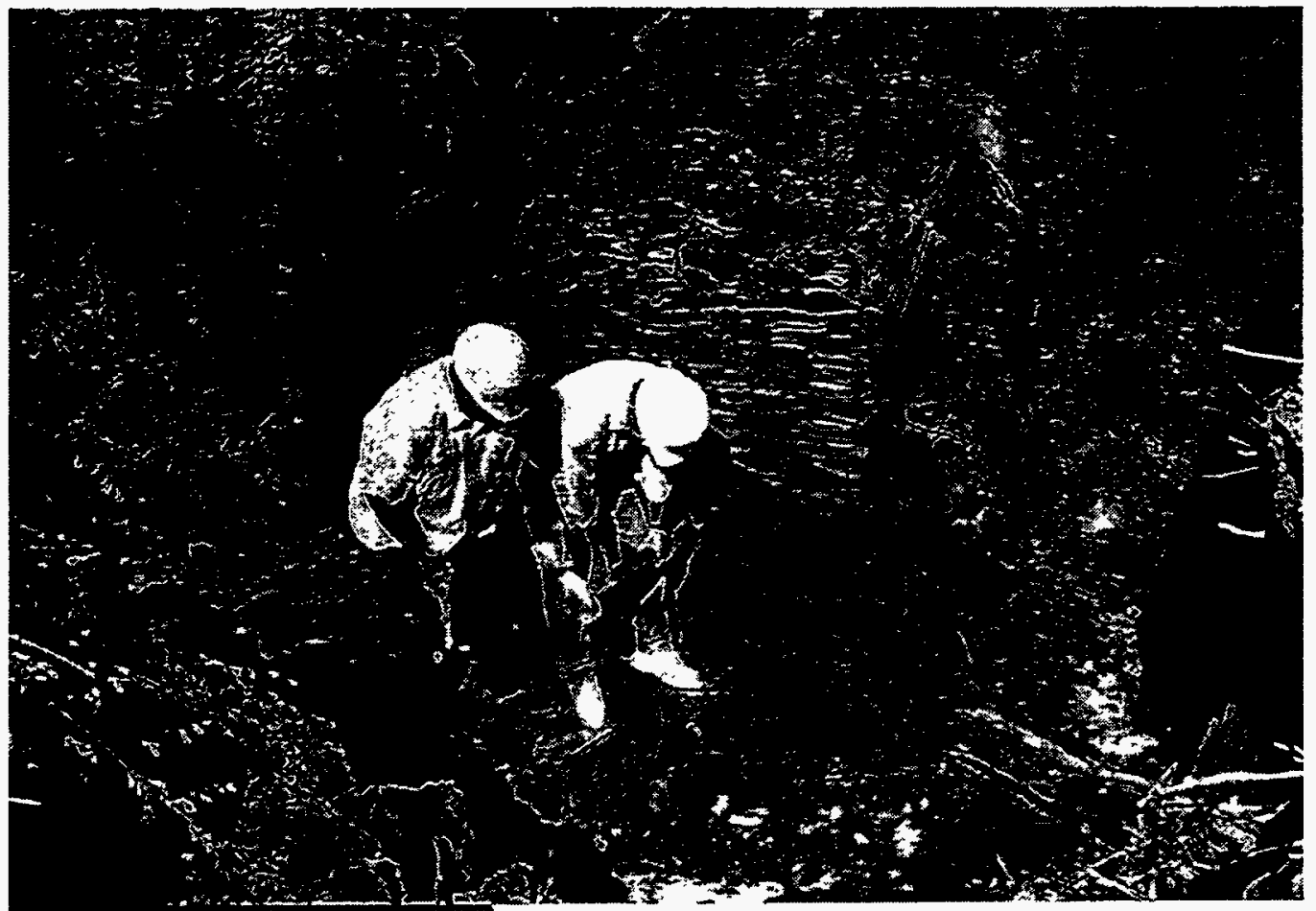

Photograph \# 2 Rush Springs, OK

Manual removal of a core sample with a Shelby tube. 


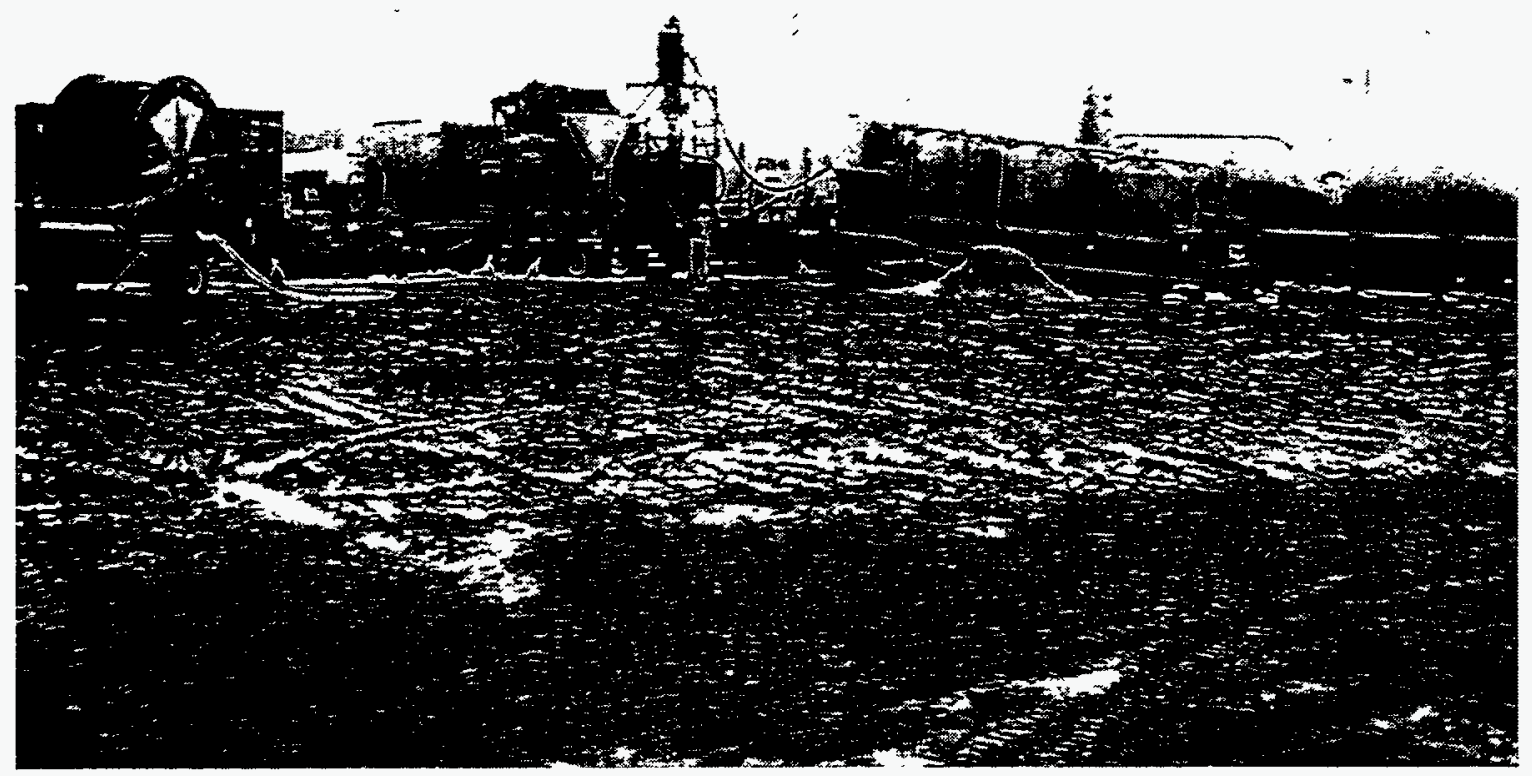

Photograph \# 3 Savannah River Site

General view of the grout mixing plant. Low pressure grout delivery hose reel, positioned at left of photograph.

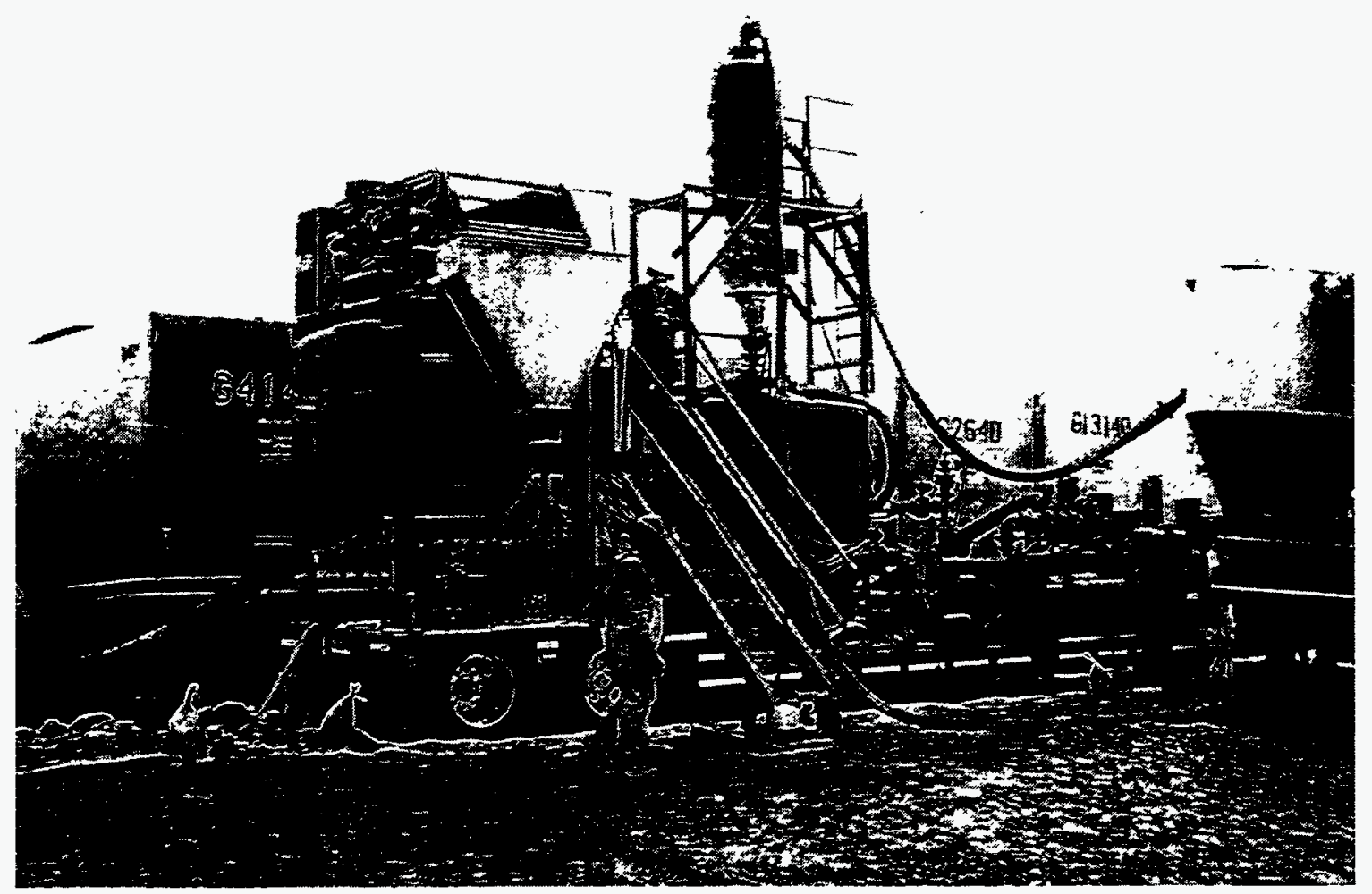

Photograph \# 4 Savannah River Site

Trailer mounted grout mixing plant complete with mix tub, vane feeder, pumps, shaker screen and surge tank. Liquid storage tanks in the background. 


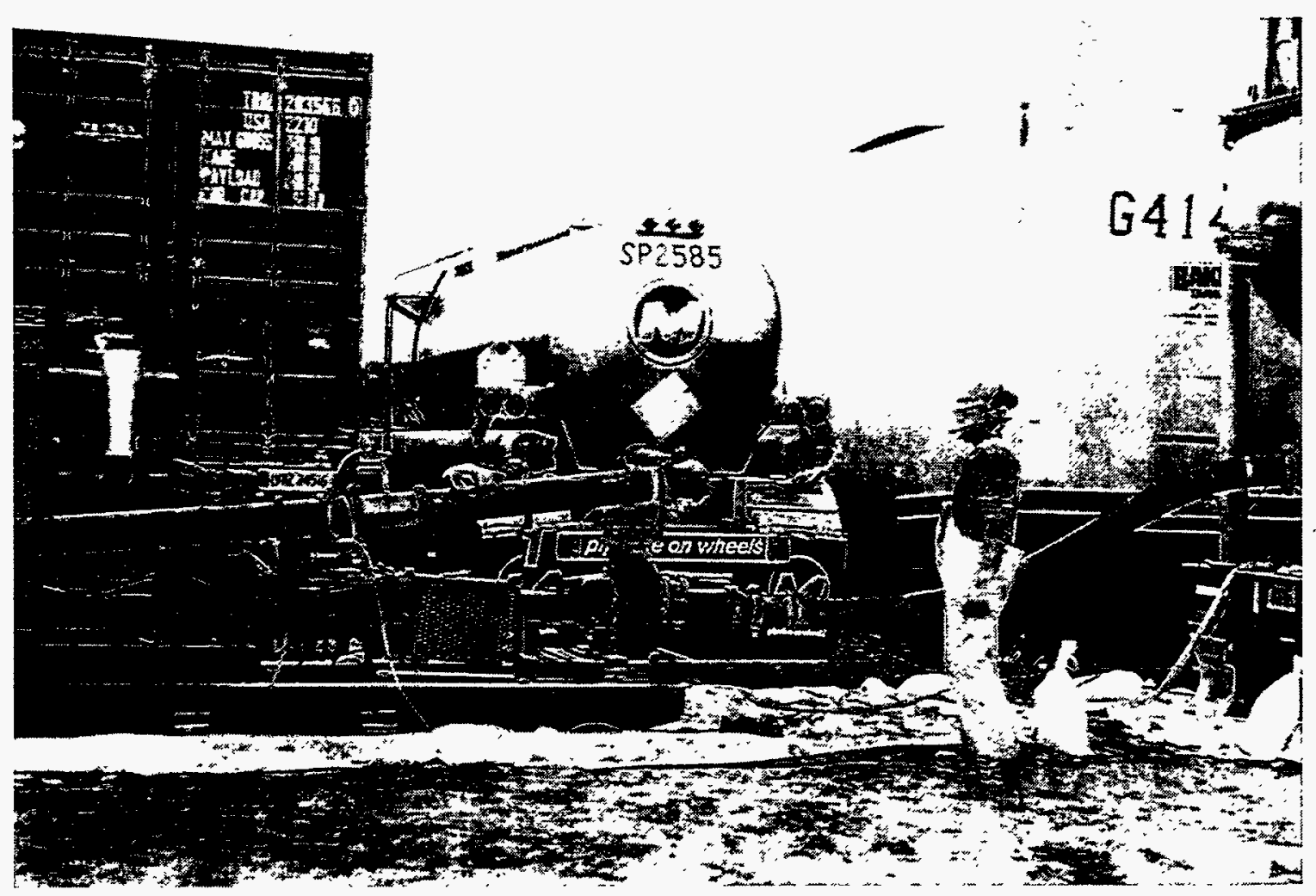

Photograph \# 5 Savannah River Site

Low pressure grout boost pump. This pump discharges to the hose reel to supply suction pressure for high pressure pumps.

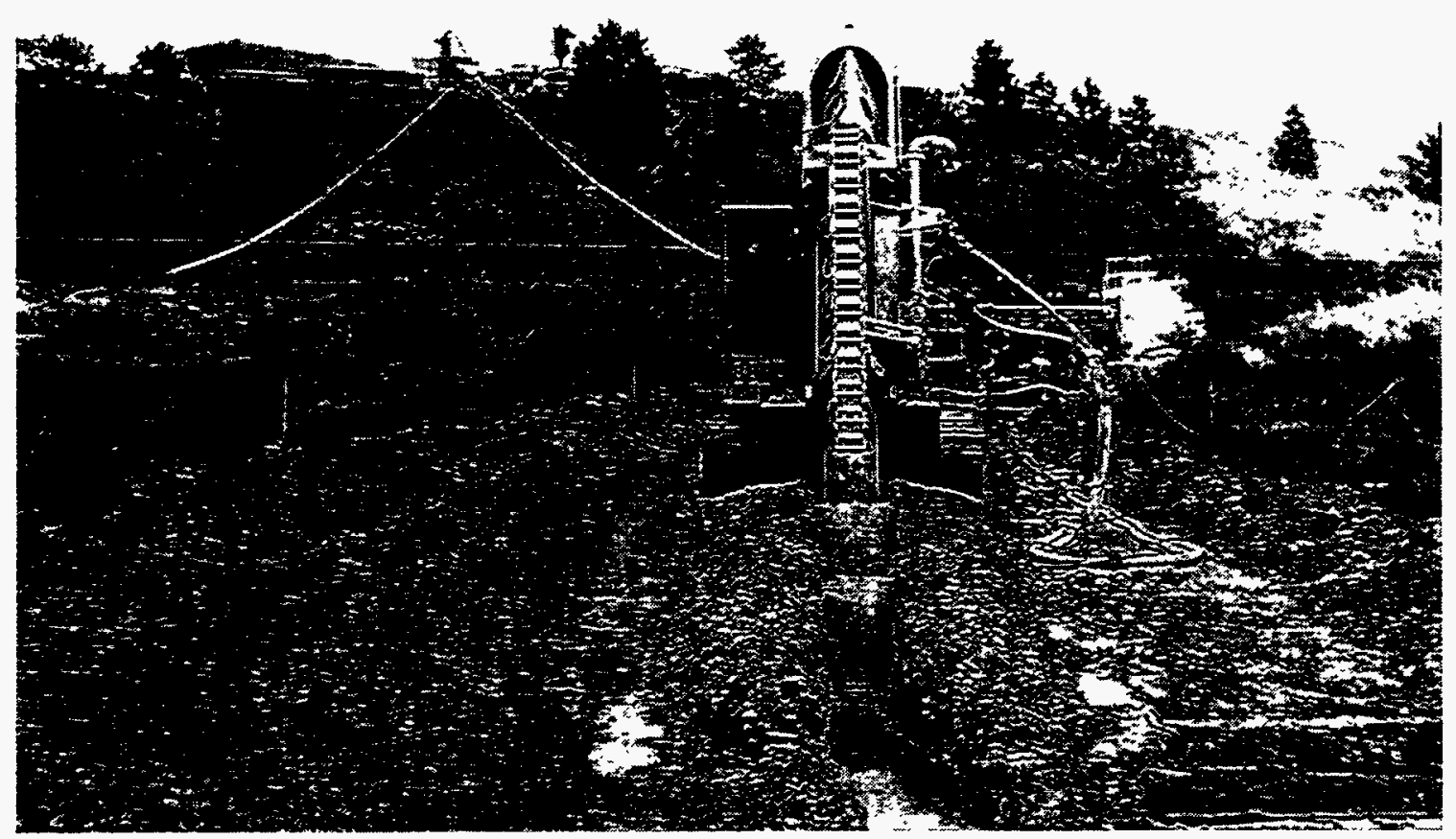

Photograph \# 6 Palestine, Texas

SoilSaw ${ }^{\mathrm{T} M}$ operating with a starter trench. 


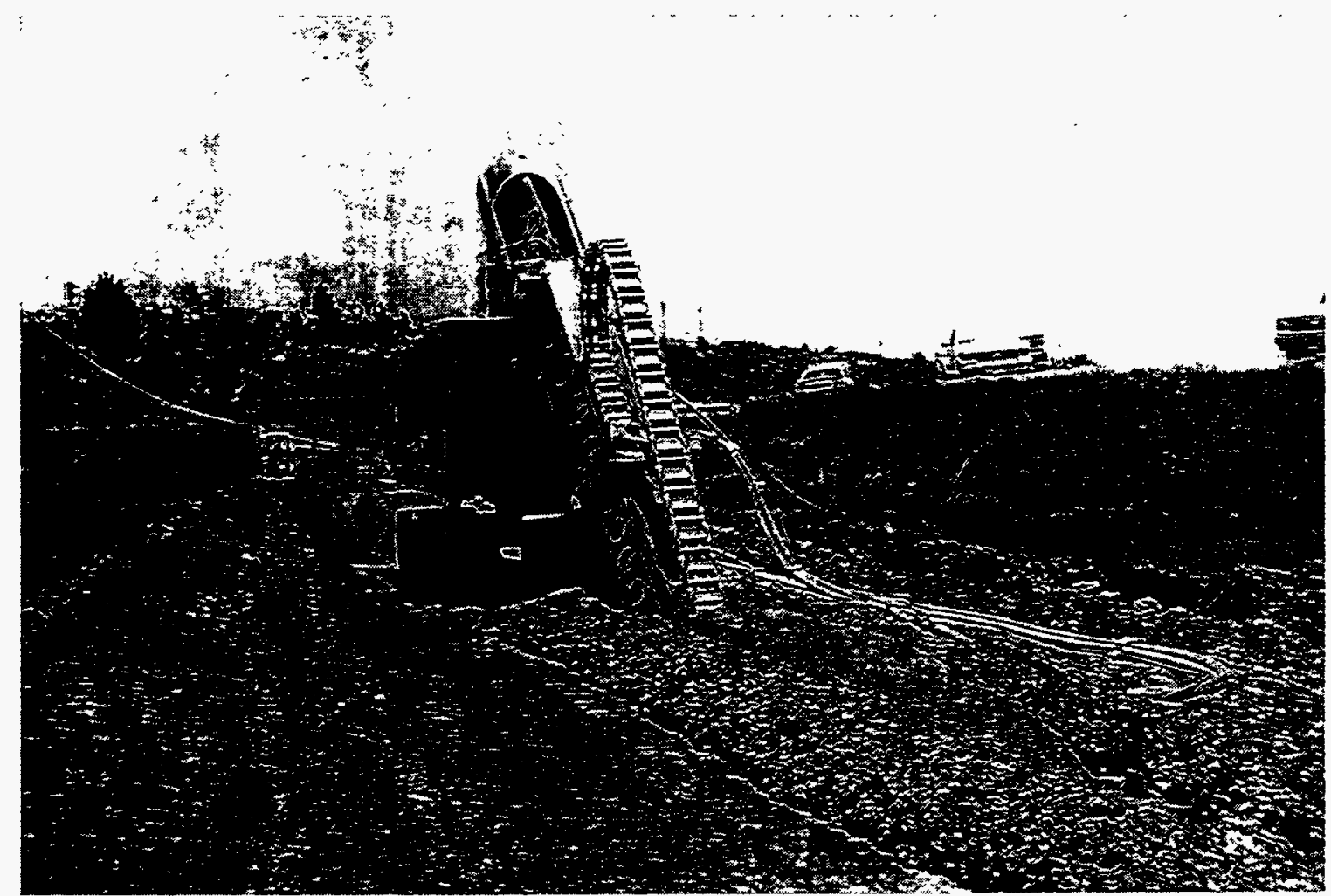

Photograph \# 7 Palestine, Texas

SoilSaw TM advancing with high production rates, with little overflow. Note that overflow will mound on top of the barrier during efficient operations.

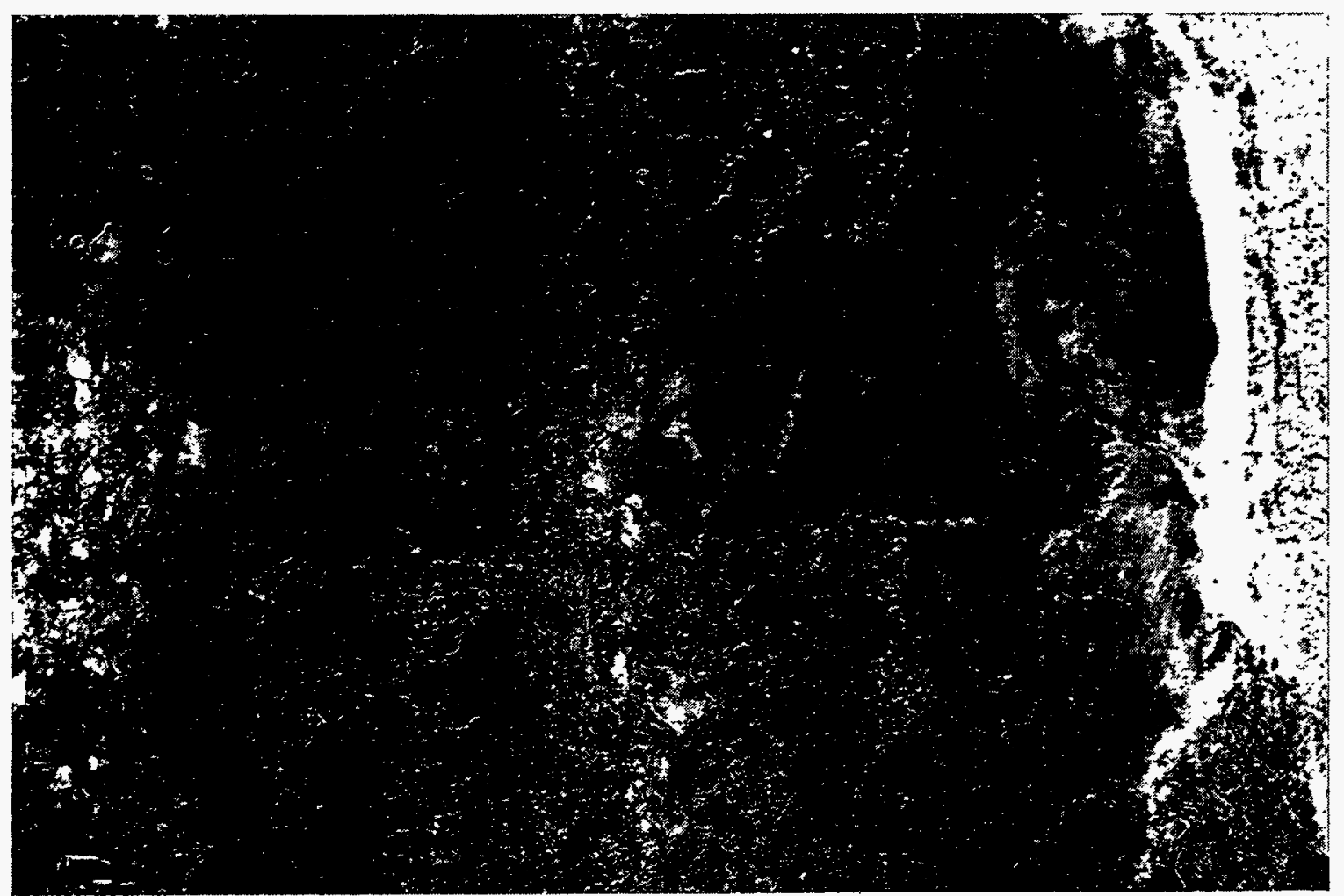

Photograph \# 8 Palestine, Texas

An excavated section of a cement/bentonite barrier. 


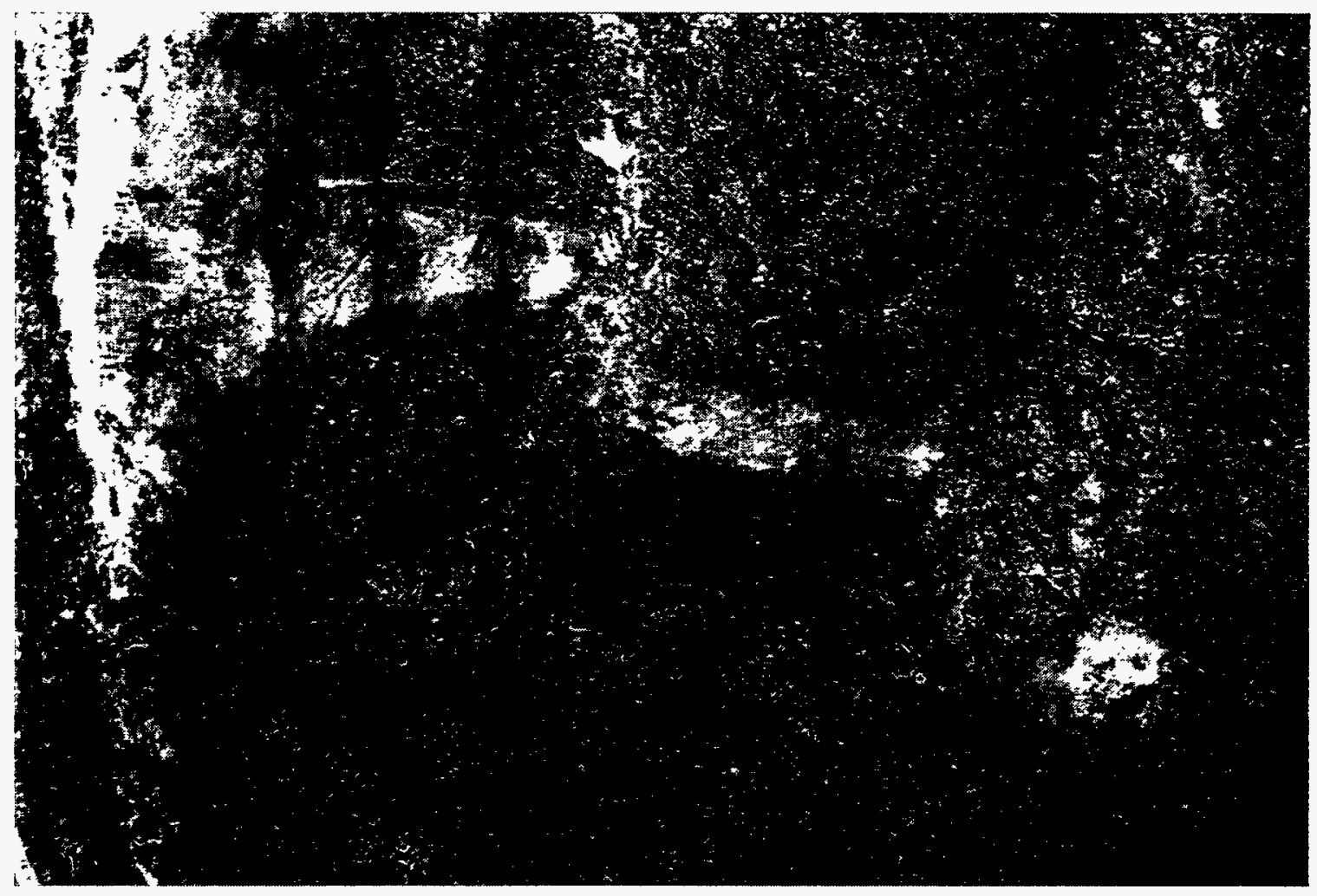

Photograph \# 9 Palestine, Texas

An excavated section of a cement/bentonite barrier giving a side view of the barrier placement.

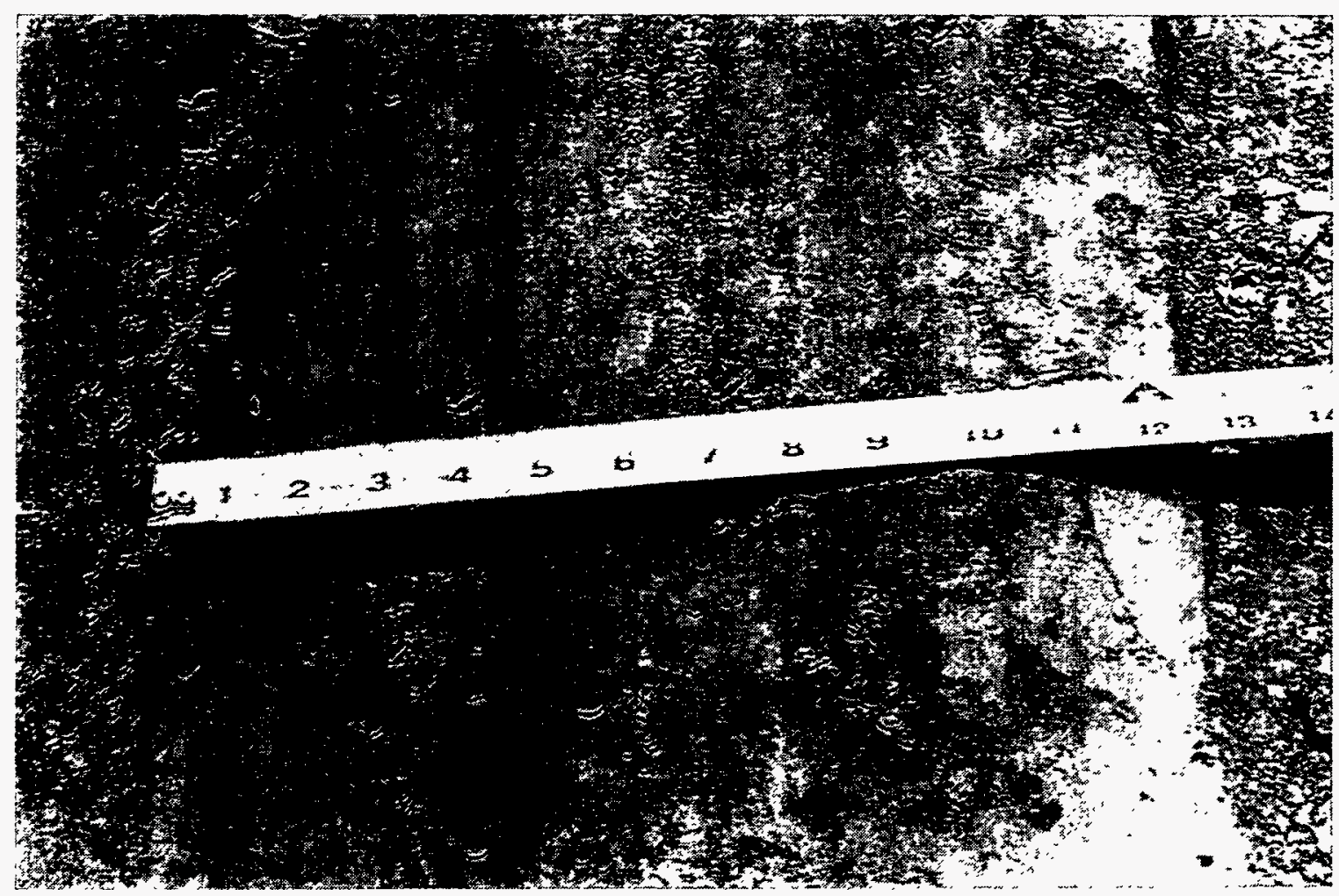

Photograph \# 10 Palestine, Texas

A top section of a barrier which shows a 12 inch consistent width. 


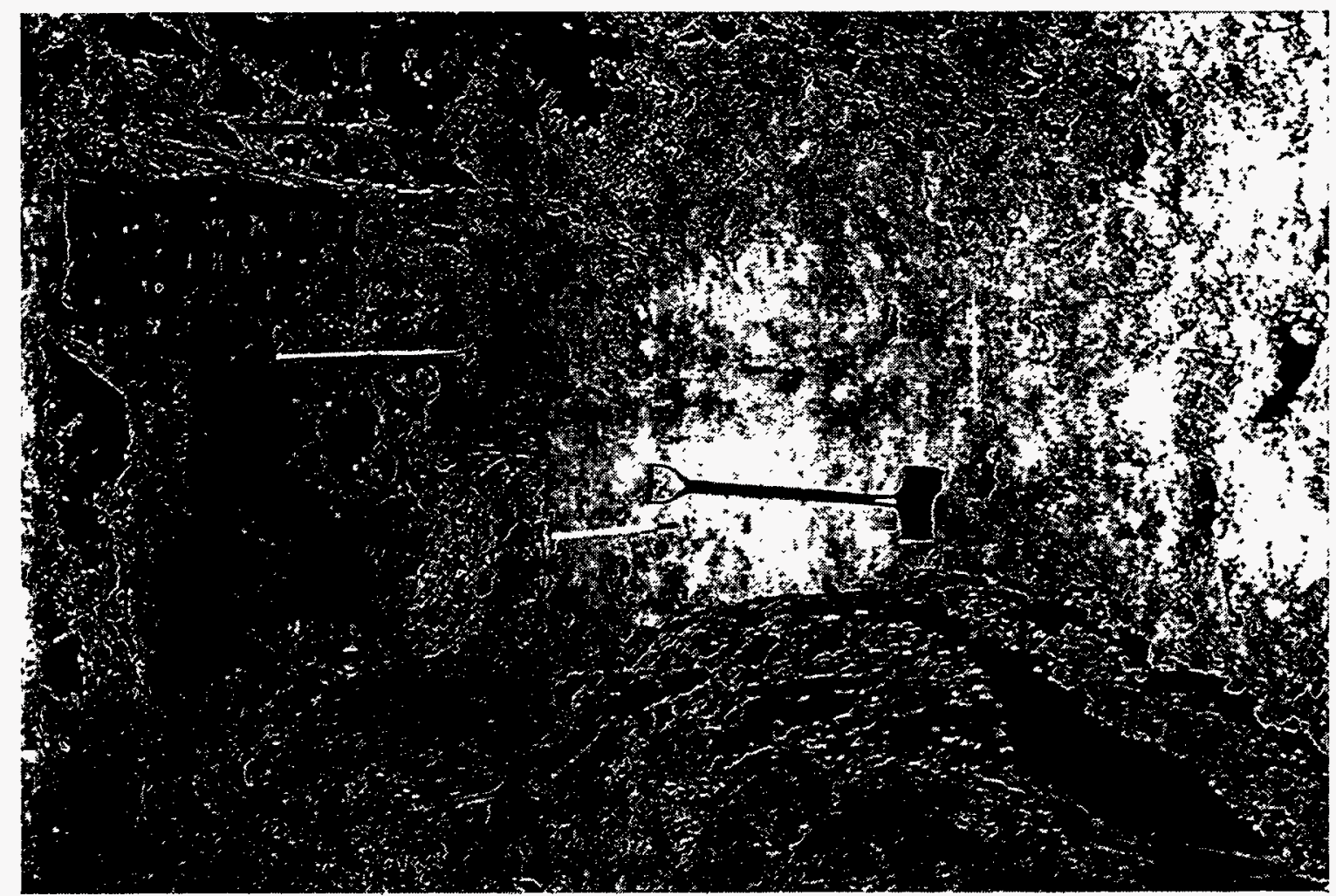

Photograph \# 11 Palestine, Texas

Exposed cement/bentonite barrier with chemical tracer which indicates the barrier surface.

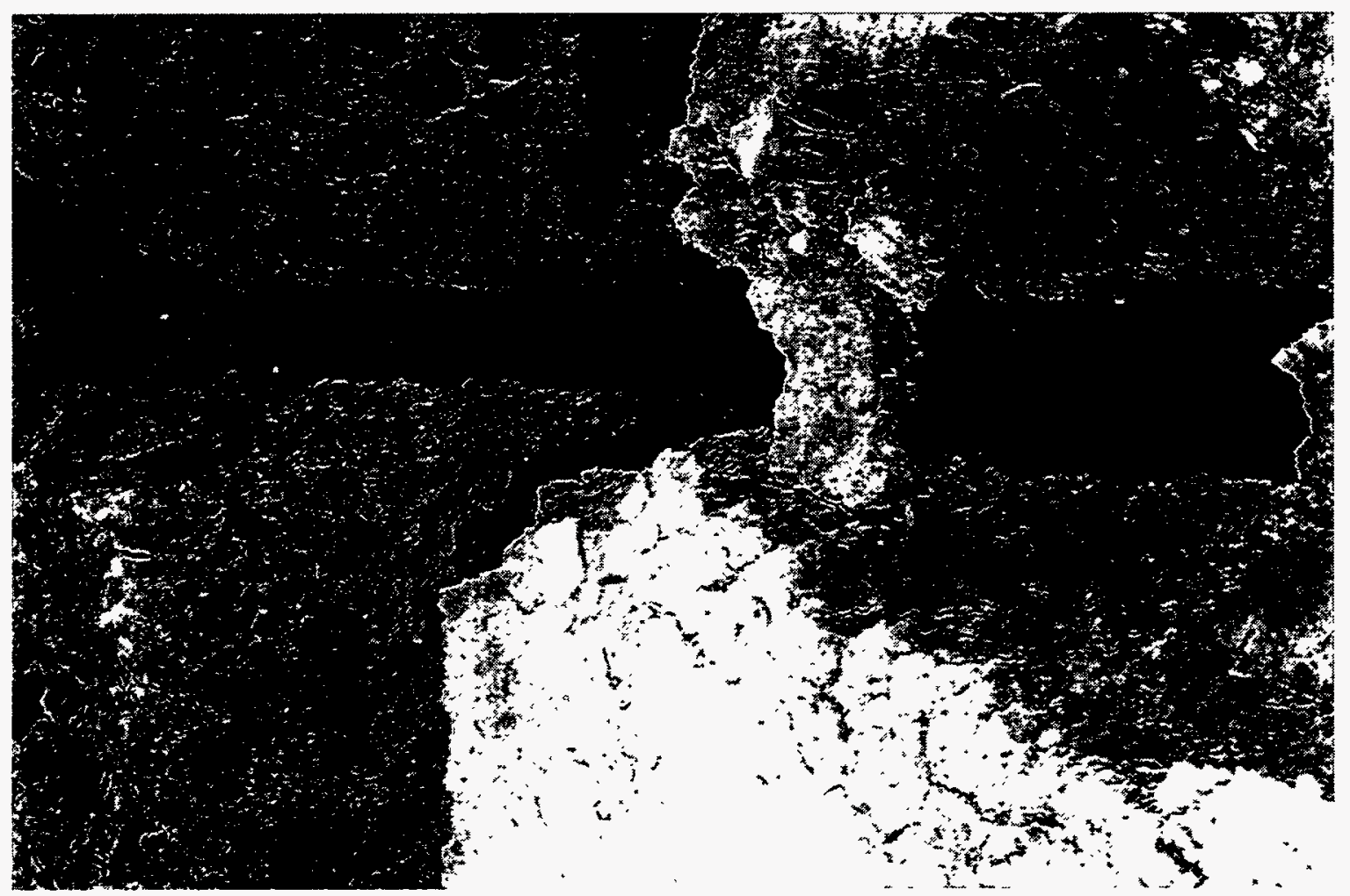

Photograph \# 12 Palestine, Texas

Exposed soil/bentonite barrier after one month. Barrier material remains flowable. 


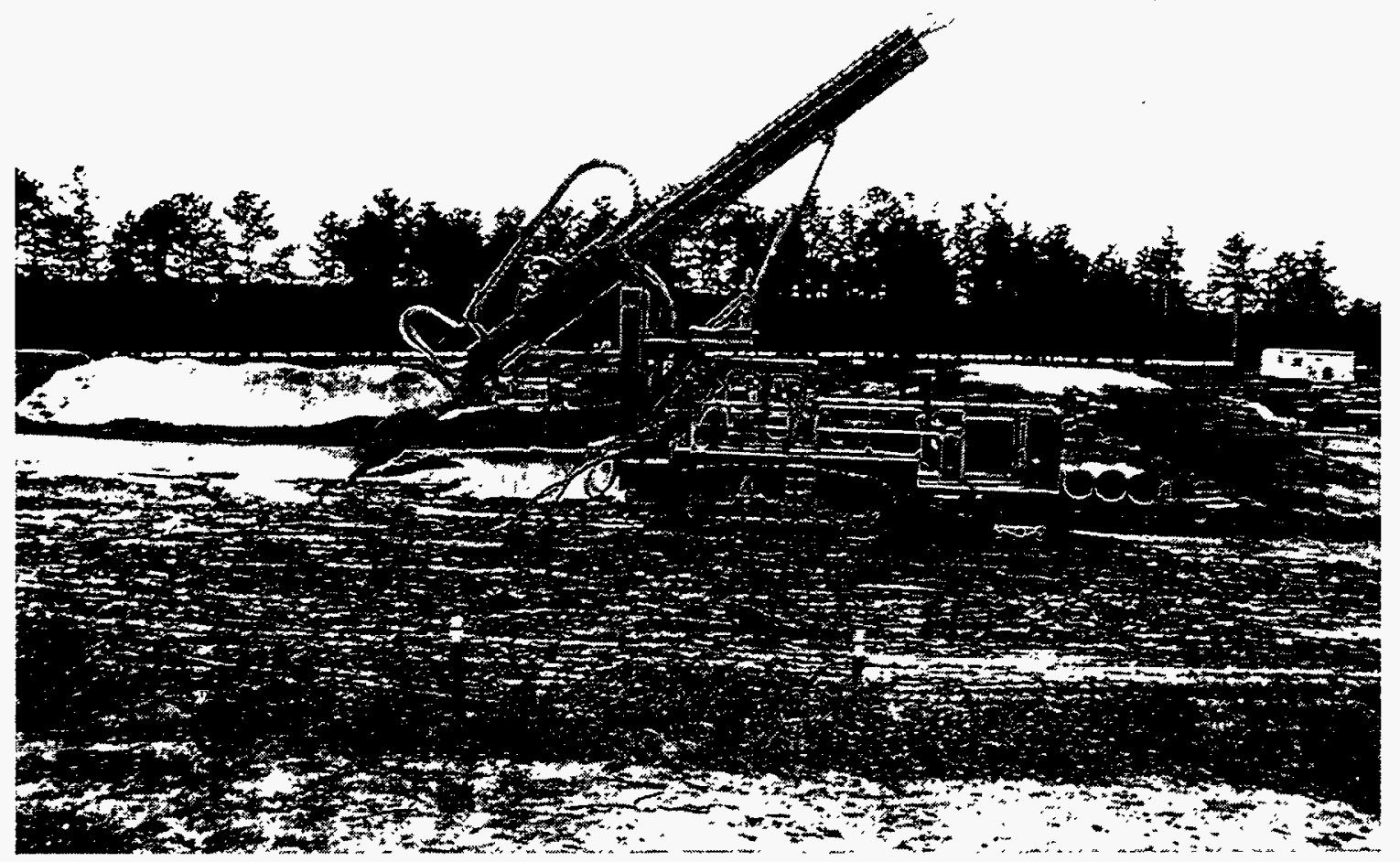

Photograph \# 13 Savannah River Site

Converted D9H Dozer with SoilSaw ${ }^{\mathrm{TM}}$ attachment. Unit constructing a Bentonite Barrier.

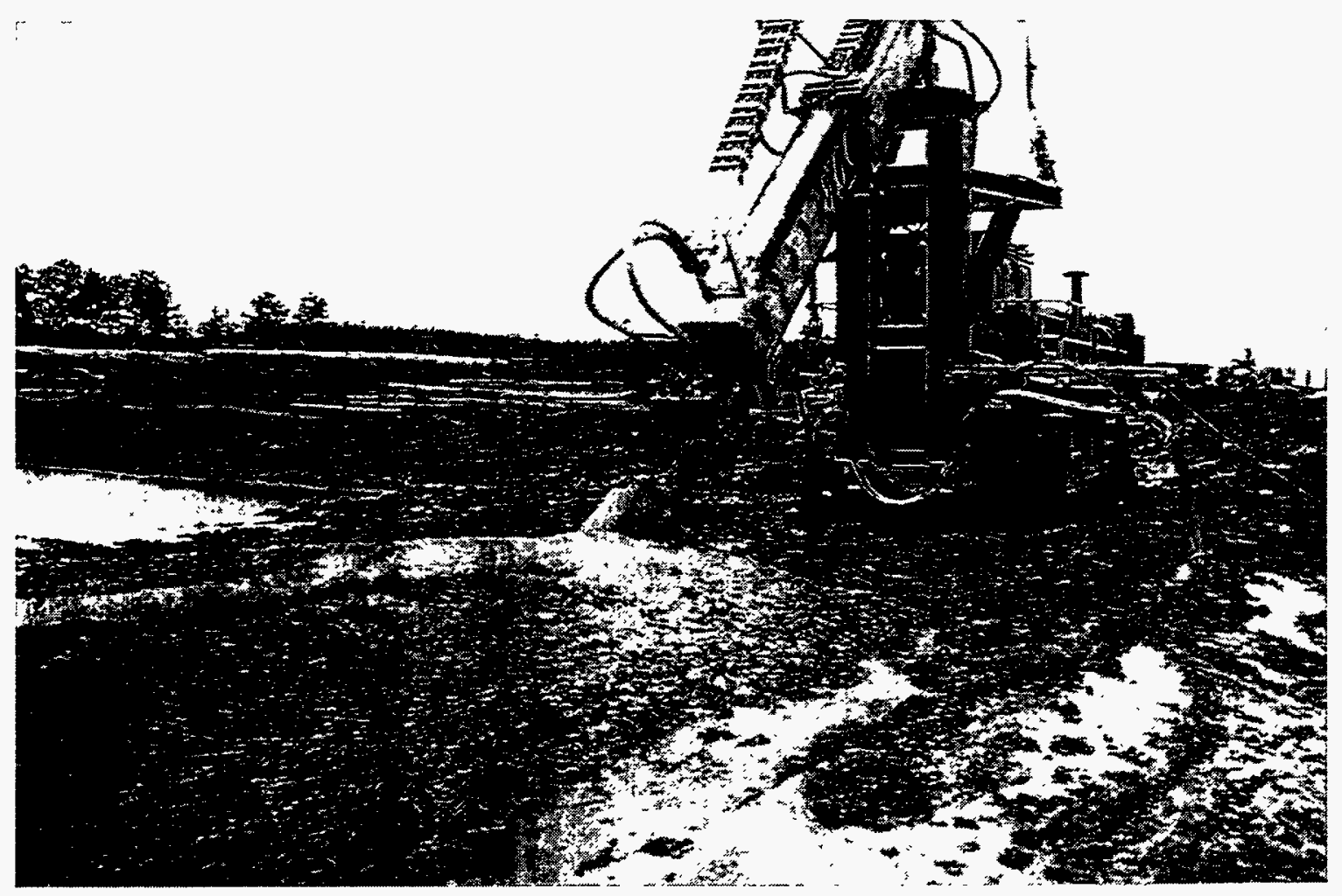

Photograph \# 14 Savannah River Site

SoilSaw ${ }^{\mathrm{TM}}$ constructing a Bentonite Barrier. 


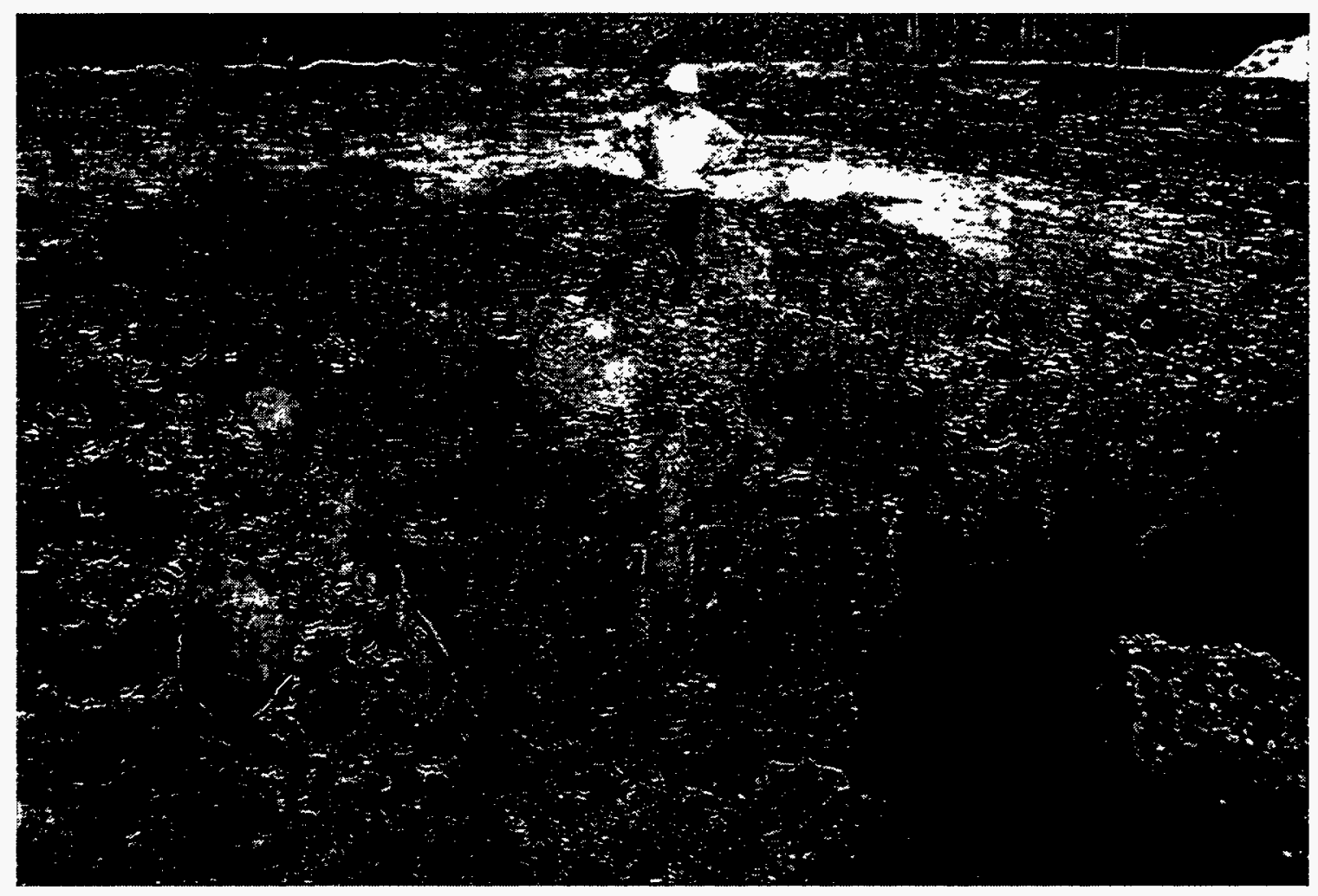

Photograph \# 15 Savannah River Site

Cross section excavation of a cement/bentonite barrier

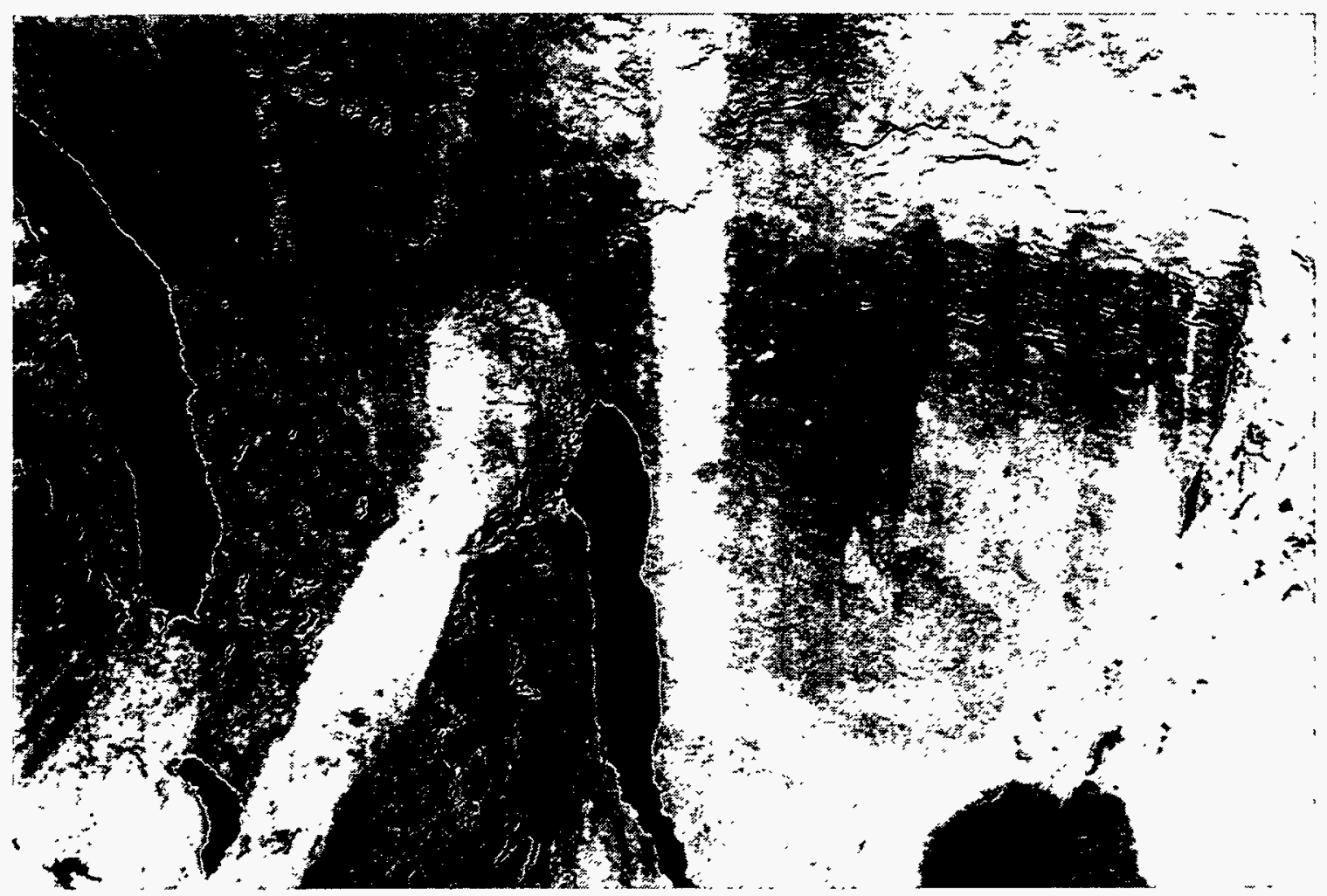

Photograph \# 16 Savannah River Site

Cross section excavation of a cement/bentonite barrier. Standing barrier with formation excavated from both sides. 


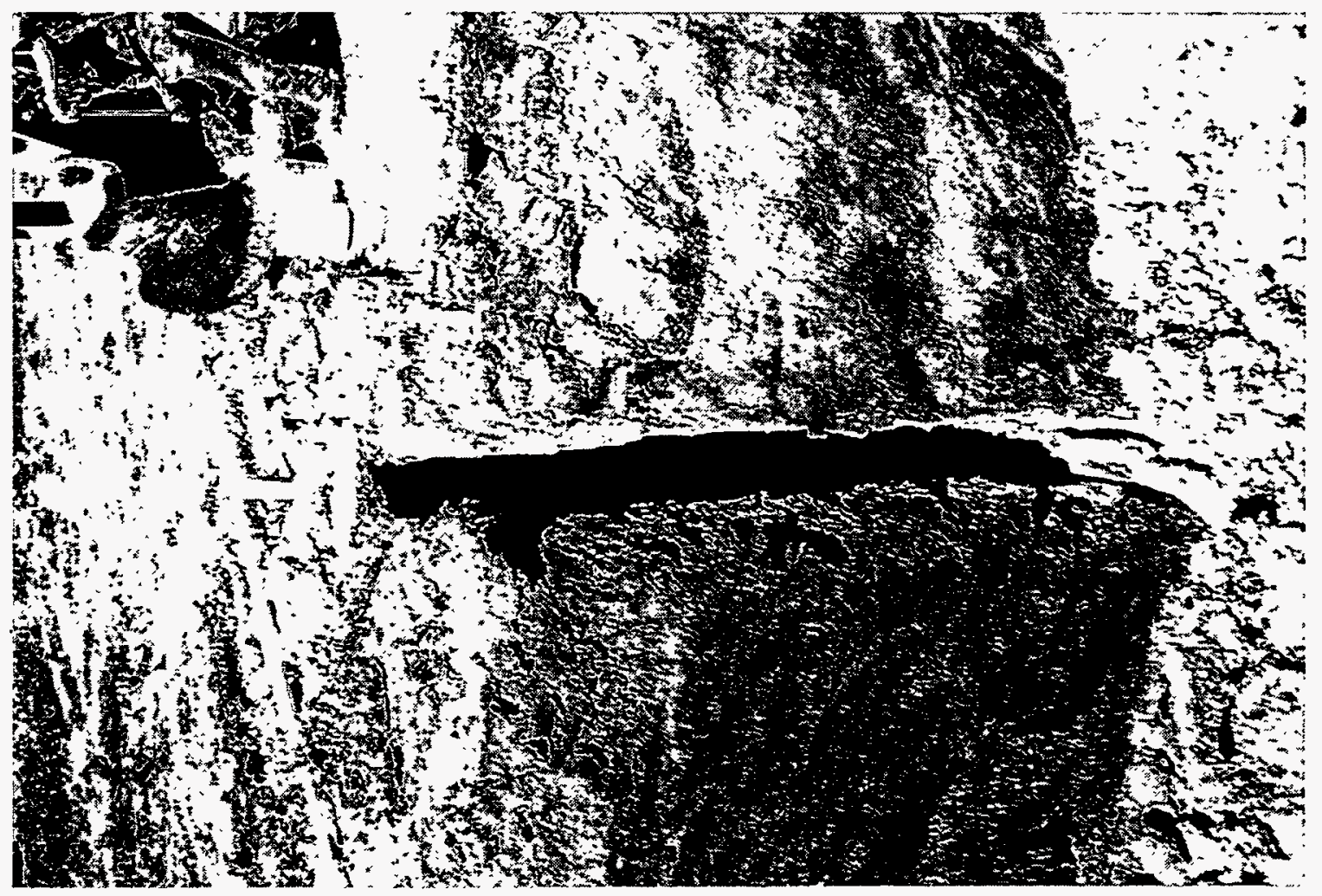

Photograph \# 17 Savannah River Site

Cross section excavation of a bentonite barrier. Sample being taken from barrier material.

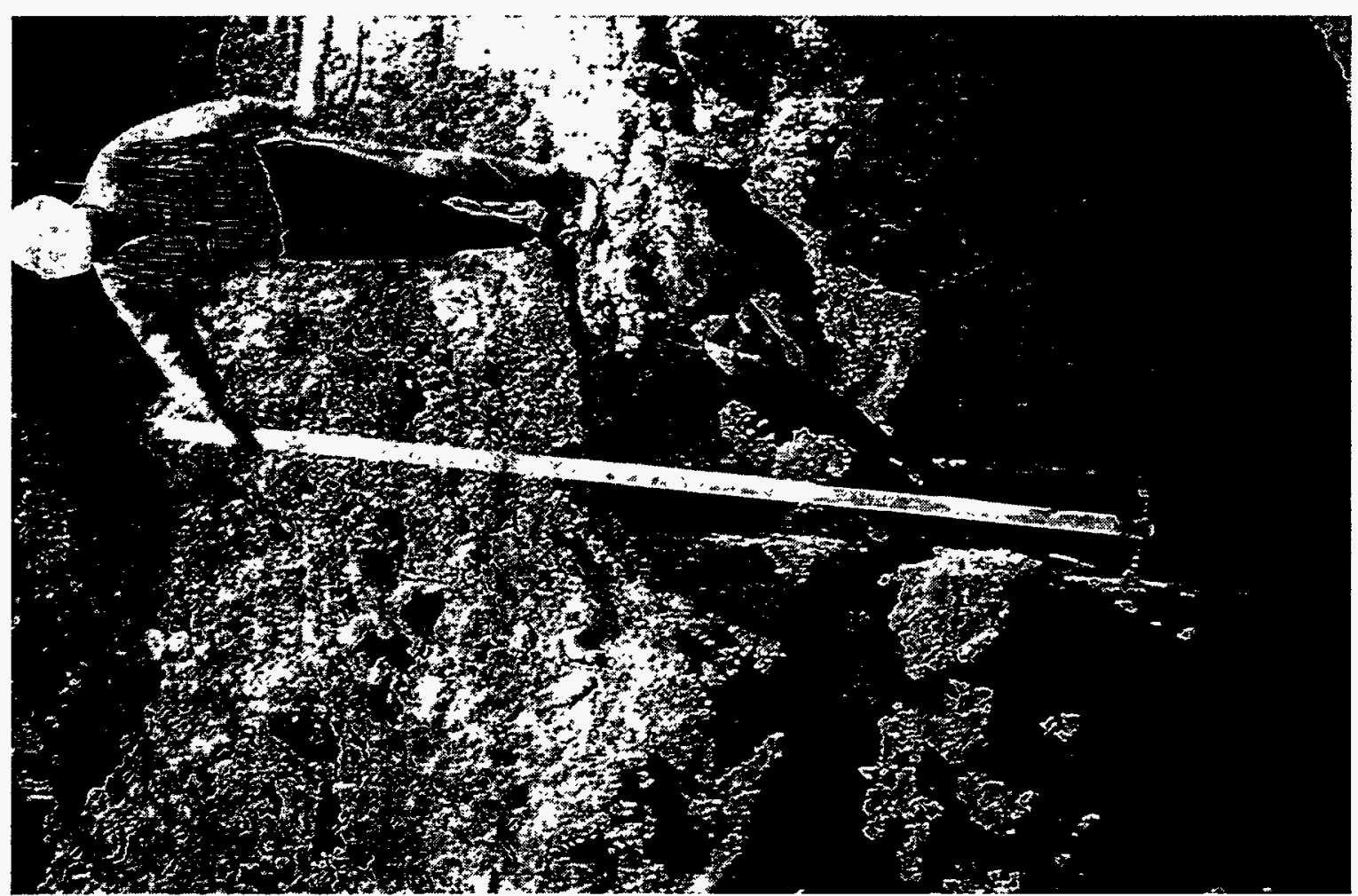

Photograph \# 18 Savannah River Site

Cross section excavation of bentonite barrier where width measurements are being taken. 


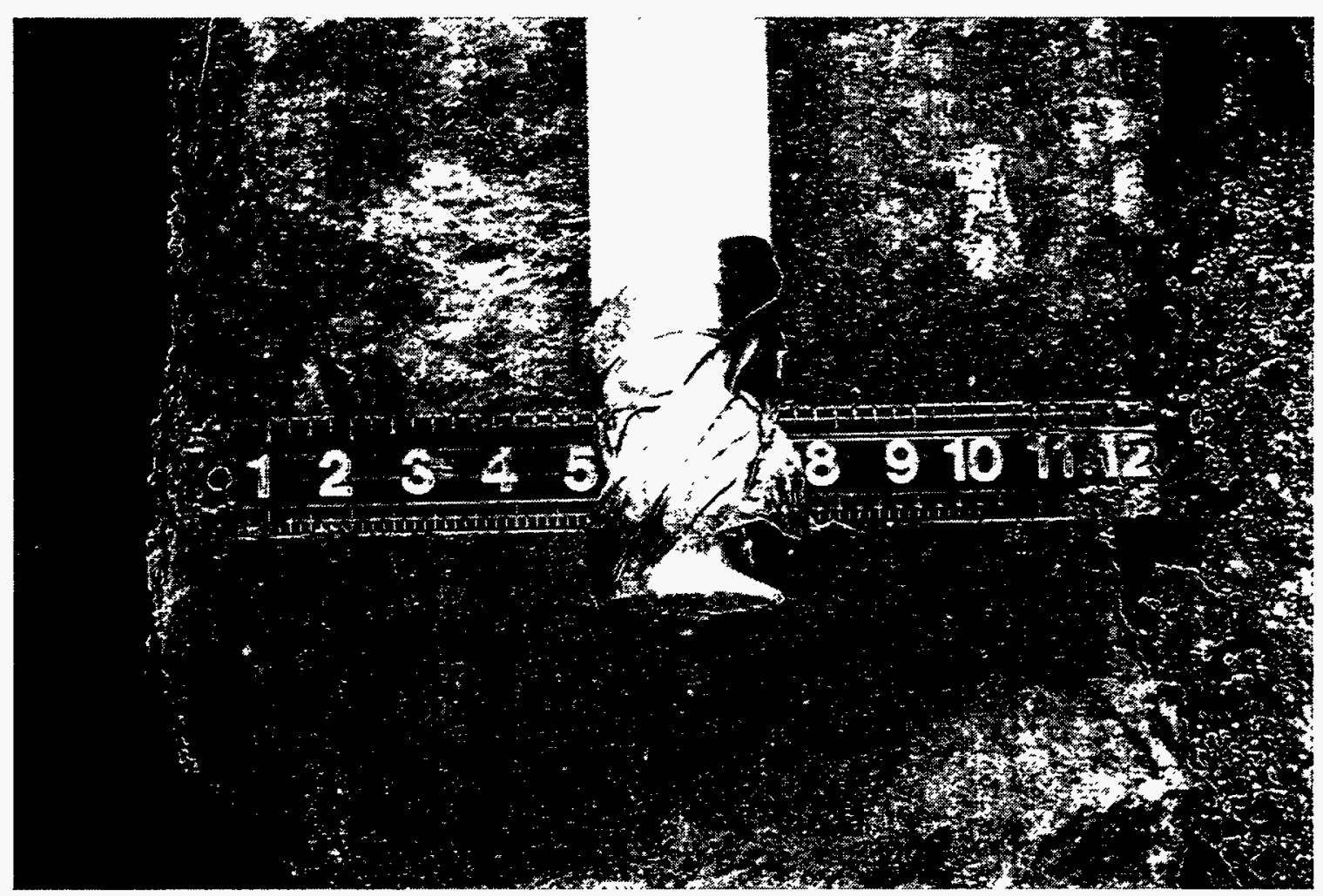

Photograph \# 19 Savannah River Site

An excavated bulk sample taken for trim and perm testing. Width and measurements consistent.

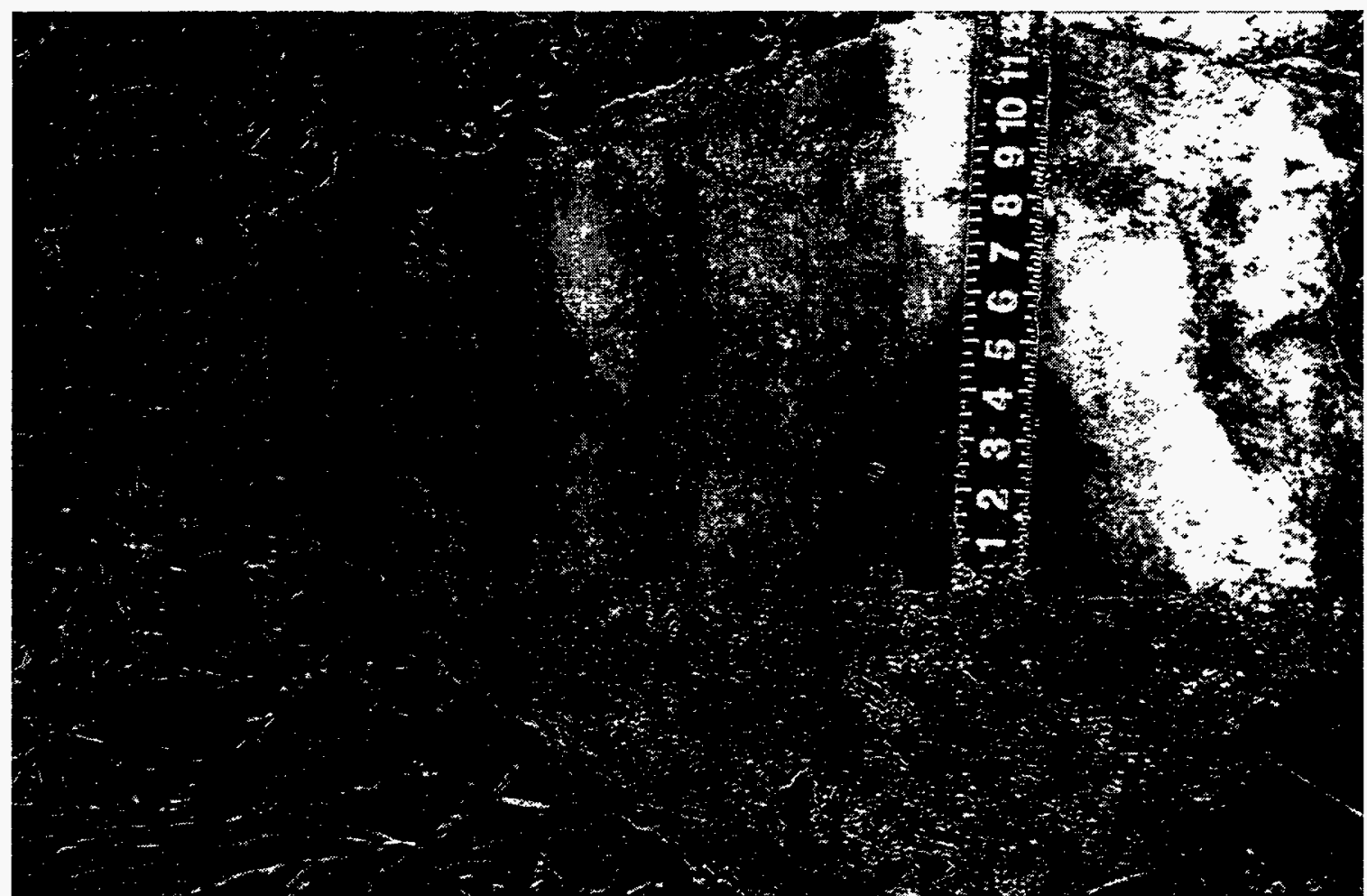

Photograph \# 20 Savannah River Site

Excavated bulk sample, note the excellent bonding to formation. 